\title{
Um suporte à captura informal de Design Rationale
}

\author{
Silvana Maria Affonso de Lara
}

Orientador: Profa. Dra. Renata Pontin de Mattos Fortes

Monografia de Dissertação apresentada ao Instituto de Ciências Matemáticas e de Computação — ICMC/USP — como parte dos requisitos necessários à obtenção do título de Mestre em Ciências de Computação e Matemática Computacional.

USP - São Carlos

Novembro/2005 


\section{Sumário}

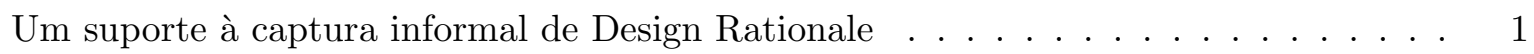

\begin{tabular}{lll}
\hline & Introdução & 10
\end{tabular}

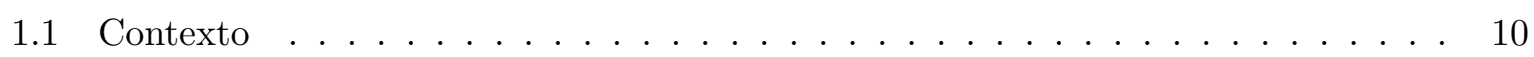

1.2 Motivação . . . . . . . . . . . . . . . . . . . . . . . 11

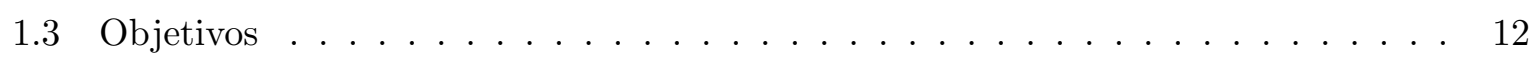

1.4 Organização do Trabalho $\ldots \ldots \ldots \ldots \ldots \ldots \ldots$

\begin{tabular}{|ll|}
2 Design Rationale & 14 \\
\hline
\end{tabular}

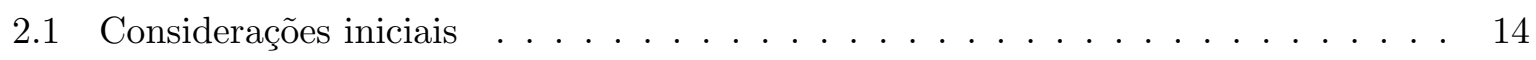

$2.2 \quad$ Definições sobre Design Rationale $\ldots \ldots \ldots \ldots \ldots$. . . . . . . . . . . 14

2.3 Abordagens para a construção de Sistemas de DR $\ldots \ldots \ldots \ldots \ldots$

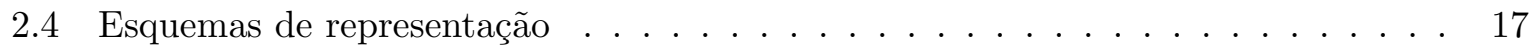

$2.5 \quad$ Formas de captura e armazenamento $\ldots \ldots \ldots \ldots \ldots \ldots$

2.6 Formas de recuperação $\ldots \ldots \ldots \ldots$

2.7 A ferramenta DocRationale . . . . . . . . . . . . . . . . . . . . . . . 21

2.7 .1 Requisitos da DocRationale . . . . . . . . . . . . . . . . 22

$2.7 .2 \quad$ O Suporte a DR na DocRationale $\ldots \ldots \ldots \ldots \ldots$

2.7 .3 Arquitetura . . . . . . . . . . . . . . . . . 23

$2.7 .4 \quad$ Interface da Ferramenta DocRationale . . . . . . . . . . . . . . . . . 24

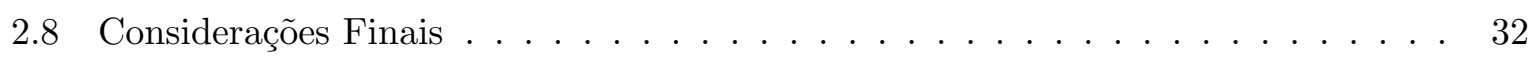

\begin{tabular}{lll}
\hline 3 & Ferramentas CASE & 34
\end{tabular}

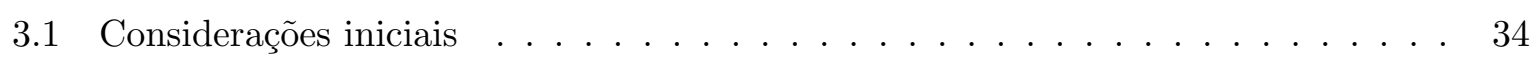

3.2 Definições de Ferramentas CASE . . . . . . . . . . . . . . . . . . . . . 35

3.3 Motivos para o uso de Ferramentas CASE . . . . . . . . . . . . . . 36

3.4 Motivos para o não uso de Ferramentas CASE $\ldots \ldots \ldots$. . . . . . . . . . . 37

$3.5 \quad$ Problemas com a adoção de Ferramentas CASE . . . . . . . . . . . . . . . . 39 
3.6 Considerações Finais $\ldots \ldots \ldots \ldots$

4 Usabilidade e Computação Ubíqua 42

$4.1 \quad$ Considerações Iniciais $\ldots \ldots \ldots \ldots$. . . . . . . . . . . . . . . . 42

4.2 Conceitos de Usabilidade e Acessibilidade . . . . . . . . . . . . . . . . . . . . 42

$4.3 \quad$ Engenharia de Usabilidade . . . . . . . . . . . . . . . . . . . . . . . 50

4.4 Avaliação de Usabilidade . . . . . . . . . . . . . . . . . . . . . . . . . . . . 54

$4.4 .1 \quad$ Inspeção de Usabilidade $\ldots \ldots \ldots \ldots$. . . . . . . . . . . . . 55

4.4 .2 Testes de Usabilidade $\ldots \ldots \ldots \ldots \ldots$. . . . . . . . . . . . 56

4.5 Computação Ubíqua $\ldots \ldots \ldots \ldots \ldots \ldots \ldots$

4.6 Projetos Relacionados $\ldots \ldots \ldots \ldots \ldots$. . . . . . . . . . . . . . . 61

$4.6 .1 \quad$ Projetos eClass \& iClass . . . . . . . . . . . . . . . . . . . . 61

$4.6 .2 \quad$ Outros Projetos Relacionados . . . . . . . . . . . . . . . . . . . . 64

4.7 Considerações Finais $\ldots \ldots \ldots \ldots \ldots \ldots \ldots$

5 DocRat: Reengenharia da Ferramenta DocRationale $\quad 67$

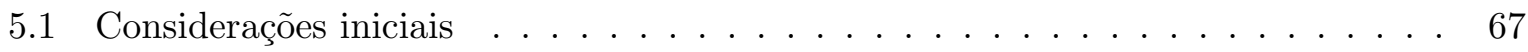

5.2 Engenharia Reversa $\ldots \ldots \ldots \ldots \ldots \ldots$

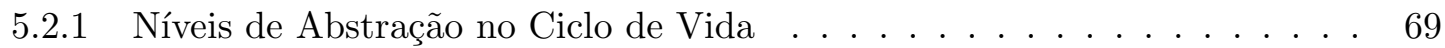

5.2.2 O Método de Engenharia Reversa FUSION-RE/I e sua aplicação na ferramenta DocRationale . . . . . . . . . . . . . . . . . . . . . 72

$5.3 \quad$ A Reengenharia da interface da Ferramenta DocRationale . . . . . . . . . . . . 76

$5.3 .1 \quad$ Atividades da Fase de Pré-Design . . . . . . . . . . . . . . . . . . 77

$5.3 .2 \quad$ Atividades da Fase de Design $\ldots \ldots \ldots \ldots$. . . . . . . . . . . 81

$5.3 .3 \quad$ Atividades de Pós-Design $\ldots \ldots \ldots$. . . . . . . . . . . . . . . 90

5.4 Dificuldades e Limitações $\ldots \ldots \ldots$. . . . . . . . . . . . . . . . . . . . 98

5.5 Considerações Finais $\ldots \ldots \ldots \ldots \ldots \ldots$

6 Evolução da Ferramenta DocRat 101

$6.1 \quad$ Considerações iniciais $\ldots \ldots \ldots \ldots$. . . . . . . . . . . . . . . 101

6.2 Visão Geral do Método de Reconhecimento de Escrita . . . . . . . . . . . . . . . . 102

6.2 .1 Extração e Reconstrução da Estrutura ～. . . . . . . . . . . . . . . . . . 103

6.2 .2 Casamento Estrutural Flexível _ . . . . . . . . . . . . . . . 105

6.2 .3 Pós-Processamento . . . . . . . . . . . . . . . . . . . . . 107

$6.3 \quad$ Jnk: A Java Ink API . . . . . . . . . . . . . . . . . . . . . . . . . . . 108

6.4 Integração da Ferramenta DocRat com a API JInk . . . . . . . . . . . . . . . . 109 
6.5 Considerações Finais $\ldots \ldots \ldots \ldots$. . . . . . . . . . . . . . . . . . 114

\begin{tabular}{lll}
\hline 7 & Conclusões & 115
\end{tabular}

7.1 Contribuições . . . . . . . . . . . . . . . . . . . . . . . . 115

7.2 Trabalhos Futuros $\ldots \ldots \ldots \ldots \ldots \ldots \ldots$

\begin{tabular}{ll}
\hline A Tarefas realizadas no teste de usabilidade & 127
\end{tabular}

B Questionário aplicado para os usuários no teste de usabilidade $\quad 129$ 


\section{Lista de Figuras}

2.1 Informações a serem manipuladas na ferramenta DocRationale . . . . . . . . . . 22

$2.2 \quad$ Arquitetura da ferramenta DocRationale $[$ Francisco, 2004$] \ldots \ldots \ldots \ldots$

2.3 Tela de "Porta de entrada" da ferramenta DocRationale [Francisco, 2004] $\ldots . .25$

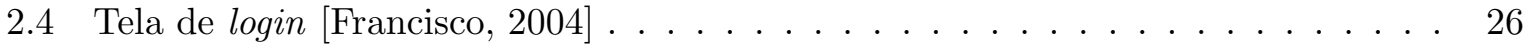

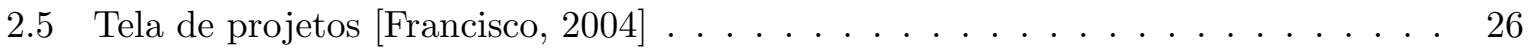

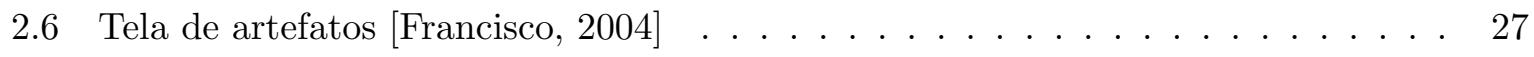

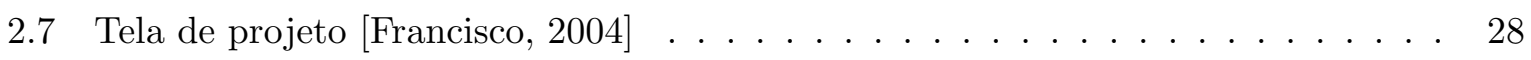

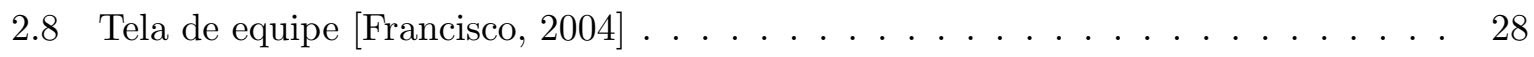

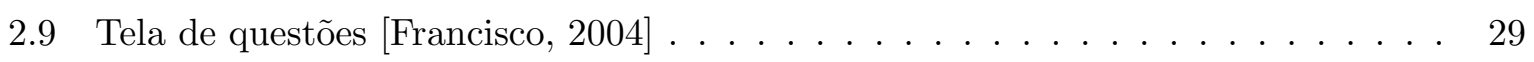

2.10 Tela de artefato $[$ Francisco, 2004$] \ldots \ldots \ldots \ldots \ldots \ldots$

2.11 Tela de projeto na CoTeia $[$ Francisco, 2004$] \ldots \ldots \ldots \ldots \ldots$

2.12 Tela de artefato na CoTeia $[$ Francisco, 2004$] \ldots \ldots \ldots \ldots$. . . . . . . . . . 31

2.13 Tela de questão no GroupNote $[$ Francisco, $2004 \ldots \ldots \ldots \ldots$

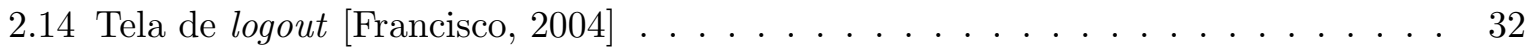

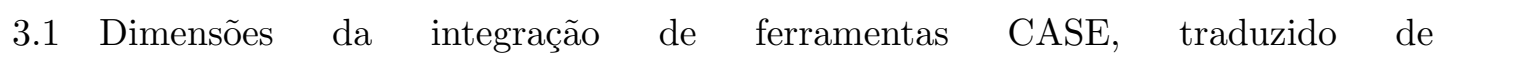

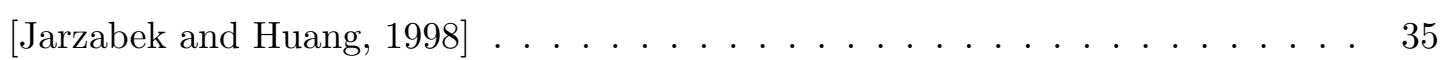

4.1 Fluxo de execução das atividades no modelo de Engenharia de Usabilidade $\mid$ Rocha and Baranauskas, 2003 $\mid \ldots \ldots \ldots \ldots \ldots \ldots \ldots \ldots$

4.2 Alguns dispositivos atuais de computação ubíqua: (a) um pda , (b) um tablet , (c) uma lousa eletrônica e (d) um mimio $\mid$ Pimentel et al., 2003| . . . . . . . . . . 59

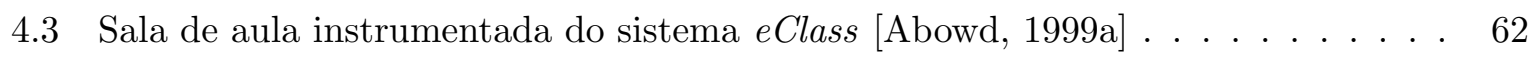

4.4 Hiperdocumentos gerado automaticamente pelo iClass: (a) slide anotado pelo professor e (b) slide de acompanhamento de curso [Pimentel et al., 2003] . . . . . 64

4.5 Visões do Tahuti: (a) slide anotado pelo desenvolvedor e (b) slide com diagrama reconhecido pelo sistema $[$ Hammond and Davis, 2002] $\ldots \ldots \ldots \ldots$. . . . . . 65 
4.6 Diagramas e objetos importados para o Microsoft Power Point: (a)esboço de um diagrama (b)os objetos gerados a partir dos esboços são automaticamente importados para o Power Point (c)os objetos reconhecidos substituem os esboços

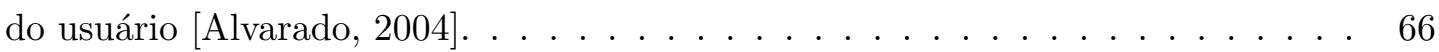

$5.1 \quad$ Engenharia Progressiva/Engenharia Reversa . . . . . . . . . . . . . . . . . . . . . 69

5.2 Níveis de entendimento do software de acordo com o ciclo de vida $\ldots$. . . . . . . 70

$5.3 \quad$ Categorias da engenharia reversa relacionadas ao ciclo de vida . . . . . . . . . . . 71

5.4 Síntese do método de engenharia reversa FUSION-RE/I [Costa, 1997 $] \ldots$. . . . . 73

5.5 Tela de exibição de projetos na primeira versão de DocRationale . . . . . . . . . 81

5.6 Novo esquema navegacional da ferramenta DocRat $\ldots \ldots \ldots$. . . . . . . . 82

5.7 Protótipo de tela da ferramenta DocRat . . . . . . . . . . . . . . . . . 84

5.8 Página com a lista de projetos na ferramenta DocRat $\ldots \ldots \ldots \ldots$. . . . . . 90

5.9 Arquitetura da ferramenta DocRat $\ldots \ldots \ldots \ldots \ldots$. . . . . . . . . 99

$6.1 \quad$ Passos do reconhecimento de escrita $\ldots \ldots \ldots$. . . . . . . . . . . . . . . . 103

6.2 (a) Direções e valores utilizados na codificação de [Freeman, 1974]. (b) Exemplos de caracteres e concatenação de segmentos e traços. (c) Identificação das primitivas e cálculo da direção, onde os pontos representam o início e o fim de cada primitiva . . . . . . . . . . . . . . . . . . . . 104

6.3 Algoritmo Casamento Estrutural Flexível . . . . . . . . . . . . . . . 106

6.4 Versões deformadas do caractere "T" resultantes de alteração no tipo (a) e na direção (b) das primitivas (adaptado de $[$ Chan and Yeung, 1999|. . . . . . . . . . 107

6.5 Tela do editor de escrita manual $\ldots \ldots \ldots \ldots$

6.6 Tela do editor para captura de artefatos de software . . . . . . . . . . . . . . . . 112

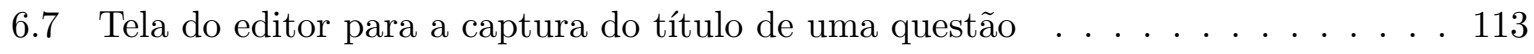

6.8 Tela do editor para captura de posição e argumentos . . . . . . . . . . . . . . 113

6.9 Tela do editor para captura $\operatorname{argumentos} \ldots \ldots \ldots \ldots$. . . . . . . . . 114 


\section{Lista de Tabelas}

$4.1 \quad$ Princípios da categoria Aprendizagem . . . . . . . . . . . . . . . . . . 45

$4.2 \quad$ Princípios da categoria Flexibilidade $\ldots \ldots \ldots \ldots \ldots$

$4.3 \quad$ Princípios da categoria Robustez $\ldots \ldots \ldots \ldots \ldots \ldots$

5.1 Tempo gasto pelos usuários para efetuar o teste em cada versão da ferramenta . 94

5.2 Número de erros cometidos pelos usuários ao efetuar o teste em cada uma das versões da ferramenta $\ldots \ldots \ldots \ldots$. . . . . . . . . . . . . . . . . . . 94

5.3 Graus de dificuldade para realização de operações, entendimento da hierarquia, e navegação pelo sistema a partir das respostas de questionários pelos usuários . 95

5.4 Classificação da localização corrente e qualidade das informações de orientação, a partir das respostas de questionários pelos usuários $\ldots \ldots$. . . . . . . . . . 96 


\section{Resumo}

Durante o processo de desenvolvimento de software, uma grande quantidade de documentos é gerada com o propósito de registrar as experiências e as decisões relacionadas ao projeto de software. Apesar do esforço empregado na documentação de tais informações, muitas vezes esses documentos não contêm informações suficientes e necessárias para o completo entendimento do software, para a reutilização das experiências adquiridas e a recuperação do processo de tomada de decisão. De maneira geral, apenas as decisões finais a respeito do projeto são documentadas. O Design Rationale (DR) consiste das informações adicionais aos documentos padrões em um processo de desenvolvimento de software, facilitando sua compreensão, manutenção e reuso. Na literatura, muitas pesquisas referem-se aos problemas relacionados à atividade de captura de $\mathrm{DR}$, principalmente no que diz respeito à sobrecarga de trabalho durante o momento de design. O desenvolvimento de mecanismos que facilitem a captura de Design Rationale durante a elaboração de artefatos de software é ainda um desafio. No contexto de ferramentas CASE (Computer Aided Software Engineering), cuja utilização enfrenta grande resistência por parte de seus usuários (desenvolvedores), torna-se imprescindível a aplicação de técnicas para garantir a máxima usabilidade dessas ferramentas, de forma a minimizar a resistência à sua utilização. $\mathrm{O}$ paradigma da computação ubíqua trouxe grandes mudanças ao desenvolvimento de aplicações da Ciência da Computação, visto que estas aplicações são transparentes, apresentam um comportamento contínuo e ciente de contexto, e visam tornar a interação com o usuário a mais natural possível. Diante desse contexto, a adoção de mecanismos de computação ubíqua na atividade de captura de DR torna-se uma abordagem de interesse científico. O uso de mecanismos de computação ubíqua faz com que a captura das informações e decisões relacionadas ao projeto de software seja realizada de forma mais natural, reduzindo a sobrecarga do uso de uma ferramenta que necessite de tempo adicional para o armazenamento do DR, seja durante o processo de tomada de decisões ou depois do mesmo. Assim sendo, o trabalho realizado neste projeto de mestrado consistiu na reengenharia de uma ferramenta de suporte a $D R$ e à sua integração com um editor gráfico que permite a escrita manual e oferece um serviço de reconhecimento de escrita, de modo a prover uma maneira mais flexível para a entrada de dados e que pode ser utilizada em dispositivos com diferentes tamanhos e características, tais como Tablet PCs e lousas eletrônicas. 


\begin{abstract}
During the process of software development, a great amount of documents is generated with the purpose of registering experiences and decisions related to software project. Despite the effort made aiming at documenting of such information, in general, these documents do not contain enough and necessary information for the complete understanding of the software, for the reuse of the acquired experiences and the recovery of the process of decision making. In general, only the final decisions regarding the project are registered. The Design Rationale (DR) consists of the additional information to standards documents in a process of software development, aiming to facilitate its understanding, maintenance and reuse. In literature, many researches reveal the problems related to the activity of DR capture, especially related to the work overload during the moment of design. The development of mechanisms to facilitate the Design Rationale capture, during the elaboration of software artifacts, is still a challenge. In the context of CASE (Computer Aided Engineering Software) tools usage, users (developers) present great resistance, so the application of techniques to achieve the maximum usability in the tools becomes essential, aiming to minimize the resistance to their adoption. The paradigm of ubiquitous computing brought great innovations to the development of applications, since the applications are transparent; they present a continuous and aware context behavior, and aim the user-computer interaction become the most natural as possible. For that reason, the adoption of ubiquitous computing mechanisms in the activity of DR capture becomes an approach of scientific interest. The use of the ubiquitous computing makes the capture of the information and decisions related to software project be carried out on a more natural way, reducing the overload of using a tool that needs additional time for the DR storage, either during the process of making decisions or just after. This master project consisted of re-engineering of a DR tool and its integration with a graphical editor. The editor allows handwriting and offers a service of writing recognition in order to provide a more flexible way for the data entry and can be used in devices of different sizes and characteristics, such as Tablet PCs and electronic blackboards.
\end{abstract}




\section{Agradecimentos}

Agradeço a Deus, por ter me dado forças e me ajudado a não desistir diante das dificuldades encontradas durante a realização deste trabalho.

Agradeço ao meu marido Eduardo, por toda compreensão, paciência e incentivo nos momentos mais difíceis.

Agradeço à minha família que sempre me ajudou e me apoiou em tudo o que foi preciso, durante toda a minha vida.

Agradeço à professora Renata, minha orientadora, por ter acreditado em mim e me dado a oportunidade de retornar ao ICMC-USP depois de tanto tempo.

Agradeço ao meus amigos André Freire e Valter Inácio, pelo incentivo e colaboração dedicados a este trabalho.

Agradeço à professora Rosely Sanches pela atenção, conselhos e contribuições dadas a este trabalho.

Agradeço a todos meus amigos que de alguma forma contribuíram para a realização deste trabalho, como Carlos, Pedro, Jane, Débora e colegas do laboratório Intermídia.

Agradeço à professora Maria da Graça Campos Pimentel pela oportunidade de trabalhar no Projeto Tidia-Ae e à FAPESP pelo apoio financeiro.

Agradeço às minhas amigas Thaís, Renata e Sandra pelos bons momentos que passamos juntas durante todo esse período.

Agradeço ao ICMC-USP e aos seus funcionários pelo apoio na realização deste trabalho. 


\section{Capítulo 1}

\section{Introdução}

\subsection{Contexto}

Nos últimos anos, devido à sua evolução e ao surgimento de novas tecnologias, a computação tem se tornado cada vez mais presente no cotidiano das pessoas, sendo utilizada não só no ambiente de trabalho e estudo, mas também no entretenimento e no auxílio às atividades domésticas. Diante desse contexto, surgiu um novo paradigma, o paradigma da computação ubíqua, que nos trouxe a idéia de tornar os serviços computacionais tão persistentes e integrados ao ambiente, que estes se tornariam transparentes aos seres humanos Abowd, 1999b.

As pesquisas realizadas em computação ubíqua apontam grandes desafios para a ciência da computação em geral, uma vez que requerem o desenvolvimento de aplicações que sobrevivam ao uso diário e contínuo Abowd, 1999b. Segundo Abowd, existem três aspectos fundamentais que devem ser observados no desenvolvimento de aplicações ubíquas:

- interfaces transparentes ou naturais: buscar alternativas apropriadas de interface, que possam substituir o tradicional desktop, de forma que o usuário não tenha a necessidade de mudar seus hábitos para fazer uso da aplicação;

- sensibilidade ao contexto: a aplicação deve possuir a habilidade de modificar seu próprio comportamento baseada no conhecimento do contexto de seu uso;

- captura automática e acesso: capturar automaticamente as experiências do usuário e possibilitar a sua recuperação ao longo do tempo.

Sob esse novo paradigma, observa-se que parte das informações que são trocadas nas experiências diárias poderiam ser capturadas, transformadas em documentos, armazenadas, recuperadas e apresentadas ao longo do tempo. Um cenário no qual esse processo pode ser explorado é o da captura de informações e decisões relativas ao ciclo de vida do software. 
Durante o processo de desenvolvimento de software, uma grande quantidade de documentos é gerada com o propósito de registrar as experiências e as decisões relacionadas ao projeto de software. O armazenamento e a recuperação da documentação relativa ao processo de desenvolvimento de software têm como objetivo facilitar a compreensão, utilização e manutenção do software.

O registro das informações relativas à decisão é muito importante, pois soluções discutidas e adotadas em um projeto podem ser relevantes também para outros projetos, uma vez que erros já cometidos poderiam ser evitados e alternativas já investigadas poderiam ser mais bem aproveitadas Souza et al., 1998.

O conjunto de informações relacionadas não só às decisões, mas também relativas às razões que direcionaram cada decisão, incluindo as alternativas consideradas, as justificativas e os argumentos que conduziram à decisão é denominado Design Rationale (DR) [Souza et al., 1998].

Neste trabalho foi desenvolvida uma aplicação com a finalidade de unir a captura do $D R$ com as facilidades propiciadas pelo uso da computação ubíqua, com o objetivo de registrar o $D R$ de artefatos de projetos de software da forma menos intrusiva possível.

\subsection{Motivação}

Embora exista um grande esforço visando garantir que as informações contidas na documentação estejam compatíveis com o estado do software em utilização, muitas vezes estes documentos não contêm informações suficientes e necessárias para o completo entendimento do software, para a reutilização das experiências e a recuperação do processo de tomada de decisão.

De maneira geral, apenas as decisões finais a respeito do projeto são documentadas, e a falta de registro das informações relativas à decisão são perdidas, levando a uma repetição dos erros anteriormente cometidos. As "razões" de projeto ou Design Rationale $(D R)$ consiste das informações adicionais aos documentos padrões do processo de desenvolvimento de software, facilitando sua compreensão, manutenção e reuso.

No contexto de ferramentas CASE (Computer Aided Software Engineering), cuja utilização enfrenta grande resistência por parte de seus usuários (desenvolvedores), torna-se imprescindível a aplicação de técnicas para garantir a máxima usabilidade dessas ferramentas, de forma a minimizar a resistência ao seu uso. Diante deste contexto, surge a necessidade de uma aplicação que torne a captura das informações e decisões relacionadas ao projeto de artefatos de software de forma mais natural, eliminando a sobrecarga do uso de uma ferramenta que necessite de tempo e atenção adicionais para o armazenamento do $D R$, seja durante o processo de tomada de decisões ou depois do mesmo. 
Assim sendo, o trabalho realizado neste projeto de mestrado consistiu na evolução de uma ferramenta de suporte a Design Rationale por meio da sua integração a um mecanismo ubíquo para a captura de $D R$ de projetos de software. Um editor gráfico que permite a escrita manual e oferece um serviço de reconhecimento de escrita foi incorporado à ferramenta de modo a prover uma maneira mais flexível para a entrada de dados e que pode ser utilizada em dispositivos com diferentes tamanhos e características, tais como Tablet PCs e lousas eletrônicas. Para a realização dessa integração foi necessária, em primeiro lugar, a reengenharia completa da ferramenta existente, de modo a resolver os problemas já conhecidos e prepará-la para posteriores evoluções.

\subsection{Objetivos}

A DocRationale Francisco, 2004 ${ }^{1}$ é uma ferramenta CASE, cujo objetivo é permitir a captura, armazenamento e recuperação de Design Rationale de artefatos de software. Foi desenvolvida como projeto de um mestrado anterior orientado pela Profa. Renata Fortes e foi utilizada como ferramenta de apoio ao processo de desenvolvimento de projetos de software em várias disciplinas oferecidas no ICMC-USP.

Conforme detalhado na qualificação de mestrado, este trabalho tem como um dos objetivos a evolução da ferramenta DocRationale, com o propósito de permitir a captura de Design Rationale de modo informal e automático, por meio da integração de um editor gráfico com reconhecimento de escrita manual.

Embora seja consenso que a documentação e o registro das razões de projeto sejam muito importantes, a resistência ao uso da DocRationale por parte dos desenvolvedores ocorre devido aos vários problemas de usabilidade existentes na ferramenta e, principalmente, devido aos esforços adicionais necessários para o registro das informações.

No decorrer do desenvolvimento do trabalho, foram observados vários problemas com a ferramenta DocRationale, tais como: incompatibilidade da interface com padrões $W e b$, problemas de usabilidade que prejudicavam sua aceitação por parte dos usuários, e a grande dificuldade de manutenção do código-fonte, o que tornava o trabalho de evolução da ferramenta muito mais complexo. Diante de todos esses fatores e tendo por finalidade facilitar o uso da ferramenta, foi constatado que não adiantaria prover um meio de captura de dados mais ubíquo (interface para escrita manual) sem antes resolver os problemas de usabilidade já existentes. Assim sendo, embora esse não fosse o foco do trabalho, decidiu-se por realizar a reengenharia da ferramenta

\footnotetext{
${ }^{1}$ Disponível on-line no endereço http://vinho.intermidia.icmc.usp.br/ docrationale/DocRat/
} 
DocRationale, que deu origem a uma nova versão da ferramenta denominada DocRat ${ }^{2}$. A reengenharia da ferramenta envolveu atividades da engenharia reversa, atividades de remodelagem da interface e das operações do sistema e, finalmente, a reimplementação de todo o código da ferramenta.

Como se pode constatar, o trabalho desenvolvido tem como propósito geral a diminuição da sobrecarga de trabalho durante ou após as reuniões, no que se refere ao registro de discussões e decisões a respeito do projeto de um artefato de software, uma vez que o tempo gasto com tal tarefa poderia ser utilizado em outras atividades no desenvolvimento do projeto.

\subsection{Organização do Trabalho}

Essa dissertação está organizada em sete capítulos. Neste primeiro capítulo foram apresentadas as considerações iniciais, a motivação e os objetivos do trabalho de mestrado.

A revisão bibliográfica é descrita nos capítulos 2, 3 e 4. No segundo capítulo são apresentadas definições de Design Rationale, os benefícios e as dificuldades a respeito de sua utilização e uma descrição detalhada da ferramenta DocRationale. No terceiro capítulo é realizada uma breve revisão sobre os principais problemas relacionados à adoção e ao uso de ferramentas CASE. No quarto capítulo são apresentados conceitos de usabilidade de sistemas computacionais, um processo de reengenharia de usabilidade e também definições sobre computação ubíqua e suas aplicações em projetos relacionados.

No quinto capítulo são apresentados os detalhes do trabalho de reengenharia da DocRationale que deu origem a uma nova versão da ferramenta, denominada DocRat. A evolução da nova ferramenta DocRat devido à sua integração com o mecanismo de computação ubíqua é descrita no sexto capítulo.

No sétimo capítulo são apresentadas as conclusões e as propostas para futuros trabalhos. Por fim, são apresentadas as referências bibliográficas e os documentos anexos.

\footnotetext{
${ }^{2}$ Disponível on-line no endereço http://notsafe.icmc.usp.br/docrat
} 


\section{Capítulo 2}

\section{Design Rationale}

\subsection{Considerações iniciais}

A documentação realizada durante o desenvolvimento de um projeto de software é de fundamental importância, na medida em que visa proporcionar melhor conhecimento a respeito do software, diminuir a complexidade de sua manutenção, facilitar a comunicação entre os membros da equipe de projeto e aumentar a possibilidade de reuso de suas informações em projetos posteriores Souza et al., 1998.

Embora exista um consenso de que a documentação é muito importante no processo de software, geralmente apenas as informações relativas às decisões finais de determinada fase são registradas Burge and Brown, 2000, uma vez que os desenvolvedores consideram onerosa a tarefa de registrar cada uma das alternativas investigadas. Caso as informações referentes às alternativas e decisões fossem registradas, além de todas as facilidades já descritas acima, haveria também maior facilidade de integração de um novo membro no projeto, visto que ele teria maior visibilidade das idéias que conduziram o projeto até o momento.

Os sistemas de suporte a Design Rationale (DR) oferecem o auxílio necessário para o armazenamento dessas informações adicionais aos documentos padrões do processo de software. As seções seguintes apresentam os fundamentos de $D R$, definições, esquemas de representação, formas de captura e recuperação, e a ferramenta DocRationale, que será utilizada para o desenvolvimento do trabalho proposto.

\subsection{Definições sobre Design Rationale}

Na literatura são encontradas várias definições a respeito do termo Design Rationale e algumas delas são apresentadas a seguir. 
Segundo Gruber \& Russel Gruber and Russel, 1991, DR se refere a explicações sobre o raciocínio do projeto, ou seja, explicações de "como" e "porque" um artefato foi projetado de uma determinada forma. Um artefato pode ser visto como qualquer informação gerada, alterada ou usada durante o processo de desenvolvimento [Jacobson et al., 1999. Assim sendo, um artefato pode estar na forma de um modelo, um elemento do modelo (uma classe, um subsistema, etc.), um documento, um arquivo contendo código fonte, ou mesmo um arquivo contendo código executável [Francisco et al., 2003].

De acordo com Souza Souza et al., 1998, DR corresponde à documentação das decisões do projeto, das alternativas consideradas, das avaliações e argumentações que conduziram a tomada dessas decisões, juntamente com suas respectivas justificativas.

Para Hu [Hu et al., 2000], $D R$ é a justificativa da decisão tomada para a elaboração de um artefato do projeto ou parte dele, incluindo suas deliberações, razões, alterações e todas as decisões intermediárias. Já para Burge \& Brown Burge and Brown, 2000, DR consiste das decisões tomadas durante o processo do projeto e as razões que determinaram tais decisões.

Portanto, pode-se dizer que $D R$ consiste das informações adicionais e relevantes à documentação básica do processo de tomada de decisões durante a elaboração de um artefato do projeto, tais como o raciocínio do projeto, as alternativas consideradas, as discussões e razões que conduziram à decisão final.

Pode-se dizer também que o uso de sistemas de $D R$ traz vários benefícios para o processo de software, dentre os quais pode-se citar:

- contribui na redução da arbitrariedade na tomada de decisões, visto que apresenta uma metodologia estruturada para apoiá-las, sendo que as justificativas e os argumentos são registrados e poderão ser recuperados em momentos posteriores Monk et al., 1995;

- contribui para a compreensão do sistema, diminuindo a complexidade da manutenção e ajudando na avaliação das conseqüências que podem surgir devido a uma alteração no sistema, possibilitando que erros já cometidos sejam evitados;

- contribui para a melhoria na comunicação entre os membros da equipe de projeto, entre os projetistas e os usuários do sistema, constituindo uma ferramenta importante no auxílio a novos integrantes da equipe, uma vez que fornece uma visão ampla do projeto (decisões e alternativas) e não só a documentação do que está implementado Souza et al., 1998;

- contribui para o acompanhamento e a descoberta de erros durante o desenvolvimento do projeto Souza et al., 1998; 
- possibilita que as discussões, razões e decisões de um projeto sirvam de base para o desenvolvimento de outros projetos, visto que muitas vezes as soluções adotadas para um projeto são relevantes também para outros.

Embora os sistemas de $D R$ apresentem todas essas vantagens, eles têm sido pouco usados na prática. Dentre os principais problemas relacionados à sua utilização pode-se destacar: (i) o tempo adicional gasto para o armazenamento do $D R$; (ii) a diferença de formato existente entre a informação fornecida pelos desenvolvedores e a representação do $D R$; (iii) a dificuldade de encontrar um sistema de $D R$ que atenda a todas as necessidades da organização e forneça um mecanismo de recuperação eficiente [Hu et al., 2000]. Observa-se que nas desvantagens apresentadas não existe uma concentração de problemas relacionados a uma determinada atividade, tal como captura, ou representação ou recuperação do $D R$. Entretanto, possibilitar mais flexibilidade na captura de $D R$ durante o desenvolvimento do projeto é um obstáculo a ser superado e que constitui o objeto de estudo deste trabalho.

\subsection{Abordagens para a construção de Sistemas de DR}

De acordo com Hu [Hu et al., 2000], as principais abordagens para a construção de sistemas de $D R$ são: abordagem orientada por processo e abordagem orientada por característica; sendo que o processo de projeto de um artefato pode passar por diferentes fases, algumas fases mais orientadas por processo e outras mais orientadas por característica.

A abordagem orientada por processo se aplica para as fases do processo de projeto em que os problemas são vagos, a solução tecnológica ainda não foi escolhida e existe pouca ou nenhuma padronização do artefato que está sendo projetado. Nesse contexto, existem muitas discussões a respeito dos requisitos (que geralmente não estão totalmente definidos) e opções a serem investigadas, ou seja, trata-se de uma fase mais dinâmica do processo, uma vez que o conhecimento vai sendo organizado de acordo com a evolução do próprio projeto.

Sistemas de $D R$ orientados por processo enfatizam o $D R$ como sendo a história do processo de projeto, nos quais as questões, opções e argumentos são capturados e organizados de acordo com o progresso do projeto. O esquema de representação utilizado pela abordagem orientada por processo é geralmente baseado em grafos, usando nós e links, sendo que os nós representam as questões, posições (opções) e argumentos, e os links indicam as relações entre os nós. Esse tipo de esquema de representação provê uma estrutura flexível e maior facilidade no registro de $D R$. No entanto, o grande desafio concentra-se na conversão da informação capturada em uma estrutura de $D R$, ou seja, na criação das ligações entre os nós de modo a tornar a informação acessível. 
A abordagem orientada por característica se aplica em fases onde há maior detalhamento do projeto, ou em atividades de rotina no processo do projeto, onde as regras e o conhecimento sobre o domínio de informação específico são considerados em cada tomada de decisão de projeto. Uma decisão de projeto, não suportada pelas regras de conhecimento, necessita ser confirmada, gerando uma revisão das regras e do conhecimento. Sistemas de $D R$ orientados por característica são geralmente desenvolvidos em um contexto de tarefa particular, usando um estudo empírico. Em geral, esses sistemas possuem bases de conhecimento do domínio que podem ser usadas para apoiar o raciocínio automatizado. Assim sendo, a abordagem orientada por característica exige mais formalidade na representação das regras e do conhecimento em relação à abordagem orientada por processo, mas possibilita que a recuperação do $D R$ seja feita mais facilmente, tanto para a consulta quanto para o reuso de $D R$.

Como as duas abordagens apresentadas possuem qualidades e restrições, propõe-se a combinação das mesmas, gerando uma abordagem híbrida, como forma de superar as limitações individuais e aproveitar as qualidades de cada abordagem. A partir da união das duas abordagens são gerados sistemas que fornecem uma estrutura lógica para o $D R$, além de gravarem o histórico do processo de projeto Hu et al., 2000.

\subsection{Esquemas de representação}

Pesquisas relacionadas a $D R$ no domínio de desenvolvimento de software se preocupam com o desenvolvimento de métodos e representações apoiadas por computador para a captura, manutenção, recuperação e reuso das decisões tomadas durante o processo de software Peña-Mora and Vadhavka, 1996 .

O $D R$ capturado é organizado, geralmente, por meio de regras, as quais são determinadas pelo esquema de representação. A organização da informação capturada em uma estrutura acessível é uma questão crítica e portanto um bom esquema de representação é essencial para permitir uma recuperação efetiva. Para escolher qual esquema de representação deve ser utilizado, deve-se primeiramente observar a perspectiva do $D R$ [Francisco et al., 2003].

Segundo Shipman \& McCall [Shipman and McCall, 1997], existem três diferentes perspectivas de $D R$ : argumentação, comunicação e documentação.

A perspectiva da argumentação considera que o $D R$ está relacionado aos diversos pontos discutidos, aos argumentos apresentados e a forma como foram selecionados, ou seja, está relacionado ao raciocínio dos projetistas na resolução de problemas. O objetivo dessa perspectiva é registrar o $D R$ para evidenciar e corrigir as deficiências dos argumentos, buscando a melhora na argumentação dos projetistas e conseqüentemente a melhora da qualidade do projeto. 
De acordo com a perspectiva da comunicação, $D R$ está relacionado à captura e recuperação de toda comunicação que ocorre entre os desenvolvedores, através de diversas mídias (áudio, vídeo, email, anotações, diagramas, etc). Essa perspectiva tem por objetivo registrar todo tipo de comunicação possível entre os desenvolvedores, com a finalidade de capturar as evoluções do projeto.

Na perspectiva da documentação, $D R$ se refere ao registro da informação sobre as decisões de um projeto, ou seja, quais decisões foram tomadas, quais foram os motivos que conduziram à tal decisão e quem foi o responsável por ela. Apenas as decisões finais e uma breve explicação das mesmas são registradas. O objetivo dessa perspectiva é armazenar as decisões tomadas da forma mais clara e objetiva possível, de forma que a documentação gerada seja usada tanto para a compreensão do projeto por pessoas externas, como para facilitar o acompanhamento do mesmo pelos membros da equipe.

Nas perspectivas de argumentação e documentação, a captura de informações é realizada de forma estruturada, sob determinada ordem, facilitando o seu armazenamento e, conseqüentemente, a sua recuperação. Na perspectiva de comunicação, as informações não são capturadas de forma ordenada, o que, de certa forma, dificulta a recuperação das mesmas.

Dentre as perspectivas apresentadas, a que possui maior aceitação entre os desenvolvedores é a perspectiva de documentação, pois de alguma forma eles têm que registrar suas funções e ações no processo de desenvolvimento. As desvantagens dessa perspectiva são o tempo e o esforço despendidos à criação da documentação, consumindo recursos que poderiam estar sendo utilizados em outras atividades do projeto, além da possibilidade de inexatidão do $D R$ armazenado.

Considerando-se que nenhuma das três perspectivas é isenta de problemas, Shipman and McCall, 1997 propõem a combinação entre elas para que se obtenha os melhores resultados. Entretanto, tal proposta não é simples de viabilizar, pois cada perspectiva tem uma estrutura própria para representar o $D R$. Assim sendo, quanto mais criteriosa for a representação do $D R$, melhor será a sua recuperação, porém menor será a efetividade na sua captura e vice-versa.

\subsection{Formas de captura e armazenamento}

A captura e a representação efetiva de $D R$ são atividades muito importantes, porém, o valor real de um $D R$ só pode ser avaliado quando ele for útil de fato em um projeto [Francisco et al., 2003].

A captura do $D R$ deve ser realizada durante todo o processo do projeto, através da aquisição das decisões, das opções ou alternativas consideradas, dos argumentos, entre outros. Após 
a captura, deve-se elaborar uma estrutura capaz de representar efetivamente o $D R$ capturado, para que o mesmo possa ser armazenado em um repositório, tornando possível a sua recuperação [Lee, 1997].

De acordo com [Hu et al., 2000], existem dois tipos de captura de $D R$ : a automática, que é executada pelos sistemas de $D R$ e a captura que requer a intervenção do usuário.

A captura automática, que geralmente utiliza a perspectiva de comunicação para a aquisição do $D R$, envolve o uso de ferramentas de apoio, tais como as ferramentas de CSCW (Computer Supported Collaborative Work), ou de uma grande variedade de dispositivos para capturar a troca de informações verbal, tais como câmeras, dispositivos de áudio, telefones, entre outros. As informações escritas e emails também podem ser capturados. A grande vantagem da captura automática é que os desenvolvedores não se envolvem diretamente no processo de captura da informação, ou seja, apenas desenvolvem suas atividades habituais. A desvantagem é que como a captura não é realizada de forma estruturada, a informação é armazenada utilizando uma representação informal, o que prejudica a posterior recuperação da mesma, pois dificulta a sua busca Hu et al., 2000.

A captura baseada na intervenção do usuário, que normalmente utiliza a perspectiva de documentação [Hu et al., 2000], é feita pelos desenvolvedores ou usuários, que são forçados a se desviarem de suas atividades habituais para registrarem o histórico das atividades do projeto, tais como: quais as decisões tomadas, quem foi o responsável, porque e quando ocorreram. A vantagem desse tipo de captura está no fato de que a informação capturada possui uma estrutura e é armazenada por meio de uma representação formal ou semi-formal, o que facilita a sua recuperação. A desvantagem está na sobrecarga de trabalho imposta aos desenvolvedores, que poderiam ocupar esse tempo em outras atividades do projeto.

\subsection{Formas de recuperação}

A recuperação de informações de $D R$ é uma tarefa de fundamental importância em um sistema de $D R$, visto que não é relevante para os desenvolvedores capturar grandes quantidades de informações detalhadas se tais informações não forem acessadas. Sabe-se que quanto mais criteriosa for a representação do $D R$, melhor será a sua recuperação e vice-versa. A consulta e o reuso de $D R$ são efetivos se o $D R$ for armazenado de uma forma que possibilite a sua correta recuperação Hu et al., 2000.

De acordo com Lee [Lee, 1997], com relação à forma de recuperação, os sistemas de $D R$ são classificados como sistemas com recuperação iniciada pelo usuário ou sistemas com recuperação iniciada pelo próprio sistema. 
O sistema de $D R$ com recuperação iniciada pelo usuário é aquele em que o usuário decide quais partes do $D R$ serão examinadas, quando e como serão visualizadas. Esses sistemas devem auxiliar os usuários a tomarem conhecimento das informações armazenadas e tornar fácil o acesso às partes desejadas.

O sistema de $D R$ com iniciativa própria é aquele em que o próprio sistema, por meio da utilização de uma base de conhecimento, decide quando e como apresentar um $D R$ ou parte dele [Lee, 1997], como por exemplo, a apresentação da especificação, das questões e comentários relacionados a um item de um diagrama quando o projetista clica com o mouse sobre ele.

Dependendo do interesse dos desenvolvedores, diferentes estratégias podem ser utilizadas na atividade de recuperação de $D R$, dentre as quais pode-se citar: navegação de $D R$ arquivado, recuperação baseada em pesquisa, acionamento automático e estratégias de recuperação híbridas Hu et al., 2000.

A navegação de $D R$ permite aos projetistas verificarem todo o $D R$ arquivado, passando de um nó a outro pelos links, obtendo um histórico do projeto Hu et al., 2000]. Para um artefato complexo, em que uma grande quantidade de informação é armazenada durante o processo do seu projeto, a estratégia de navegação não se mostra eficiente devido ao fato da potencial dificuldade, e demora da busca por respostas específicas.

A estratégia de recuperação com base em pesquisa se mostra mais eficiente com relação a anterior porque permite a recuperação de acordo com o interesse dos projetistas. As pesquisas devem ser baseadas em perguntas a serem respondidas por meio da exploração de diferentes opções (perguntas do tipo 'o que - se?') ou por meio de um retorno à rede de nós e links para se descobrir a argumentação ou a razão por trás da decisão (perguntas do tipo 'por que?') Hu et al., 2000.

No acionamento automático, é realizada uma monitoração do desenvolvimento do projeto, de acordo com as regras e critérios do projeto em questão Hu et al., 2000. É utilizado um monitor para verificar o processo do projeto e comparar as decisões feitas com as regras e critérios da biblioteca de $D R$ ou da base de conhecimento. Caso diferenças sejam constatadas, o $D R$ é mostrado automaticamente.

Finalmente, as estratégias de recuperação híbridas se constituem de uma combinação das estratégias de navegação, recuperação baseada em pesquisa e acionamento automático, fazendo com que a recuperação seja mais eficiente Hu et al., 2000. 


\subsection{A ferramenta DocRationale}

Os sistemas de $D R$ têm como objetivo apoiar a tarefa de documentação das decisões de um projeto, registrando como e porque tais decisões foram tomadas. Em geral, os sistemas de $D R$ são pouco utilizados na prática porque, ou acarretam muito esforço aos desenvolvedores para a sua captura, interferindo nas atividades habituais do desenvolvimento do processo, embora facilitem sua recuperação, ou então, facilitam a captura mas tornam a recuperação do $D R$ ineficiente.

A DocRationale Francisco, 2004 é uma ferramenta para Web que foi elaborada com o propósito de permitir captura, estruturação, armazenamento e recuperação de $D R$ relacionado aos artefatos de software.

A DocRationale possui uma representação simples de $D R$ para facilitar o seu uso e não acarretar tanto esforço aos desenvolvedores. Não faz uso de técnicas de Inteligência Artificial, muito utilizada em outros sistemas, pois o objetivo da DocRationale não é fazer inferências sobre uma base de informações de projetos, mas sim documentar informações importantes de projeto tendo em vista o reuso dessas mesmas informações em outros projetos. Para tanto, a ferramenta privilegia o fator de colaboração entre os membros da equipe de desenvolvimento para obtenção de $D R$. A implementação da ferramenta aproveita-se ainda da infra-estrutura fornecida pela CoTeia Arruda Jr. et al., 2002 e pela API Annotation Izeki, 2001.

A ferramenta DocRationale foi construída sob a abordagem orientada por processo, pois pensou-se em projetos que seriam inseridos na ferramenta sem que se conhecesse seu domínio, ou seja, projetos em que ainda não se tivesse certeza de quais $D R s$ seriam capturados e recuperados. Assim, abriu-se a possibilidade do usuário inserir/excluir fases, atividades e artefatos durante todo o desenvolvimento, ou até de fazer uso de um modelo inicial, já que tal modelo também pode sofrer modificações.

Em busca de uma recuperação satisfatória, a DocRationale adotou uma combinação das perspectivas de comunicação-documentação e de argumentação para a captura e armazenamento do $D R$. Sob a perspectiva de comunicação-documentação, a ferramenta possibilita que todas as formas de comunicação digital (arquivos de áudio, vídeo, email, etc) sejam anexadas, de forma organizada, complementando a documentação do processo. Para a perspectiva de argumentação foram utilizadas as características do esquema de representação PHI (Procedural Hierarchy of Issues) McCall, 1986 apud Shum, 1991. A adoção de PHI ocorreu devido à sua simplicidade na representação de $D R$ e sua estruturação para armazenar $D R$ capturado de forma hierárquica e ordenado cronologicamente, além do fato de ter sido adotada a abordagem por processo. Na DocRationale, o esquema foi simplificado para utilizar apenas três tipos de nós: questões, 
posições (respostas) e argumentos. Dessa forma, tem-se uma captura com intervenção do usuário. Para a recuperação foi estabelecida apenas a navegação, sendo que outras opções de recuperação estão sendo desenvolvidas em outro projeto de mestrado.

\subsubsection{Requisitos da DocRationale}

Para que a ferramenta DocRationale fornecesse suporte ao $D R$ de artefatos de software, verificouse a necessidade de que, para cada projeto iniciado, diversos artefatos deveriam ser elaborados, os quais seriam determinados por uma série de questões, posições e argumentos, além de outros arquivos que representem o $D R$. Foi visto também que cada projeto possui uma equipe composta por desenvolvedores e um gerente responsável pelo desenvolvimento. Tais requisitos, relativos à estruturação das informações na DocRationale podem ser melhor visualizados na Figura 2.1.

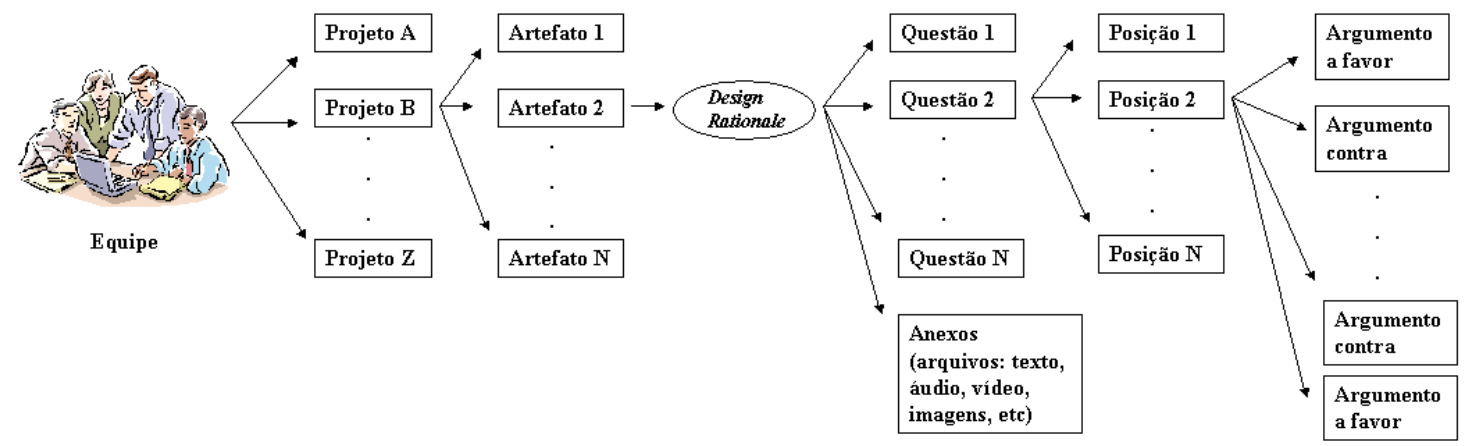

Figura 2.1: Informações a serem manipuladas na ferramenta DocRationale

Outro requisito necessário foi o controle de acesso, pois não seria interessante que qualquer pessoa pudesse ter acesso às informações da DocRationale, e além de estarem cadastrados, os usuários deveriam ter permissão de acesso de acordo com sua função. Assim, os tipos de usuários e suas respectivas funções são:

1. Administrador de Usuários: adicionar, remover, editar e consultar usuários;

2. Administrador de Projetos: inserir, remover, editar e consultar usuários da equipe de projeto; inserir, remover, editar e consultar projetos; inserir, remover, editar e consultar artefatos; inserir e consultar questões, posições e argumentos;

3. Membro do Projeto: consultar usuários da equipe de projeto; consultar projetos; inserir, remover, editar e consultar artefatos; inserir e consultar questões, posições e argumentos;

4. Visitante: consultar usuários da equipe de projeto, consultar projetos, consultar artefatos e consultar questões e inserir posições e argumentos. 
Com relação aos requisitos não-funcionais, decidiu-se pelo desenvolvimento da ferramenta para $W e b$, para que os usuários pudessem acessá-la remotamente, possibilitando que embora não estivessem no mesmo espaço físico ao mesmo tempo, pudessem trabalhar no desenvolvimento de seu sistema.

\subsubsection{O Suporte a DR na DocRationale}

Para apoiar a principal funcionalidade da DocRationale, o suporte a $D R$, foi estabelecida sua integração com a ferramenta CoTeia Arruda Jr. et al., 2002 e com o GroupNote Pimentel et al., 2001b.

A CoTeia é uma ferramenta hipermídia colaborativa assíncrona que permite a criação de páginas $W e b$. Possui diversas funcionalidades, sendo que as mais interessantes para a DocRationale são: (i) criação e edição de páginas $W e b$ que são feitas no próprio browser via formulário HTML (HyperText Markup Language); (ii) histórico, que permite o acesso ao conteúdo das últimas versões de cada hiperdocumento; e (iii) upload, que possibilita a submissão de arquivos (nos formatos permitidos) ao servidor CoTeia.

O GroupNote é um serviço aberto de anotações colaborativas na Web implementado como uma API (Application Programming Interface). As características mais interessantes para a DocRationale são: (i) compartilhamento de anotações por grupos de usuários e (ii) fornecimento da funcionalidade de hierarquia de nós.

Dessa forma, torna-se possível a autoria colaborativa e a inclusão de anexos $(D R)$ por meio da integração da CoTeia. Com a integração do GroupNote tem-se a qualificação das anotações como questão, posição e argumento contra ou a favor.

\subsubsection{Arquitetura}

A arquitetura da ferramenta DocRationale pode ser visualizada na Figura 2.2 .

O módulo de Controle de Acesso (CA) é responsável pelo controle de acesso aos módulos da DocRationale, CoTeia e GroupNote. Os usuários que fazem parte do grupo Administrador de Usuários só acessam o módulo de Gerenciamento de Usuários (GU). Por outro lado, os usuários dos grupos Administrador de Projetos, Membro e Visitante podem acessar os demais módulos da DocRationale, bem como os módulos da CoTeia e GroupNote. Cabe salientar que esses usuários possuem diferentes níveis de permissão nesses módulos. O módulo GU, conforme mencionado anteriormente, só pode ser acessado por usuários do grupo Administrador de Usuários, os quais são responsáveis por cadastrar usuários, autorizar ou rejeitar uma solicitação de cadastro e, ainda, definir qual o papel a ser desempenhado por esse usuário na DocRationale. Os módulos 
gerenciadores Gerenciamento de Projetos (GP), Gerenciamento de Artefatos (GAr), Gerenciamento de Equipes (GE), Gerenciamento de fases (GF) e Gerenciamento de Atividades (GAt) são responsáveis pela manutenção de seus respectivos dados, ou seja, inserir, editar e excluir. Nos módulos de Gerenciamento de Questões (GQ) e Anotações (Posições e Argumentos) as operações permitidas são apenas as de inserção e consulta, visto que tais módulos estão relacionados com o registro de $D R$. Todos os módulos permitem ainda a realização de consultas aos dados. Cabe ressaltar a interdependência entre esses módulos, como por exemplo o fato de que o GQ sempre estar relacionado ao GAr e, esse sempre estar relacionado ao GP. Os módulos tradutores TDC e TDG são responsáveis pela comunicação entre a DocRationale e a CoTeia e entre a DocRationale e o GroupNote, respectivamente. Esses módulos são compostos por funções que recebem dados provenientes da DocRationale, os quais são trabalhados e, posteriormente, repassados às funções da CoTeia ou do GroupNote para atualização de suas respectivas bases de dados.

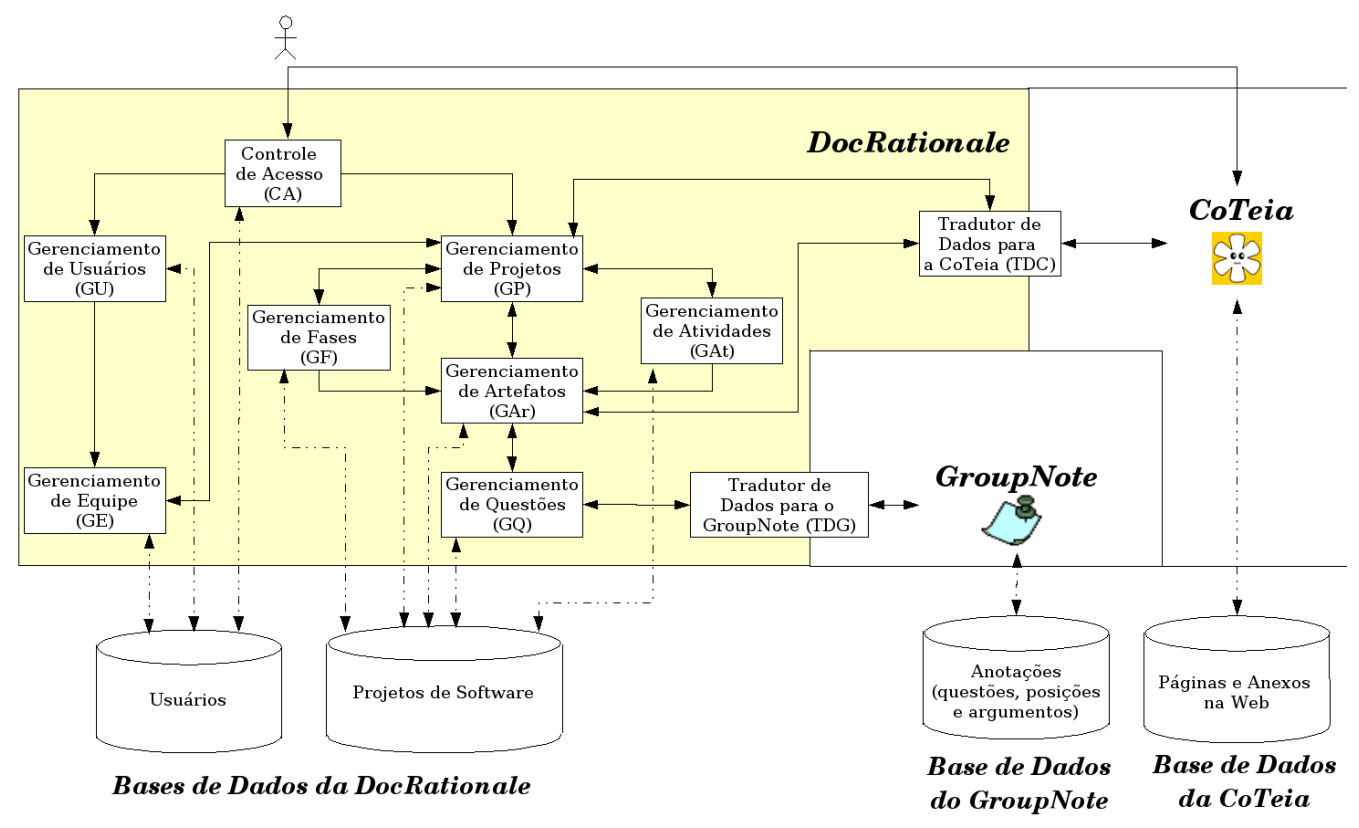

Figura 2.2: Arquitetura da ferramenta DocRationale Francisco, 2004]

\subsubsection{Interface da Ferramenta DocRationale}

Nas telas de projetos, artefatos e questões, que são semelhantes, as funcionalidades disponíveis são facilmente visualizadas a cada instante. As telas possuem um cabeçalho com o nome da ferramenta e operação que está sendo fornecida no momento. Logo abaixo do cabeçalho, encontra-se um menu com todas as operações possíveis e, no rodapé, podem ser encontradas informações sobre o usuário e sua permissão no sistema e projeto, nome do projeto e do artefato em que o usuário se encontra. Na parte central da tela aparecem as informações relevantes à opção feita 
pelo usuário anteriormente, onde se encontram ícones que levam à CoTeia ou ao GroupNote. Para validar os dados a serem enviados pelos usuários, ainda no lado do cliente, foi utilizada a linguagem JavaScript, uma vez que essa pode ser inserida dentro do código HTML e é facilmente interpretada pela maioria dos browsers existentes. A seguir são exibidas telas da DocRationale, como se um usuário estivesse acessando-a. Dessa forma, a primeira tela a ser visualizada pode ser observada na Figura 2.3. Essa tela serve como uma tela de "porta de entrada" para a ferramenta DocRationale.

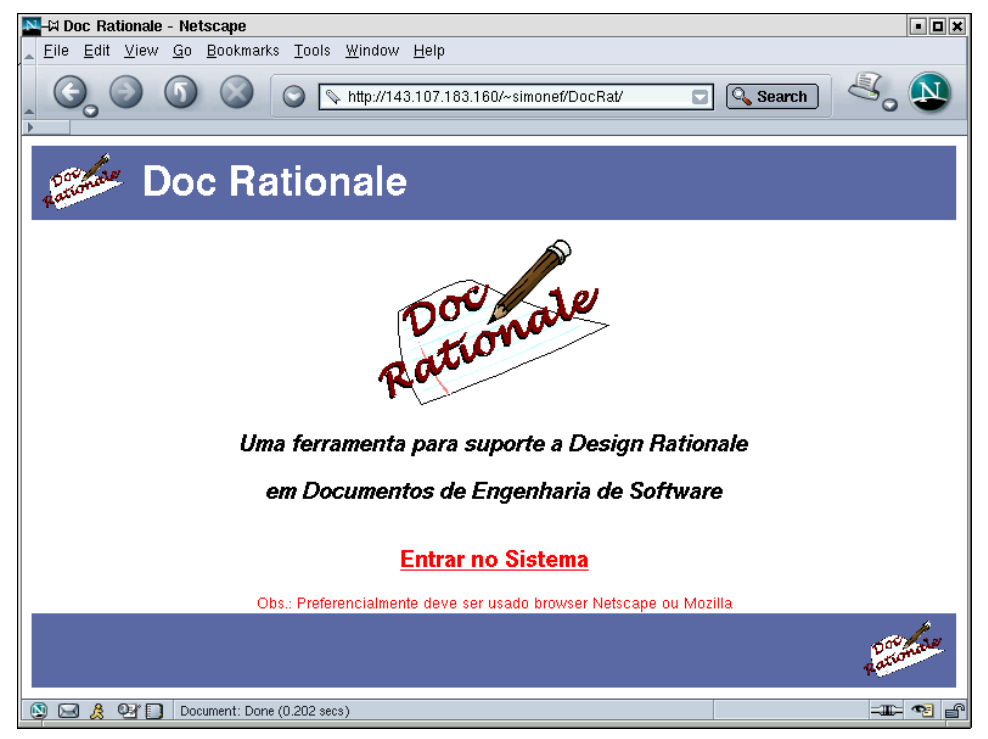

Figura 2.3: Tela de "Porta de entrada" da ferramenta DocRationale Francisco, 2004

A próxima tela a ser vista pelo usuário é a tela de login (Figura 2.4 , na qual é solicitado o seu nome de usuário e sua senha. Na mesma tela são apresentadas as opções de solicitação de senha, caso o usuário a tenha esquecido, e solicitação de conta na ferramenta DocRationale.

Após ter sido efetuado o login com sucesso, o usuário passa a navegar pelas informações contidas na ferramenta DocRationale. Inicialmente, o usuário é levado até a página que contém a lista de todos os projetos dos quais ele faz parte, seja como gerente, membro ou visitante, como pode ser visto na Figura 2.5. Também nessa tela é disponibilizado um menu com opções gerais, além de um menu específico de operações sobre os projetos listados, que se encontra acima da lista de projetos, na parte central da tela. As opções desse menu específico dependem do tipo de permissão que o usuário possui. No caso da Figura 2.5, as opções do menu geral são: Alterar Senha e Sair e, como o usuário logado tem permissão de Administrador de Projetos (informação presente no rodapé da tela), as opções do menu específico são: Inserir, Localizar, Editar e Excluir. Na tabela que lista os projetos, existe um link que conduz o usuário para página correspondente ao projeto na CoTeia, um campo para seleção de projeto para edição ou 


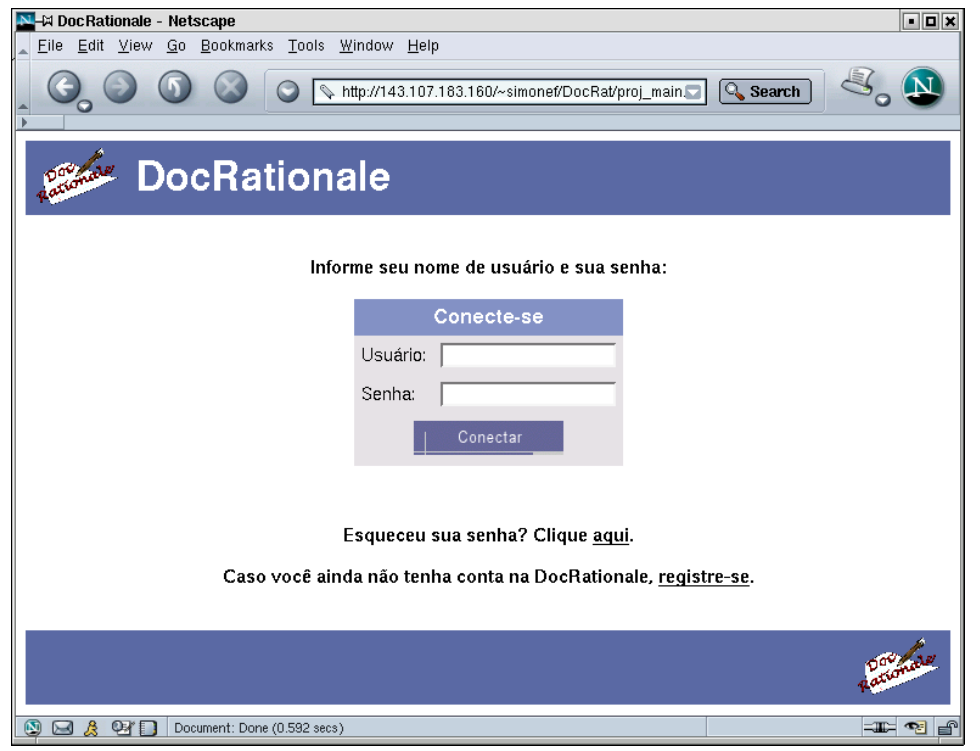

Figura 2.4: Tela de login Francisco, 2004

exclusão e, ainda, no próprio nome do projeto existe um link que apresenta a tela contendo a lista de artefatos desse projeto. Ainda na parte central da tela, tem-se uma legenda na parte inferior à esquerda, indicando através das cores vermelha, azul e preta se os projetos estão atrasados, em andamento dentro do prazo previsto ou já finalizados, respectivamente.

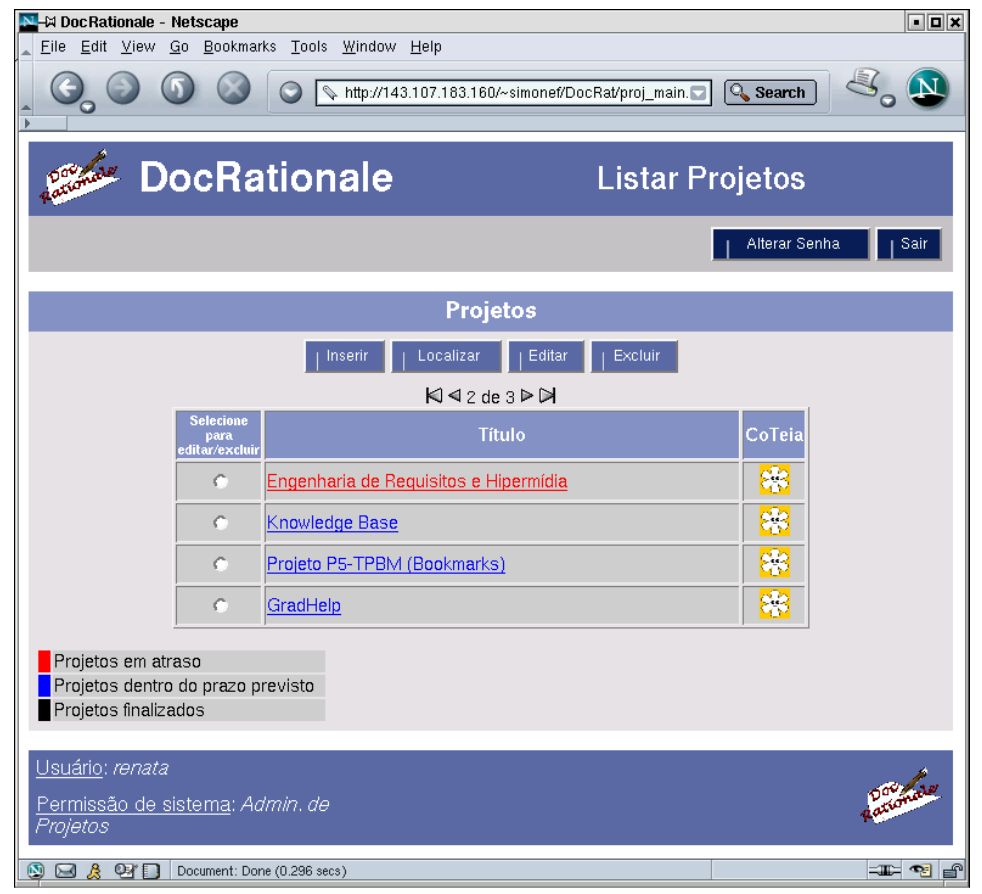

Figura 2.5: Tela de projetos Francisco, 2004

A seguir serão mostradas algumas telas da ferramenta DocRationale. Essas telas pertencem 
à disciplina de Hipermídia. Na Figura 2.6 é exibida a lista de artefatos pertencente ao projeto GradHelp. Essa figura segue o mesmo esquema da tela que exibe a lista de projetos. No rodapé estão as informações como o nome do projeto em que o usuário está e qual a sua permissão nesse projeto. Na parte central, juntamente com a lista dos artefatos, encontra-se o menu específico com as mesmas opções do menu específico da lista de projetos, só que tais opções são disponibilizadas para as ações sobre os artefatos. Na tabela é apresentada a possibilidade de acesso à página da CoTeia correspondente a cada artefato. Também existe o campo para seleção do artefato que se deseja editar ou excluir (essas opções são possíveis devido a permissão do usuário no projeto), além do link no próprio nome que leva o usuário a página com a lista de todas as questões discutidas durante a elaboração de determinado artefato. E novamente, tem-se a legenda seguindo o mesmo esquema da tela da lista de projetos.

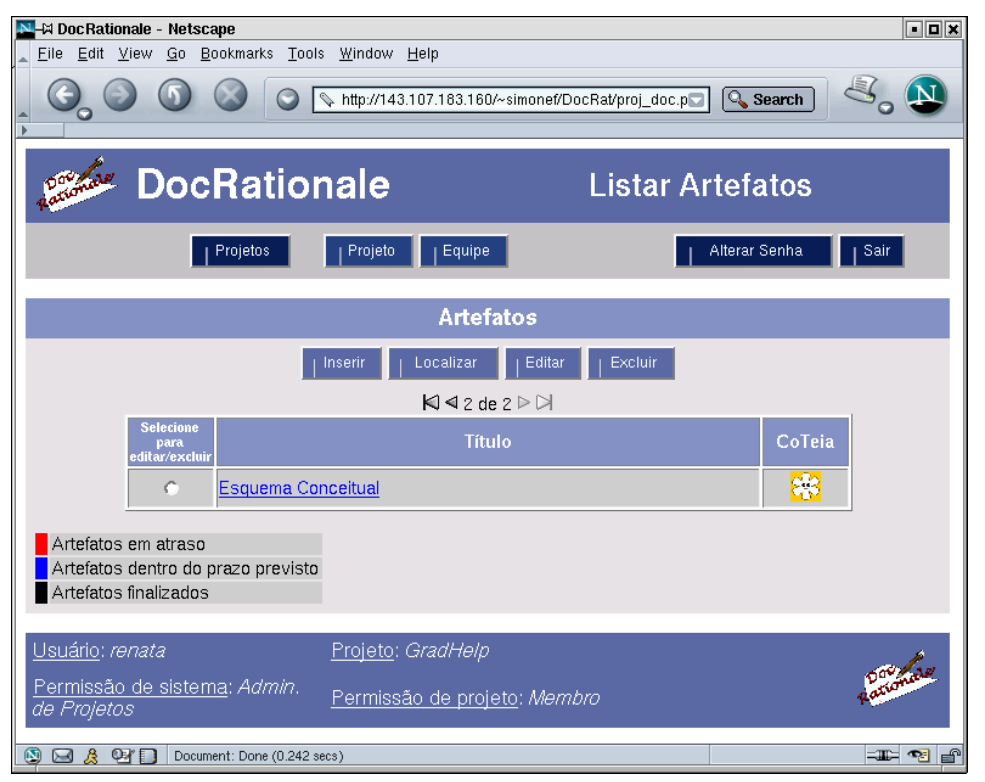

Figura 2.6: Tela de artefatos Francisco, 2004

Feita a escolha pela opção Projeto do menu geral (Figura 2.6), a tela exibida é a que aparece na Figura 2.7. Nessa tela aparecem as informações sobre o projeto em questão: nome, fases (diversas fases que podem existir no projeto), atividades (diversas atividades que podem fazer parte do projeto), data de início, data prevista do término, data do término, responsável pelo projeto (administrador do projeto), condição do projeto (em andamento dentro do prazo previsto, atrasado ou finalizado) e um link para a página correspondente do projeto na CoTeia. Se o usuário tivesse permissão de Administrador de Projetos nesse projeto, poderia ainda editar e/ou excluir as fases e/ou atividades do projeto.

Caso fosse feita a escolha da opção Equipe do menu geral (Figura 2.6 ou Figura 2.7), o usuário 
teria a sua disposição a tela com a lista dos usuários que formam a equipe de desenvolvimento do projeto (Figura 2.8). Como o usuário em questão tem permissão de membro nesse projeto, ele apenas pode localizar um usuário participante da equipe. Se o usuário possuísse a permissão de Administrador do Projeto, ele poderia inserir/editar/excluir usuários da equipe.

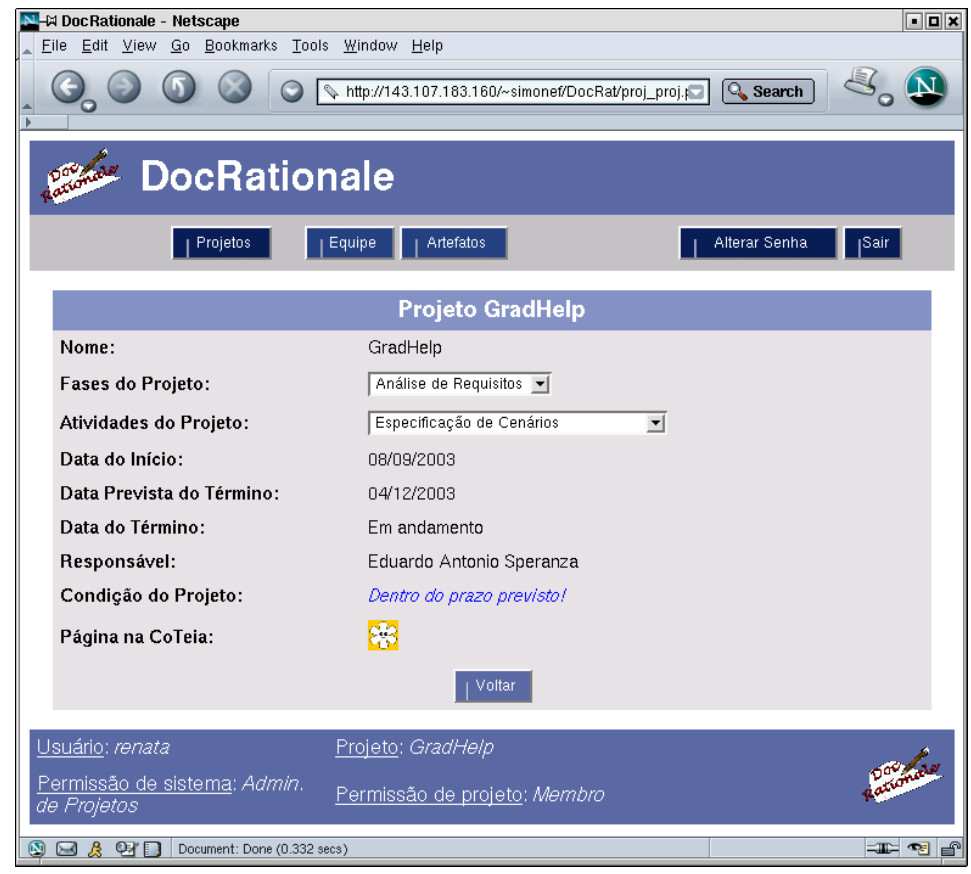

Figura 2.7: Tela de projeto Francisco, 2004

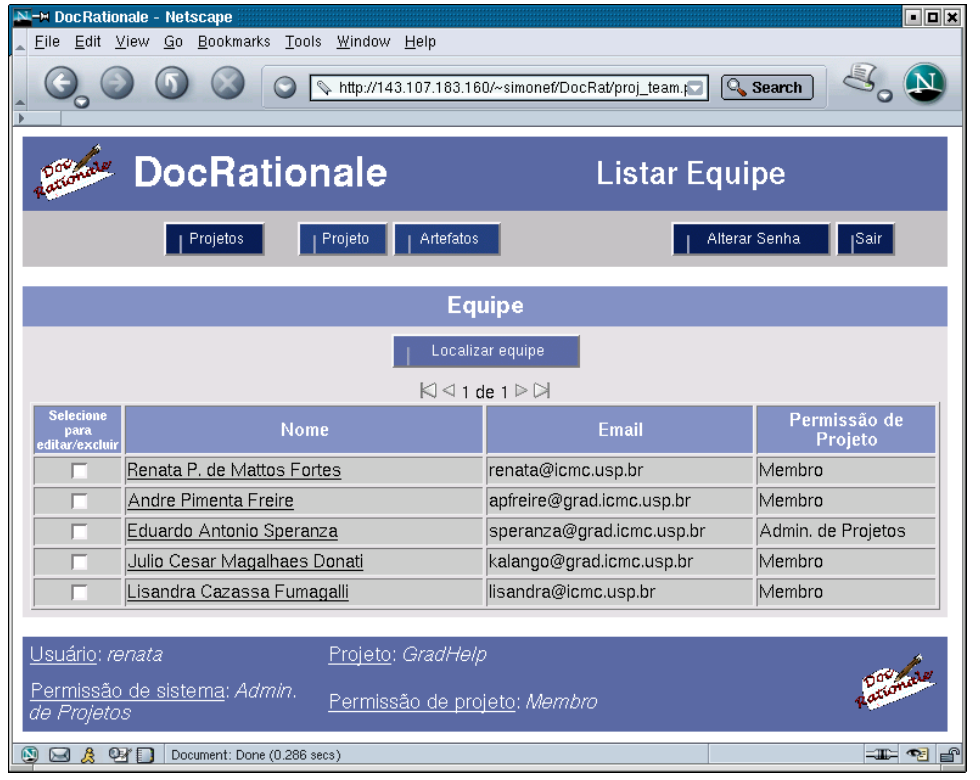

Figura 2.8: Tela de equipe Francisco, 2004

Se o usuário escolhesse um dos artefatos apresentados na Figura 2.6, a tela a ser exibida seria 
a da Figura 2.9. Nessa figura encontra-se a lista de questões referentes ao artefato escolhido. No menu geral tem-se as opções Projetos (lista dos projetos nos quais o usuário faz parte), Projeto (informações sobre o projeto atual), Artefatos (lista de artefatos do projeto atual) e Artefato (informações sobre o artefato atual), além das opções Alterar Senha e Sair. Também é possível, por meio do menu específico, inserir, localizar e finalizar questões, desde que o usuário não tenha permissão de visitante, que pode apenas localizar questões. No rodapé a informação acrescentada é o nome do artefato. Na parte central da tela, além do menu específico, já mencionado, tem-se a lista das questões com links para sua anotação respectiva (GroupNote), onde encontram-se, as posições e argumentos a favor e contra. Existe também um campo para seleção da questão que deseja-se finalizar (para finalizar uma questão o usuário deve informar a que conclusão a equipe chegou a respeito da questão discutida). Quando finalizada, a questão recebe outro tipo de link que apresenta a conclusão a respeito da mesma. Ainda, na parte central existe a legenda com duas possíveis cores para as questões: azul, para questão em discussão, ainda aberta, e preta, para questão finalizada, já concluída.

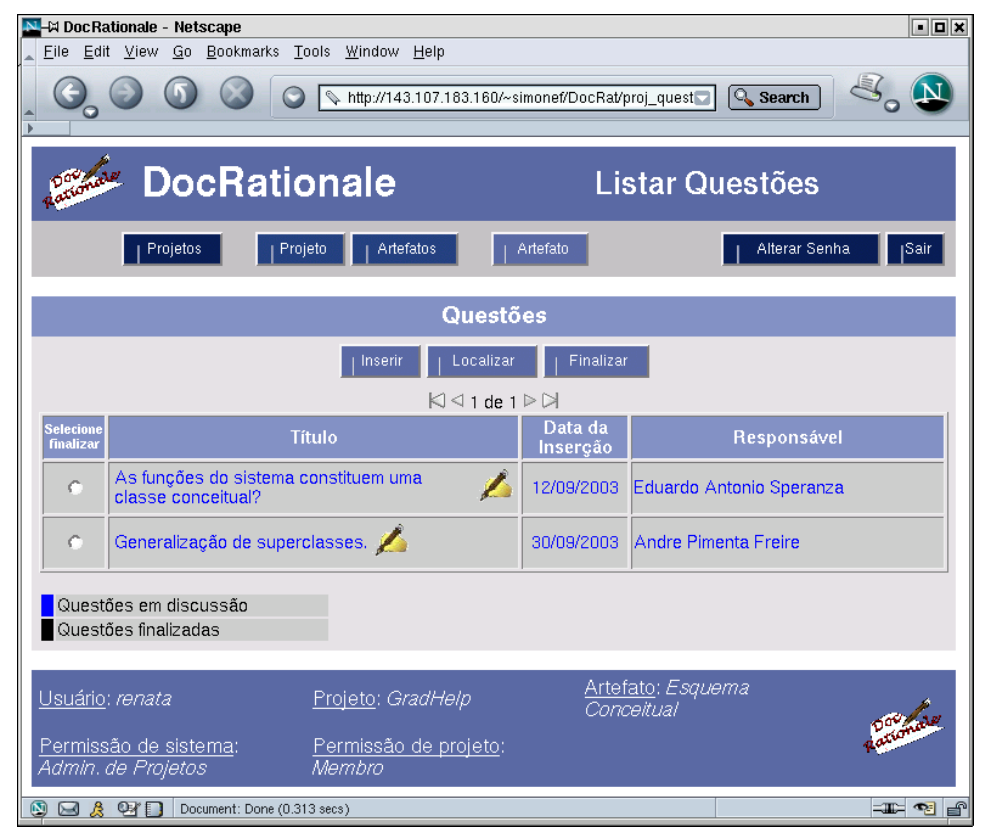

Figura 2.9: Tela de questões Francisco, 2004

Feita a escolha pela opção Artefato do menu geral (Figura 2.9), a tela exibida é a que aparece na Figura 2.10. Nessa tela aparecem as informações sobre o artefato selecionado: nome, fase (a qual pertence o artefato), atividade (a qual pertence o artefato), data de início, data prevista do término, data do término, responsável pelo artefato, condição do artefato (em andamento dentro do prazo previsto, atrasado ou finalizado) e um link para a página correspondente do artefato na CoTeia. 


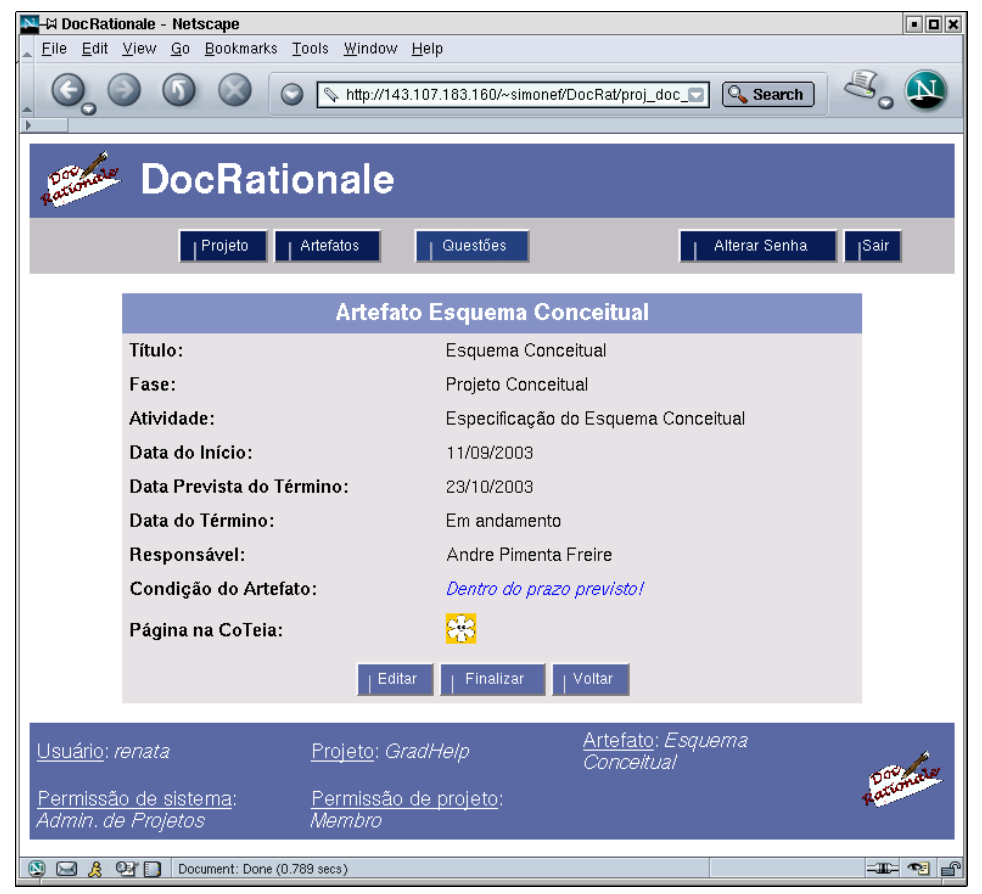

Figura 2.10: Tela de artefato [Francisco, 2004

Na Figura 2.11 é mostrada a página do projeto GradHelp na CoTeia. Como pode ser observado, na página da CoTeia referente ao projeto encontram-se as informações a respeito do projeto e também a lista com todos os seus artefatos. Caso alguma alteração nos dados do projeto seja feita na DocRationale, a página da CoTeia também é atualizada, assim como quando há inserção de um novo artefato.

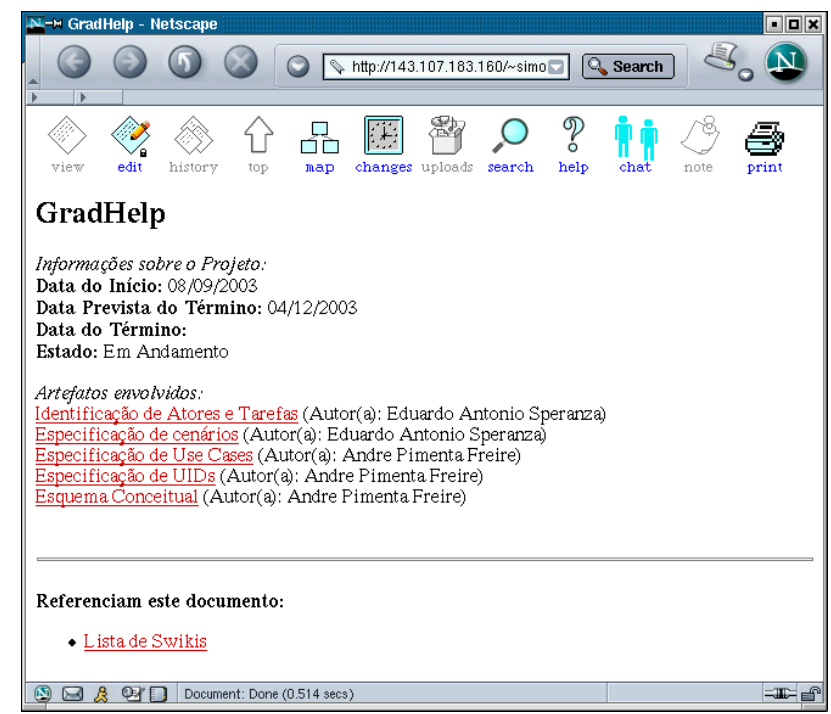

Figura 2.11: Tela de projeto na CoTeia [Francisco, 2004]

Na Figura 2.12 é exibida a página do artefato Esquema Conceitual do projeto GradHelp na 
CoTeia. Na página podem ser encontradas informações sobre o artefato, questões relacionadas ao mesmo com links para o GroupNote onde encontram-se as posições e argumentos a favor e contra, arquivos relacionados ao artefato, além do próprio artefato. Esses arquivos são inseridos na página CoTeia do artefato por meio da opção uploads do menu da página. Também é possível ter nessa página uma lista com páginas relacionadas ao artefato, as quais podem ser criadas através do ícone Nova Página que se encontra no corpo da página do artefato. A lista de questões recebe o mesmo link que recebe a lista de questões da DocRationale quando tal questão é finalizada, disponibilizando a conclusão da questão também na CoTeia.

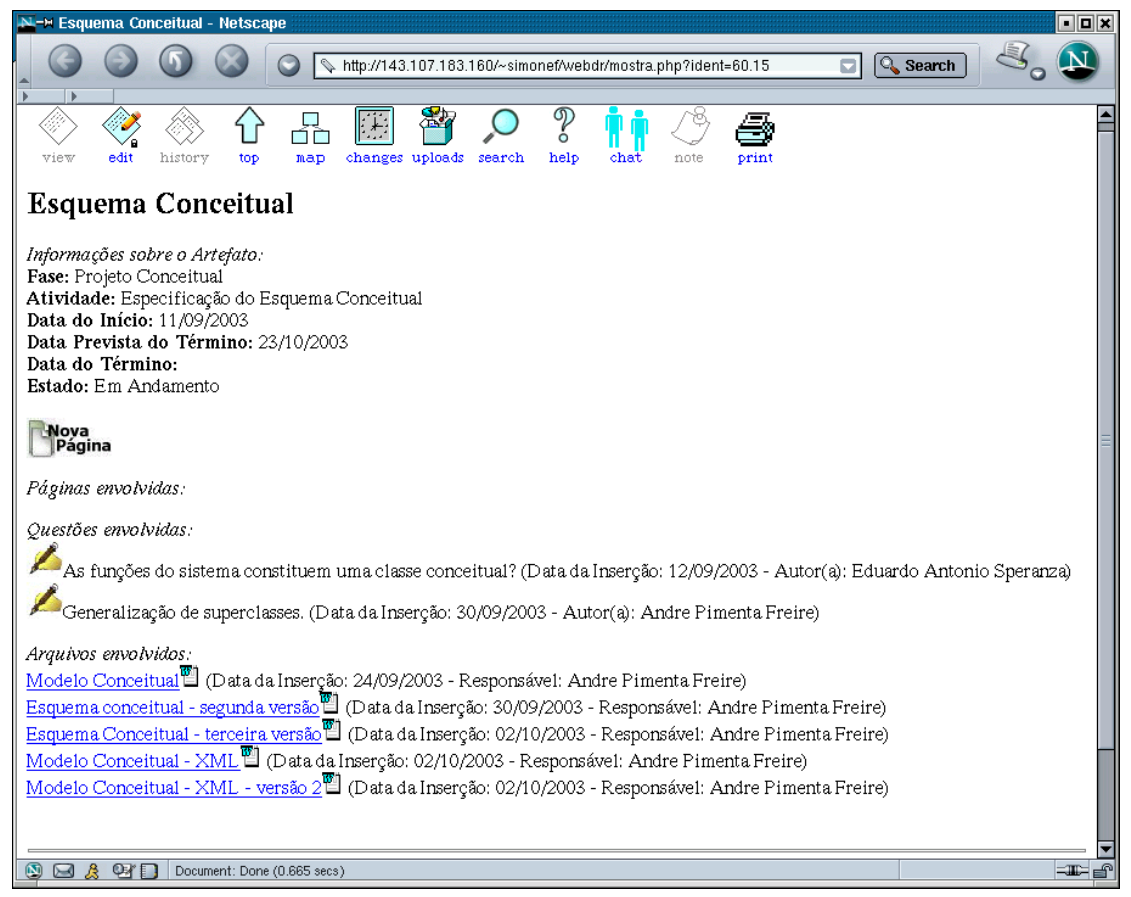

Figura 2.12: Tela de artefato na CoTeia Francisco, 2004]

A anotação do GroupNote que contém a questão "Que tipo de usuário poderá excluir provas anteriores?", suas posições e argumentos a favor e contra podem ser vistos na Figura 2.13. Como pode ser observado, as posições ficam num primeiro nível e os argumentos em um segundo nível. No exemplo, essa questão possui duas posições, sendo a primeira com um argumento contra e a segunda com um argumento a favor. Juntamente com a posição ou argumento vêm a data, a hora e o nome do usuário que fez sua contribuição.

Caso o usuário queira efetuar logout é só escolher a opção Sair que se encontra no menu geral da ferramenta DocRationale. Assim que é efetuado o logout, é apresentada uma tela com uma mensagem de agradecimento pelo uso da ferramenta e um link para possível retorno à tela inicial da DocRationale, caso o usuário queira usar novamente a ferramenta, como pode ser visto na Figura 2.14 . 


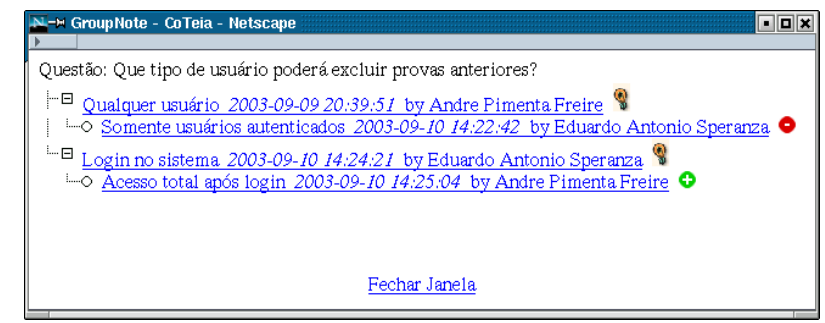

Figura 2.13: Tela de questão no GroupNote Francisco, 2004

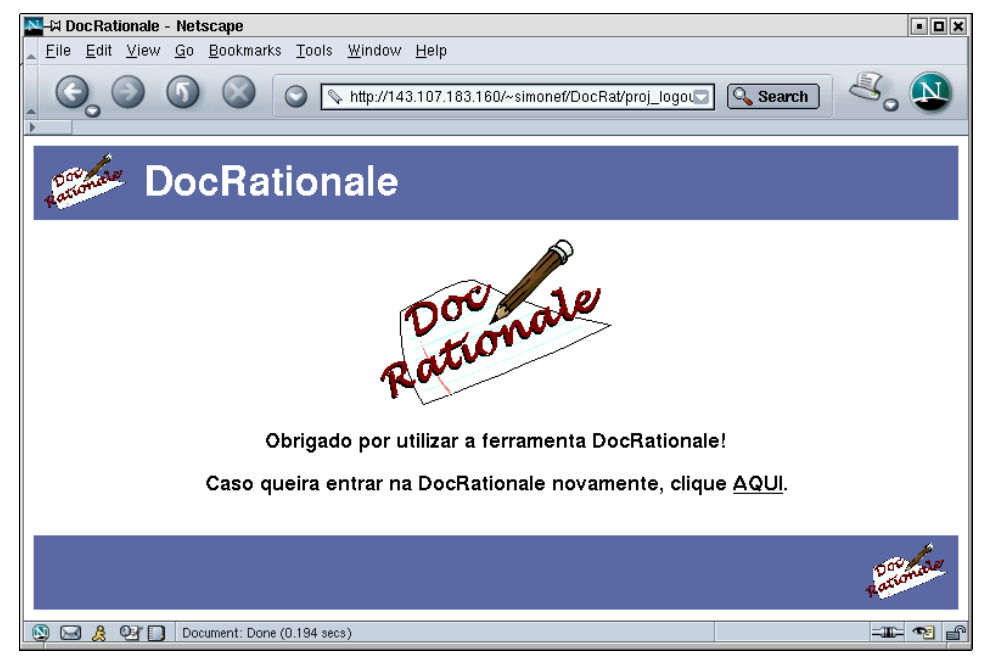

Figura 2.14: Tela de logout [Francisco, 2004]

As telas para alteração de senha (opção encontrada no menu geral da DocRationale), registro (solicitação de cadastro na DocRationale que se encontra na tela de login) e solicitação de nova senha por esquecimento da antiga (encontra-se também na tela de login) são formulários comuns de preenchimento e sem ênfase no domínio da ferramenta. Quando o usuário logado tem permissão de Administrador de Usuário, ele não vê nenhuma dessas telas com conteúdo dos projetos, artefatos ou questões mostradas anteriormente, pois seu acesso é restrito às operações sobre os usuários. O Administrador de Usuários terá uma tela com a lista de usuários da ferramenta e outra com a lista de candidatos a usuários da ferramenta, que seguem o mesmo esquema da tela com a lista de projetos, tornando-se desnecessária a exibição das mesmas.

\subsection{Considerações Finais}

Embora exista um consenso de que a documentação é muito importante no processo de software, na medida em que facilita a compreensão, manutenção e o reuso do software, geralmente apenas as informações relativas às decisões finais de determinada fase são registradas 
Burge and Brown, 2000, uma vez que a maioria dos desenvolvedores consideram onerosa a tarefa de registrar cada uma das alternativas investigadas.

A DocRationale é uma ferramenta CASE que foi desenvolvida com o objetivo de oferecer o suporte necessário para a captura, o armazenamento e a recuperação de Design Rationale de artefatos de software. A ferramenta privilegia o fator de colaboração entre os membros de uma equipe para a obtenção de $D R$ e faz uso de armazenamento estruturado que, apesar de causar certo ônus ao usuário, facilita a recuperação do $D R$ em momentos posteriores [Francisco, 2004.

No entanto, pode-se observar que a ferramenta DocRationale oferece poucos recursos para a geração de documentos durante as fases de análise e design de um projeto, visto que apenas um editor de texto é disponibilizado ao usuário por meio do uso da CoTeia. O editor de texto oferecido pela CoTeia exige alguns conhecimentos de tags HTML (Hypertext Markup Language) para a formatação do texto, o que dificulta ainda mais a sua utilização. Pelo fato de ser apenas textual, o editor restringe a modelagem de diferentes aspectos de um sistema de software, tais como: requisitos funcionais e de interface, estruturas modulares, estruturas de dados, comportamento do sistema, entre outros.

Além disso, observando-se a descrição do uso da ferramenta, pode-se notar que as diversas interações exigidas na captura de $D R$ por meio da DocRationale poderiam ser melhor realizadas se o paradigma de computação ubíqua fosse adotado.

Nesse sentido, este projeto de mestrado consistiu em investigar a incorporação de características de captura ubíqua à ferramenta DocRationale com o objetivo de fornecer suporte às fases de análise e design de um projeto de software, incentivando a solução do problema e os vários elementos a ela relacionados, tais como: a criatividade, a compreensão, o surgimento de idéias, o pensamento livre e sem restrições, as analogias, os objetivos, as razões, os interesses, enfim, tudo o que contribui para a formação do modelo mental do usuário durante a resolução de um problema e que deve ser registrado como o Design Rationale do processo de desenvolvimento de software. 


\section{Capítulo 3}

\section{Ferramentas CASE}

\subsection{Considerações iniciais}

As ferramentas CASE (Computer-Aided Software/System Engineering) são adquiridas com a finalidade principal de aumentar a eficiência no desenvolvimento de software e sistemas de informação, sendo essa eficiência medida em termos de produtividade no desenvolvimento de sistemas e qualidade do sistema desenvolvido Iivari, 1996.

Existem diversos tipos de ferramentas CASE que apoiam diferentes fases do ciclo de vida de projetos de software. Algumas ferramentas CASE apoiam as fases de análise e design, oferecem suporte à geração de código e à realização de testes, por exemplo. Outras ferramentas fornecem funcionalidades que são executadas em paralelo ao ciclo de vida, tais como: ferramentas para gerenciamento de projeto, ferramentas para gerenciamento de configuração, e ferramentas para documentação. A visão de um ambiente completo para a engenharia de software é a da integração de várias ferramentas CASE, que apóiem todos os aspectos do processo de desenvolvimento de software IEEE Std. 1348, 1996.

Muitas organizações de desenvolvimento de software têm adotado ferramentas CASE na tentativa de melhorar a maneira como o software é desenvolvido. Entretanto, embora o potencial das ferramentas CASE seja grande, algumas organizações não alcançaram os benefícios esperados com a sua adoção. A DocRationale é uma ferramenta CASE cujo objetivo é facilitar a captura, o armazenamento e a recuperação de Design Rationale de artefatos de software. A partir de problemas de usabilidade encontrados na ferramenta, observou-se a necessidade de se efetuar melhorias e evoluções na mesma, de modo a facilitar o seu uso e torná-la mais amigável e acessível ao usuário, de modo a diminuir a resistência dos mesmos em utilizá-la.

As seções estão divididas da seguinte forma: na Seção 2 são apresentadas definições sobre as ferramentas CASE, na Seção 3 são mostrados os principais motivos da adoção de ferramentas 
CASE; na Seção 4 são discutidos os principais problemas encontrados na adoção de ferramentas CASE e finalmente na Seção 5 são apresentadas as conclusões finais a respeito das ferramentas CASE.

\subsection{Definições de Ferramentas CASE}

Uma ferramenta CASE é um produto baseado em computador que tem como objetivo apoiar a execução de uma ou mais técnicas dentro do método de desenvolvimento de software adotado [Jarzabek and Huang, 1998], como por exemplo o método estruturado ou o método orientado a objetos. Existem produtos CASE que atendem múltiplos métodos. As ferramentas CASE denominadas Upper-CASE fornecem apoio para as fases de análise e design lógico de sistemas enquanto que as ferramentas denominadas Lower-CASE apoiam a construção do sistema de software. As ferramentas CASE podem ser integradas a outras ferramentas de modo a criar um sofisticado ambiente CASE. Isto pode ser feito em várias dimensões, tais como: integração na apresentação, integração de controle, integração de processo e integração de dados, como pode ser visto na figura 3.1 .

\section{Integração da Apresentação}
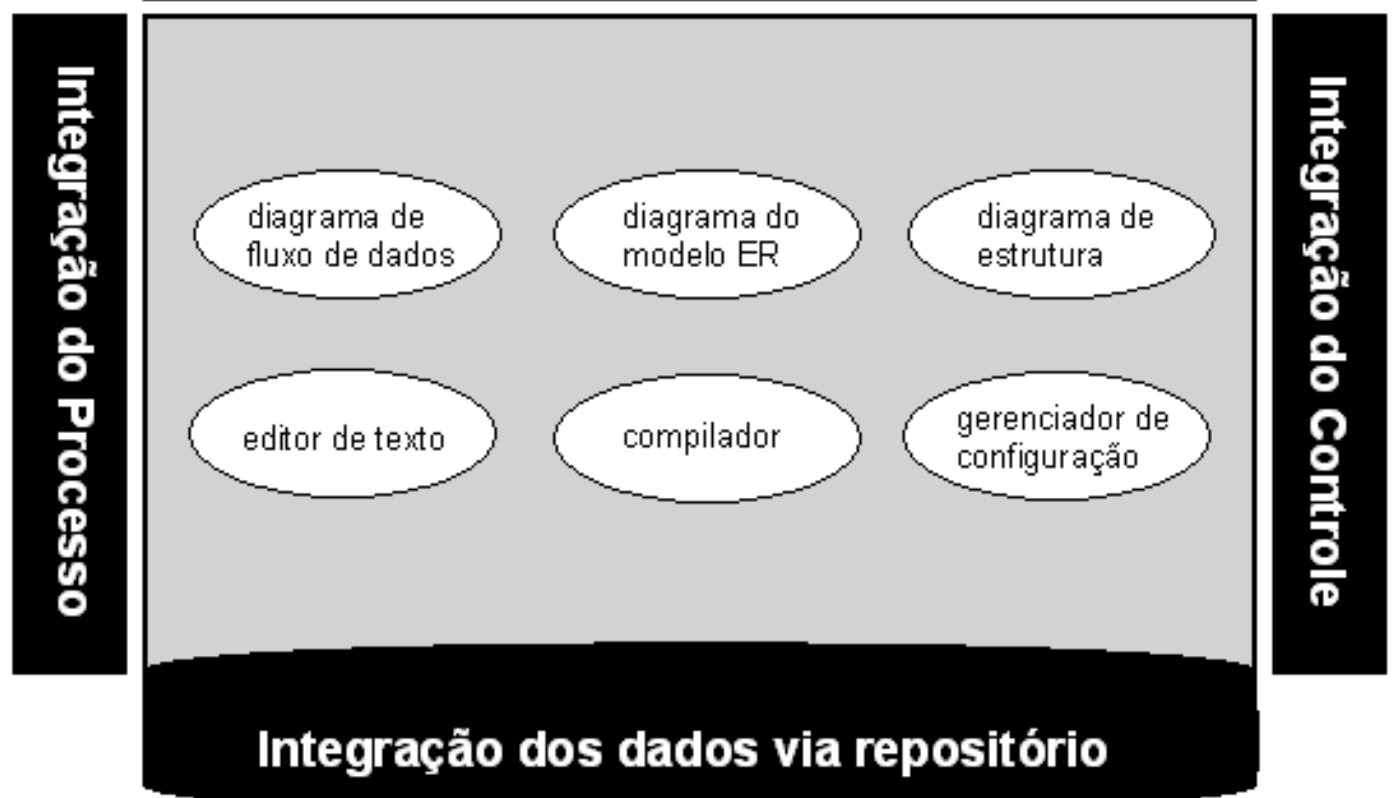

Figura 3.1: Dimensões da integração de ferramentas CASE, traduzido de Jarzabek and Huang, 1998

Segundo Jarzabek and Huang, 1998, uma ferramenta CASE típica deve oferecer um edi- 
tor gráfico para auxiliar os desenvolvedores a modelar os diferentes aspectos de um sistema de software, tais como: requisitos funcionais, estruturas modulares, estruturas de dados, comportamento do sistema entre outros, de acordo com as convenções de um determinado método. As ferramentas CASE devem possuir o conhecimento das regras do método para conseguirem desenhar corretamente diagramas de dados e gerar um esquema relacional a partir de diagramas de Entidade-Relacionamento. Esse conhecimento permite que as ferramentas CASE verifiquem se os desenvolvedores estão seguindo as regras do método e permitem também a automatização da transição entre fases do desenvolvimento de software, incluindo até a geração de código.

\subsection{Motivos para o uso de Ferramentas CASE}

Um dos principais motivos para a utilização de ferramentas CASE nas organizações é o alcance da competitividade, visto que continuamente essas organizações estão em busca de novas possibilidades para obter melhorias em seu processo de desenvolvimento de projetos de software. A competitividade pode ser alcançada por meio do aumento da produtividade, tornando o processo de desenvolvimento mais rápido, e da melhoria da qualidade do produto Jarzabek and Huang, 1998.

Para tornar o processo de desenvolvimento de software mais rápido, as organizações querem padronizar ao máximo as atividades realizadas no desenvolvimento de software, ou seja, procuram estruturar seu processo de desenvolvimento por meio do uso de métodos.

A melhoria da qualidade do produto é outro forte argumento para a adoção de ferramentas CASE. O termo produto significa o sistema de software que é entregue ao cliente. A razão para este argumento é que existe um número muito maior de solicitações dos clientes do que a equipe de desenvolvedores é capaz de atender. O aumento da competência dos desenvolvedores de sistemas pode ser alcançado dentre outras maneiras, por meio da melhoria do método utilizado. Os principais aspectos que as organizações buscam para alcançarem a melhoria do produto são Cronholm, 1995:

- ser capaz de trabalhar de forma mais flexível;

- obter a melhoria do diálogo com clientes/usuários finais;

- obter maior consistência na documentação;

- ser capaz de produzir documentação gráfica com facilidade;

- adquirir maior experiência para a solução de problemas. 
Ser capaz de trabalhar de forma mais flexível significa que as organizações querem ter várias opções para executar o desenvolvimento do sistema de software, de acordo com a natureza e o domínio da aplicação. As organizações querem ter a possibilidade de escolher partes de métodos de ferramentas CASE de acordo com uma situação específica.

O diálogo com os clientes/usuários finais pode ser obtido por meio da consistência na documentação do sistema que está sendo desenvolvido. Com o uso de ferramentas CASE é possível conseguir o controle automático de que todos os elementos pertencentes a um gráfico estejam descritos em um repositório, por exemplo, ou ainda se a descrição realizada está de acordo com as regras do método, entre outras. As ferramentas CASE oferecem funcionalidades que permitem a minimização dos erros e das ambigüidades, melhorando a compreensão dos usuários a respeito do sistema que se encontra em desenvolvimento.

A documentação gráfica também é outro motivo identificado para o uso de ferramentas CASE. A documentação gráfica de boa qualidade melhora a legibilidade da documentação e reduz o tempo gasto em procedimentos de documentação, tempo este que pode ser melhor aproveitado para a solução de novos sistemas.

Algumas organizações decidem adotar ferramentas CASE como forma de conseguir a implantação e o uso de novas tecnologias, tais como métodos formais ou estruturados para design de sistemas. Nesses casos, a adoção de ferramentas CASE ocorre em paralelo com uma significante modificação do processo IEEE Std. 1348, 1996.

Um fator importante que está implícito nos principais motivos apresentados é a racionalização do processo de desenvolvimento, por meio da simplificação dos procedimentos de trabalho, com o objetivo de aperfeiçoar o método utilizado, obter maior rapidez no processo de desenvolvimento de sistemas de software e melhorar a qualidade do produto.

\subsection{Motivos para o não uso de Ferramentas CASE}

A avaliação da satisfação e benefícios provenientes do uso de ferramentas CASE raramente é realizada nas organizações que adotaram este tipo de ferramenta, visto que tais organizações consideram difícil medir os benefícios em função do investimento realizado e principalmente porque consideram a atividade de avaliação uma perda de tempo.

Pode-se dizer que os principais fatores da desistência de uso de ferramentas CASE são: baixo grau de cobertura e instabilidade da ferramenta.

Baixo grau de cobertura significa que as funcionalidades oferecidas pela ferramenta atendem poucas partes do método, ou seja, não oferecem total apoio ao método utilizado para o desenvolvimento do sistema. Como exemplo, pode-se citar a falta de suporte à prototipação e à 
geração de código.

A instabilidade da ferramenta pode ser comprovada quando muitas de suas funcionalidades não atuam como deveriam e causam interrupções inesperadas durante o seu uso.

Há ainda outras questões que devem ser avaliadas e que em muitos casos, não contribuem para a adoção de ferramentas CASE [IEEE Std. 1348, 1996]:

- o retorno do investimento em ferramentas CASE: é muito difícil determinar o valor real de uma ferramenta CASE devido à falta de métricas em processos e projetos de desenvolvimento de software;

- o compromisso da gerência em utilizar a ferramenta CASE: a adoção de ferramentas CASE é um investimento a longo prazo, que pode não produzir resultados imediatos, e com isso desestimular o seu uso;

- processos e métodos: a freqüente não correspondência entre os processos e métodos apoiados pela ferramenta CASE e os processos e métodos utilizados na organização é um grande obstáculo para sua adoção;

- escalabilidade da ferramenta: muitas ferramentas CASE apresentam capacidades limitadas para o trabalho em grandes sistemas;

- integração com outras ferramentas: as ferramentas CASE são freqüentemente difíceis de serem usadas em conjunto com outras ferramentas. As dificuldades provêm dos diferentes paradigmas utilizados pelas ferramentas e da transferência de dados e controles de uma ferramenta para outra;

- sobrecarga de trabalho: algumas ferramentas CASE exigem muito esforço para a realização de atividades pequenas e acabam por sobrecarregar demais os desenvolvedores ao invés de obter os benefícios da disciplina que a ferramenta impõe;

- pessoal envolvido: muitas vezes as atitudes negativas de pessoas para com a adoção de novas ferramentas CASE são as maiores contribuintes para o fracasso da adoção;

- mecanismos de apoio: as despesas com as ferramentas CASE e o treinamento da equipe também devem ser previstos antecipadamente.

A implantação de uma ferramenta CASE em uma organização requer, além da sua integração com as demais ferramentas existentes no ambiente de desenvolvimento de sistemas, a adequação ao método de desenvolvimento usado e principalmente o treinamento da equipe para que a sua utilização seja eficiente. A adoção de uma ferramenta CASE não está limitada apenas ao seu 
uso. Ao contrário, envolve o planejamento e a implementação de um conjunto de atividades técnicas, organizacionais, culturais, e principalmente de gerenciamento de processo, necessárias para alcançar as melhorias esperadas pela organização [IEEE Std. 1348, 1996.

Os passos a serem seguidos para que a adoção de uma ferramenta CASE tenha sucesso são IEEE Std. 1348, 1996]:

- definição das necessidades;

- avaliação e seleção de ferramentas CASE;

- Execução de um piloto;

- Adoção de uma rotina de uso da ferramenta.

O impacto da adoção de uma ferramenta CASE em uma organização varia de acordo com situações específicas. Muitas organizações adotam ferramentas CASE para automatizar processos já existentes e aumentar assim a produtividade e a qualidade. Nessas situações, as mudanças nos processos da organização ficam limitadas a torná-los receptivos à automatização, ou ainda ampliá-los em seu escopo IEEE Std. 1348, 1996.

Outras organizações selecionam ferramentas que se integram bem às ferramentas já existentes. Esta abordagem pode simplificar muito o processo de adoção da ferramenta. Entretanto, tentar adotar um conjunto inteiro de ferramentas pode ser problemático, uma vez que a complexidade do processo de adoção varia de acordo com o aumento no número de mudanças a ser realizado para suportar a nova ferramenta.

Vale destacar que a adoção de ferramentas CASE não garante uma melhoria revolucionária no desenvolvimento de software das organizações e nas suas atividades de manutenção. O processo de adoção de ferramentas CASE contribui para a descoberta de necessidades particulares da organização e como retorno, melhorias gradativas no processo de desenvolvimento e nas atividades de manutenção podem ser esperadas.

\subsection{Problemas com a adoção de Ferramentas CASE}

O interesse em ferramentas CASE é baseada nas expectativas de aumento de produtividade, melhoria da qualidade do produto, facilidade de manutenção e em tornar o desenvolvimento de software uma tarefa mais agradável de ser executada. Entretanto, as experiências de uso mostram que raramente as ferramentas CASE fazem com que todos os benefícios prometidos sejam alcançados e embora essas ferramentas já estejam no mercado há algumas décadas, elas ainda não são amplamente adotadas. 
Segundo Jarzabek and Huang, 1998 esse problema ocorre porque as principais ferramentas encontradas atualmente são orientadas à modelagem de software e à construção de métodos. As ferramentas CASE orientadas a métodos não são atrativas para o usuário, pois não estão de acordo com o modelo mental que o usuário cria para o desenvolvimento de software. As ferramentas CASE deveriam apoiar outros aspectos relacionados ao desenvolvimento de software, tais como criatividade e percepção, sendo orientadas ao processo de desenvolvimento ao invés de orientadas a métodos. A separação de métodos de desenvolvimento (análise estruturada ou método orientado a objetos, por exemplo) de outros aspectos que contribuem para o sucesso de um projeto de software não é benéfica para os usuários, nem para programadores e tampouco para os gerentes de projeto.

Para as ferramentas CASE se tornarem mais atraentes aos usuários elas deveriam apoiar os principais elementos que constituem um projeto de software de sucesso, tais como: métodos de modelagem e construção, processo de software e representação do conhecimento sobre o processo do mundo real apoiado por sistemas de software. Cada um desses elementos possuem aspectos "hard" (técnicas, documentação, rigor) e aspectos "soft" (criatividade, solução de problemas) que as ferramentas CASE deveríam apoiar. No entanto, as ferramentas CASE atuais são particularmente fracas no atendimento aos aspectos "soft" do desenvolvimento de software. Um aspecto "soft" do desenvolvimento de software é a solução do problema e os vários elementos a ela relacionados, tais como: a criatividade, a compreensão, o surgimento de idéias, o pensamento livre e sem restrições, a intuição, as analogias, os objetivos, as razões, os interesses, as emoções e tudo mais que provém da mente humana. Atualmente as ferramentas CASE são construídas para apoiar métodos e oferecem pouco apoio aos aspectos "soft" do desenvolvimento de software.

Muitas vezes os desenvolvedores devem se concentrar no contexto do negócio, nas suas intenções e objetivos, e no Design Rationale, além de criar alternativas para a solução e avaliar as implicações da decisão de acordo com os objetivos a serem alcançados no projeto. Normalmente, os desenvolvedores não encontram apoio das ferramentas CASE para a realização desse tipo de atividade. Eles encontram apenas diagramas e editores muito restritivos, que muito pouco ajudam na realização de seus trabalhos.

Durante a solução de problemas relacionados com o projeto de software, os desenvolvedores precisam expressar suas idéias e necessitam de ferramentas que apóiem os conceitos de objetivos, decisões, razões, conseqüências, impactos e soluções alternativas. Para uma ferramenta ser atrativa ao usuário ela deve considerar três principais aspectos: possuir boa interface, simular o comportamento do usuário e possuir uma boa representação do conhecimento. 
O objetivo principal da reimplementação da ferramenta DocRationale foi o de facilitar a sua utilização. Para isso foram adotados vários conceitos de usabilidade como forma de melhorar a sua interface. Além disso, foi adicionado um mecanismo de escrita manual que oferece um serviço de reconhecimento de escrita textual e ainda possui os seguintes elementos: canetas, cores e borracha, como forma de apoiar os aspectos "soft" envolvidos na solução de um problema, facilitando a realização das atividades iniciais de um projeto de software, como por exemplo, a escrita livre para captura de requisitos de interface e para o registro de Design Rationale.

\subsection{Considerações Finais}

Neste capítulo foram analisados os principais motivos que levam as organizações a usarem ferramentas CASE em seu processo de desenvolvimento de projetos de software. Foram discutidas também as dificuldades e problemas que impedem a adoção de tais ferramentas.

Um outro importante fator que foi destacado e que não contribui para a adoção de ferramentas CASE é o fato de que esse tipo de ferramenta não é atrativa ao usuário, visto que são ferramentas orientadas a métodos e não ao usuário, e tampouco provêm uma orientação natural ao processo de desenvolvimento de software. As ferramentas CASE deveriam dar suporte aos aspectos criativos da solução de problemas bem como da sua rigorosa modelagem.

Com o intuito de tornar a ferramenta DocRat mais atrativa ao usuário e disponibilizar uma maneira mais natural de atender às necessidades da fase de análise e design de um projeto de software, foi realizado o trabalho de reengenharia de usabilidade e de integração da ferramenta DocRat com um mecanismo ubíquo de captura de conteúdo de artefatos de software, que será descrito nos Capítulos "DocRat: Reengenharia da Ferramenta DocRationale"e "Evolução da Ferramenta DocRat". 


\section{Capítulo 4}

\section{Usabilidade e Computação Ubíqua}

\subsection{Considerações Iniciais}

O desenvolvimento de interfaces que facilitem a operação de sistemas computacionais tem sido alvo de diversos esforços de pesquisa Nielsen, 1993. Em particular, a criação de aplicações para $W e b$ com alto grau de usabilidade tem recebido grande atenção pela comunidade acadêmica e por empresas de desenvolvimento de software.

Computação Ubíqua é um tema relativamente novo. A principal referência a este tema data de 1991, quando Mark Weiser, pesquisador do Xerox PARC, publicou a sua visão do que seria a computação ubíqua: tecnologia integrada ao ambiente para auxiliar atividades humanas, porém de forma não intrusiva Weiser, 1991.

Um dos principais aspectos abordados pela computação ubíqua é o da interação transparente ou interfaces naturais [Abowd, 1999b], que estuda e realiza avanços relativos à usabilidade dos sistema computacionais, de modo a possibilitar que um sistema seja construído de acordo com as tarefas e modelos mentais do usuário, onde o objetivo principal é adaptar as interfaces aos usuários, de forma que os mesmos não tenham que mudar seus hábitos para realizarem suas tarefas.

A seguir, serão mostrados os principais conceitos sobre usabilidade e acessibilidade em sistemas de software. O processo de Engenharia de Usabilidade e conceitos sobre Avaliação de Usabilidade também são mostrados. É realizada uma breve descrição sobre Computação Ubíqua e suas contribuições para a melhoria da usabilidade em sistemas computacionais.

\subsection{Conceitos de Usabilidade e Acessibilidade}

O termo usabilidade tem sido usado com diferentes significados. Usabilidade se refere a um conjunto de atributos de qualidade independentes, como performance, satisfação, facili- 
dade de aprendizado, ou eles todos juntos Bevan and Azuma, 1997. Do ponto de vista de um atributo de qualidade de software, a usabilidade não foi definida de forma consistente pelas organizações que estabelecem padrões e nem pela indústria de desenvolvimento de software. As seguintes definições ilustram como o termo usabilidade tem sido utilizado por três padrões Seffah and Metzker, 2004]:

- "A capacidade de um produto de software ser entendido, aprendido, fácil de usar, e atrativo para o usuário, quando utilizado em condições específicas" ISO 9126, 1991;

- "A extensão na qual um produto pode ser utilizado por usuários específicos de forma a atingir seus objetivos de forma efetiva, com eficiência e com satisfação em um contexto de uso específico" [SO/DIS 9241-11, 1996];

- "A facilidade com que um usuário pode aprender a operar, preparar a entrada e interpretar as saídas de um sistema ou componente" IEEE Std. 1061, 1998.

É importante levar em conta que usabilidade não é uma propriedade única e uni-dimensional de uma interface com usuário. Usabilidade é um conceito relacionado a diversos componentes, e tradicionalmente é associada a cinco atributos Nielsen, 1993:

- Facilidade de Aprendizado: O sistema deve ser fácil para aprender, de forma que um usuário possa começar a utilizá-lo de forma rápida;

- Eficiência: O sistema deve ser eficiente ao ser utilizado, de forma que uma vez que o usuário tenha aprendido a utilizá-lo, ele possa ter uma alta produtividade com o mesmo;

- Facilidade de memorização: Deve ser fácil se lembrar de como utilizar o sistema, de forma que um usuário casual possa ser capaz de voltar a usar o sistema depois de um período sem utilizá-lo, sem a necessidade de aprender tudo novamente;

- Erros: O sistema deve ter uma baixa taxa de erro, de forma que os usuários cometam poucos erros durante o seu uso, e que caso eles cometam erros, seja possível se recuperar deles de forma fácil. Além disso, erros catastróficos não devem ocorrer;

- Satisfação: O sistema deve ser agradável de se utilizar, de forma que os usuários se sintam subjetivamente satisfeitos enquanto o utilizam.

Para guiar o desenvolvimento de aplicações visando usabilidade, Nielsen, 1993 enumera dez heurísticas que endereçam alguns dos principais pontos que devem verificados durante o desenvolvimento de um sistema de software: 
1. Visibilidade do status do sistema: o sistema precisa manter os usuários informados sobre o que está acontecendo, fornecendo um feedback adequado dentro de um tempo razoável;

2. Compatibilidade do sistema com o mundo real: o sistema precisa falar a linguagem do usuário, com palavras, frases e conceitos familiares ao usuário, ao invés de termos orientados ao sistema. O sistema deve seguir convenções do mundo real, fazendo com que a informação apareça numa ordem natural e lógica;

3. Controle do usuário e liberdade: usuários freqüentemente escolhem funções do sistema por engano e precisam ter claras saídas de emergência para sair do estado indesejado, sem ter que percorrer um extenso diálogo. Para tal, é necessário prover funções de undo e redo;

4. Consistência e Padrões: usuários não precisam adivinhar que diferentes palavras, situações ou ações significam a mesma coisa. Portanto, é necessário seguir convenções da plataforma computacional;

5. Prevenção de erros: melhor do que uma boa mensagem de erro é um design cuidadoso, que previne o erro antes dele acontecer;

6. Reconhecimento ao invés de relembrança: tornar objetos, ações e opções visíveis. O usuário não deve ter que lembrar informações de uma parte para outra de um diálogo. Instruções para uso do sistema devem estar visíveis e facilmente recuperáveis quando necessário;

7. Flexibilidade e eficiência de uso: usuários novatos se tornam peritos com o uso. Prover aceleradores de forma a aumentar a velocidade de interação, assim como permitir que usuários experientes possam "cortar caminho" em ações freqüentes é um aspecto importante para usabilidade;

8. Estética e Design Minimalista: diálogos não devem conter informação irrelevante ou raramente necessária. Qualquer unidade de informação extra no diálogo irá competir com unidades relevantes de informação e diminuir sua visibilidade relativa;

9. Ajudar os usuários a reconhecer, diagnosticar e corrigir erros: mensagens de erro devem ser expressas em linguagem clara (sem códigos) indicando precisamente o problema e sugerindo uma solução construtivamente;

10. Help e Documentação: Embora o ideal seja um sistema que possa ser usado sem auxílio nenhum, é necessário prover a opção de help e documentação. Essas informações devem 
ser fáceis de encontrar, focalizadas na tarefa do usuário e não muito extensas.

Um conjunto ainda mais amplo de princípios de usabilidade é definido em [Dix et al., 1998, onde os princípios de usabilidade são classificados em três categorias principais: Aprendizagem, Flexibilidade e Robustez. A categoria Aprendizagem refere-se ao esforço necessário para que novos usuários aprendam a utilizar e atingir a melhor produtividade e eficiência na execução das tarefas implementadas no sistema. A categoria Flexibilidade refere-se à multiplicidade de formas de interação entre usuário e sistema. A categoria Robustez refere-se ao apoio oferecido ao usuário para que este obtenha sucesso na realização das tarefas desejadas. As definições dos princípios de usabilidade Dix et al., 1998] que compõem estas três categorias são listadas nas tabelas $4.1,4.2 \mathrm{e} 4.3$ a seguir.

\begin{tabular}{|l|l|}
\hline \hline Aprendizagem & Definição \\
\hline \hline Príncipio & $\begin{array}{l}\text { Permitir ao usuário prever o efeito de suas ações futuras baseando-se no histórico de } \\
\text { ações passadas, ou então nas informações a ele apresentadas por meio da interface em } \\
\text { um dado instante de tempo. }\end{array}$ \\
\hline \hline Previsibilidade & $\begin{array}{l}\text { Acesso a resultados de operações passadas. Permitir ao usuário visualizar ou verificar } \\
\text { o resultado conseqüente da execução de tarefas passadas. }\end{array}$ \\
\hline Fisibilidade & $\begin{array}{l}\text { Capacidade do usuário utilizar seus conhecimentos, adquiridos em outros sistemas } \\
\text { computacionais ou no mundo real, na interação com o sistema. }\end{array}$ \\
\hline Generalidade & $\begin{array}{l}\text { Capacidade do usuário utilizar seus conhecimentos, adquiridos com a execução de } \\
\text { tarefas que possuem objetivos semelhantes, durante a execução de uma tarefa no } \\
\text { sistema. }\end{array}$ \\
\hline Consistência & $\begin{array}{l}\text { Apresentação de comportamento semelhante do sistema (dados de entrada e saída) } \\
\text { em situações similares ou na realização de tarefas de objetivos similares. }\end{array}$ \\
\hline
\end{tabular}

Tabela 4.1: Princípios da categoria Aprendizagem

Em aplicações $W e b$ a usabilidade tem um caráter ainda mais crítico do que em aplicações convencionais, principalmente pelo fato de que o usuário experimenta a usabilidade de uma aplicação Web antes de decidir adotá-la [Nielsen, 2000].

Durante o desenvolvimento de aplicações $W e b$, é necessário considerar diversas características particulares dessas aplicações, em especial o fato de que sua interface é interpretada por diferentes browsers e acessada em diferentes contextos.

Alguns princípios básicos que devem ser considerados durante o design de aplicações Web, apontados por Nielsen, 2000], são:

- Clareza na arquitetura da informação: é essencial que o usuário consiga discernir o que é prioritário e o que é secundário em um Web site. Ou seja, é necessário obter um 


\begin{tabular}{|c|c|}
\hline \multicolumn{2}{|l|}{ Flexibilidade } \\
\hline Príncipio & Definição \\
\hline Iniciativa de Diálogo & $\begin{array}{l}\text { Oferecer liberdade de ação ao usuário em diálogos inicializados pelo próprio sistema. } \\
\text { Permitir ao usuário executar outras tarefas que não especificamente associadas ao } \\
\text { diálogo. }\end{array}$ \\
\hline Multi-Tarefa & $\begin{array}{l}\text { Execução de múltiplas interações simultâneas entre usuário e sistema. Múltiplas in- } \\
\text { terações simultâneas referem-se à execução de mais que uma tarefa do sistema em um } \\
\text { mesmo instante de tempo. }\end{array}$ \\
\hline Migração de Tarefa & $\begin{array}{l}\text { Migração do controle de tarefas entre usuários e sistema. Usuário ou sistema transfere } \\
\text { o controle da tarefa um ao outro, ou então compartilham o controle entre eles. }\end{array}$ \\
\hline Substituição & $\begin{array}{l}\text { Capacidade de substituir valores (dados de entrada e saída) equivalentes uns pelos } \\
\text { outros. Permitir ao usuário trabalhar com padrões ou unidades usuais ao contexto de } \\
\text { aplicação da tarefa. }\end{array}$ \\
\hline Customização & $\begin{array}{l}\text { Permitir ao usuário ou ao sistema modificar a interface. Limites devem ser cuida- } \\
\text { dosamente impostos quanto às modificações realizadas pelo usuário. Estas devem } \\
\text { restringir-se à superfície de apresentação da interface. }\end{array}$ \\
\hline
\end{tabular}

Tabela 4.2: Princípios da categoria Flexibilidade

\begin{tabular}{|l|l|}
\hline \hline Robustez & Definição \\
\hline \hline Príncipio & $\begin{array}{l}\text { Permitir ao usuário reconhecer o estado interno de execução do sistema através da } \\
\text { interface. }\end{array}$ \\
\hline \hline Reconhecimento & $\begin{array}{l}\text { Permitir ao usuário atingir seus objetivos após identificar a ocorrência de estados } \\
\text { de erro. Esta recuperação pode ocorrer voltando-se ao estado anterior à ocorrência } \\
\text { do erro ou dando continuidade à execução de tarefas posteriores considerando-se os } \\
\text { resultados conseqüentes do erro. }\end{array}$ \\
\hline Tempo de resposta & $\begin{array}{l}\text { Apresentar pequeno tempo de resposta a requisições do usuário. Respostas referem-se } \\
\text { a mudanças de comportamento do sistema após o usuário requisitar a execução de } \\
\text { tarefas. }\end{array}$ \\
\hline $\begin{array}{l}\text { Conformidade de } \\
\text { Tarefas }\end{array}$ & $\begin{array}{l}\text { Implementação de todas tarefas requisitadas pelo usuário e referentes ao domínio da } \\
\text { aplicação do sistema. Além disso, estas tarefas devem ser implementadas como o } \\
\text { usuário realmente deseja executá-las. }\end{array}$ \\
\hline
\end{tabular}

Tabela 4.3: Princípios da categoria Robustez 
bom arranjo da informação;

- Facilidade de navegação: uma máxima é que o usuário deveria conseguir acessar a informação desejada em no máximo três cliques. Conseguir organizar a informação dentro disso já é um bom princípio;

- Simplicidade: a estrutura de um web site deve ser simples e tornar fácil o entendimento do conteúdo, sem recursos visuais muito carregados. Cuidados devem ser tomados para que a simplicidade não signifique ausência de informação;

- A relevância do conteúdo: o principal elemento de um web site que atrai os usuários é o seu conteúdo. Desta forma, o design de um web site deve privilegiar sobretudo o conteúdo da informação disponibilizada;

- Manter a consistência: a consistência é um poderoso princípio de usabilidade na $W e b$. Manter a interface sempre dentro de um padrão facilita o aprendizado do usuário e aumenta a sua segurança para operar o web site;

- Tempo suportável: o tempo de carga das páginas deve ser necessariamente curto. Estudos indicam que 10 segundos é o máximo de tempo antes que as pessoas percam o interesse;

- Foco nos usuários: novamente, todos os princípios podem ser sumarizados em um só: o foco deve estar nas atividades dos usuários.

Além dos princípios mais tradicionalmente referenciados na literatura, Globe et al. Goble et al., 2000 argumentam que o design hipertexto e o estudo de usabilidade na Web estão tradicionalmente concentrados nos princípios de navegação e/ou orientação.

Navegação é um termo amplo. No seu sentido comum, navegação significa movimentar através do espaço. Na Web, navegação inclui o movimento virtual através de espaços cognitivos formados por informações, e pelo conhecimento que daí emerge. Tornar o conteúdo de um site compreensível e navegável não é uma tarefa fácil. A navegação deve ser centrada em objetivos e ações, conceitos chave para a realização de um bom projeto de navegação. De acordo com Fleming Fleming, 1998, existem dez qualidades comuns que devem estar presentes em um projeto navegacional de sucesso:

1. Ser facilmente aprendida: se os visitantes forem obrigados a gastar muito tempo aprendendo como se utiliza um mecanismo complexo não terão energia para absorver o conteúdo; 
2. Ter consistência: a mesma abordagem de navegação deve ser aplicada em todas as páginas;

3. Prover feedback: o usuário deve receber uma resposta a toda ação que é executada no sistema;

4. Oferecer contextualização: para que as pessoas possam tomar decisões sobre movimentos, elas precisam ver rotas, ou seja, os elementos de navegação devem estar sempre visíveis;

5. Oferecer alternativas: os usuários são diferentes, desde o equipamento que usam até suas preferências e portanto, deve-se explorar alternativas. Alternativas como diferentes versões de um mesmo site (gráfica e textual), mapas ou mecanismos de busca, por exemplo, são de grande importância;

6. Prover economia de ações: deve-se evitar sites com muitos níveis hierárquicos, nos quais o usuário tem que realizar um número muito grande de passos para alcançar conteúdos importantes;

7. Prover mensagens visuais claras: o design gráfico de um site deve servir como um guia ao usuário, pois a apresentação das opções de navegação está ligada à usabilidade do sistema;

8. Selecionar títulos precisos: na seleção de termos a serem empregados na navegação, deve-se utilizar a terminologia dos usuários e não a linguagem burocrática da organização;

9. A navegação deve ser adequada aos objetivos: a abordagem vai depender muito de qual é o objetivo dos usuários. Um site comercial não deve ter o mesmo tipo de solução que um site de divulgação de informações;

10. Apoiar o comportamento do usuário: o objetivo da navegação é dar suporte às tarefas dos usuários. A compreensão sobre o que as pessoas querem fazer e como se comportam é um dos aspectos mais importantes a serem considerados durante um projeto de navegação.

Além de todos esses princípios, outra característica importante que deve ser considerada durante o design de aplicações $W e b$ é a acessibilidade.

Acessibilidade na $W e b$ corresponde a possibilitar que qualquer usuário, utilizando qualquer agente ( software ou hardware que recupera e serializa conteúdo $W e b$ ), possa entender e interagir com o conteúdo de um Web site. Os diferentes agentes podem ser tecnologias assistivas de 
hardware e software (leitores de tela, browsers braille), dispositivos móveis, TV's digitais, entre outros.

Acessibilidade incorpora a idéia de que todas as pessoas têm o direito de ser incluídas na sociedade, independente de deficiências, localização geográfica, barreiras de linguagem, ou outro fator Thatcher et al., 2002.

O W3C (World Wide Web Consortium) ${ }^{1}$ possui um grupo de trabalho, denominado WAI (Web Accessibility Initiative), que é responsável por alavancar iniciativas para promover a acessibilidade na $W e b$. Entre as recomendações produzidas pelo grupo está o WCAG 1.0 W3C, 1999 (Web Content Accessibility Guidelines), que define diversas guidelines e checkpoints para guiar o desenvolvimento de conteúdo Web visando acessibilidade. As quatorze guidelines do WCAG 1.0 estão listadas a seguir:

1. Fornecer alternativas equivalentes ao conteúdo sonoro e visual;

2. Não recorrer apenas à cor para expressar significado de informações;

3. Utilizar corretamente marcações e folhas de estilo;

4. Indicar claramente qual o idioma utilizado;

5. Criar tabelas passíveis de transformação harmoniosa;

6. Assegurar que as páginas dotadas de novas tecnologias sejam transformadas harmoniosamente;

7. Assegurar o controle do usuário sobre as alterações temporais do conteúdo;

8. Assegurar a acessibilidade direta de interfaces do usuário integradas;

9. Projetar páginas considerando a independência de dispositivos;

10. Utilizar soluções de transição;

11. Utilizar tecnologias e recomendações do W3C;

12. Fornecer informações de contexto e orientações;

13. Fornecer mecanismos de navegação claros;

14. Assegurar a clareza e a simplicidade dos documentos.

\footnotetext{
${ }^{1}$ http://www.w4c.org
} 
Cada uma das guidelines possui diversos checkpoints relacionados. De forma geral, as guidelines endereçam dois objetivos principais: as páginas devem permitir que o seu conteúdo possa ser transformado de forma harmoniosa quando exibido em diferentes dispositivos e browsers, e o conteúdo deve ser compreensível e navegável. Um estudo minucioso sobre essas guidelines e checkpoints de acessibilidade foi realizado durante esta pesquisa de mestrado, resultando nas publicações de dois minicursos Fortes et al., 2005a Fortes et al., 2005b.

\subsection{Engenharia de Usabilidade}

Engenharia de Usabilidade é o termo usado para definir o processo de design de sistemas computacionais que visam a facilidade de aprendizado, de uso, e que sejam agradáveis para os usuários Rocha and Baranauskas, 2003.

O processo de design para usabilidade foi inicialmente uma recomendação de vários pesquisadores independentes Gould and Lewis, 1985, Nielsen, 1993 e grupos de pesquisa na DEC e IBM em Engenharia de Usabilidade que, já na década de 80, constataram que confiar na experiência do designer, em padrões e guidelines não era suficiente para chegar a bons sistemas de computador. A Engenharia de Usabilidade propõe a aplicação de métodos empíricos ao design de sistemas computacionais Rocha and Baranauskas, 2003.

O modelo de Engenharia de Usabilidade proposto por Nielsen, 1993 compreende a realização das seguintes atividades:

1. Conhecer os usuários
(a) Características Individuais
(b) Tarefas atualmente realizadas e tarefas desejadas
(c) Análise funcional
(d) Evolução do usuário na realização de tarefas

2. Análise competitiva

3. Definição de Metas de Usabilidade

(a) Análise de impactos financeiros

4. Design paralelo com vários desenvolvedores

5. Design participativo

6. Design coordenado da interface total 
7. Aplicação de guidelines e avaliação heurística

8. Prototipação

9. Testes empíricos

10. Design interativo

\section{(a) Capturar Design Rationale}

11. Coletar feedback através de pesquisa de campo

O primeiro passo do processo de engenharia de usabilidade é estudar a intenção do usuário e o uso do produto. Características individuais do usuário e suas variações na maneira de executar as tarefas são fatores que impactam na usabilidade e que precisam ser estudados cuidadosamente. Ao se pensar em "usuário", deve-se considerar que usuários incluem instaladores, administradores de sistemas, equipe de manutenção e suporte, bem como os usuários que operam o sistema. O conceito de usuário deve incluir todos aqueles cujo trabalho, de alguma maneira, é afetado pelo uso do produto.

Conhecendo as características individuais dos usuários, tais como: experiência de trabalho, nível educacional, idade, experiência com o uso de computadores, dentre outras, é possível antecipar algumas de suas dificuldades de aprendizado e estabelecer os limites da complexidade da interface com o usuário.

A análise das tarefas é essencial para o processo de design do sistema. As expectativas dos usuários com relação à execução das tarefas devem ser estudadas, bem como a forma com que as mesmas têm sido executadas até o momento. Deve-se observar quais informações são necessárias para sua execução e como tais tarefas são realizadas sob condições excepcionais ou em situações de emergência. A observação sistemática do diálogo entre usuários e clientes pode revelar a necessidade de informações de entrada e de saída para a realização de uma transação do sistema, por exemplo. Um resultado típico da análise de tarefas é uma lista de tudo o que o usuário deseja realizar no sistema (os objetivos), todas as informações de que eles necessitam para alcançar os objetivos (pré-condições), os passos necessários para isso e a interdependência entre eles, todas as saídas e relatórios que precisam ser produzidos, os critérios utilizados para determinar a qualidade e a aceitação dos resultados, e finalmente a comunicação necessária entre os usuários e as pessoas com as quais esses usuários trocam informações enquanto executam as tarefas ou se preparam para fazê-la.

A análise funcional também é um passo muito importante do processo de design, visto que sua finalidade é evitar que o design de um novo sistema de computador propague as mesmas 
formas com que as tarefas são realizadas no momento, mesmo quando essas formas não são as melhores, e que foram instituídas por causa das limitações de tecnologias anteriores, uma vez que as mesmas podem ser melhoradas ou otimizadas.

Outro fator que deve ser levado em consideração é a evolução do usuário, dado que os usuários mudam após usar um sistema computacional depois de algum tempo. Uma mudança típica é que os usuários tornam-se experts no uso do sistema e desejam realizar as mesmas tarefas seguindo caminhos mais curtos, utilizando shortcuts por exemplo. Assim sendo, um bom design deve ser flexível ao ponto de satisfazer tanto os usuários novatos quanto os peritos no uso do sistema.

A análise competitiva envolve testes em produtos já totalmente implementados, uma vez que testes com produtos já existentes são mais realísticos do que testes com protótipos. É interessante analisar os produtos já existentes (e muitas vezes concorrentes), pois assim os usuários podem verificar quais tarefas estão disponíveis e tentar realizá-las, aprender quais são as funcionalidades do sistema e as técnicas de interação com o usuário que são utilizadas, entre outras. Vale ressaltar que a análise competitiva não consiste em roubar os projetos de interface com o usuário de outras pessoas, mas sim em melhorar um projeto inicial a partir de uma análise de seus pontos fortes e pontos fracos em relação aos outros sistemas.

Conforme mencionado anteriormente, usabilidade não é um atributo unidimensional de um sistema. Usabilidade compreende vários componentes que algumas vezes podem ser conflitantes entre si. Normalmente, não se pode atribuir pesos iguais a todos os aspectos de usabilidade em um projeto. Para que as metas de usabilidade possam ser definidas é preciso estabelecer prioridades, com base na análise do usuário e suas tarefas. Ao mesmo tempo em que as metas de usabilidade estão sendo definidas, é importante realizar uma análise do impacto financeiro da usabilidade do sistema. Tal análise envolve, por exemplo, estimativa do número de usuários que utilizará o sistema, bem como o tempo aproximado de uso do sistema.

Design Paralelo é o procedimento em que diferentes designers trabalham de forma independente em projetos de design preliminares. A idéia do design paralelo é explorar diferentes alternativas de design antes de optar por uma única abordagem. Esse procedimento é especialmente importante durante a construção de sistemas inovadores, onde há poucos exemplos do que pode ser utilizado como design inicial. Para sistemas tradicionais, onde produtos concorrentes podem ser observados (análise competitiva) e podem servir como design inicial, o design paralelo pode contribuir para a exploração de possibilidades adicionais.

O Design Participativo faz com que a pessoa que realmente executa o trabalho que está sendo modelado, participe efetivamente do projeto de design, visto que muitas vezes os gerentes não conhecem todos os aspectos envolvidos na execução de uma tarefa de rotina do usuário. 
O Design Coordenado trata da consistência, que é uma das mais importantes características de usabilidade. A consistência deve ser aplicada em todas as diferentes mídias que compõem a interface com o usuário, incluindo não só as telas da aplicação, mas também a documentação, a ajuda on-line, os tutoriais em vídeo, etc.

Guidelines constituem uma lista de princípios que devem ser seguidos durante o projeto de design de interface. Em qualquer projeto, diferentes níveis de guidelines podem ser aplicados: guidelines gerais, aplicáveis para todo o tipo de interface com o usuário; guidelines específicas por categoria, que dependem do tipo de sistema que está sendo desenvolvido, como por exemplo, interfaces por voz acessadas por meio de telefone; guidelines específicas por produto, que são escolhidas de acordo com as características particulares do produto. Todas essas guidelines podem ser utilizadas como base para a avaliação heurística.

A Prototipação consiste no desenvolvimento de protótipos do sistema final para a realização de avaliações de usabilidade. Não é recomendável que a implementação total do sistema seja iniciada sem antes se realizar várias avaliações, ou até que a compreensão completa do design da interface seja alcançada.

Com relação à avaliação de interface, a recomendação mais forte é de que ela seja feita, e em especial deve ser realizada com usuários. Independentemente do método de avaliação empregado, o principal resultado da avaliação será uma lista dos problemas de usabilidade encontrados e algumas sugestões para melhor apoiar as estratégias adotadas pelos usuários para a realização das tarefas. Nem sempre é possível resolver todos os problemas, e portanto é necessário priorizá-los. Prioridades são baseadas em dados experimentais sobre o impacto dos problemas na performance do usuário, como por exemplo, quantas pessoas apresentaram o mesmo problema ou quanto tempo as pessoas perderam por causa de tal problema.

O Design Interativo consiste na elaboração de uma nova versão da interface a partir dos problemas de usabilidade encontrados na versão atual e a partir das oportunidades reveladas pelo teste empírico. Alguns métodos de teste como o Think Aloud fornecem visões suficientes da natureza dos problemas. Arquivos de log das interações dos usuários também auxiliam, na medida em que mostram em que ponto o usuário realizou uma pausa ou onde ele mais perdeu tempo, e quais erros foram encontrados mais freqüentemente. Uma vez que as mudanças de interface serão realizadas com alta freqüência, é importante registrar as razões que motivaram as alterações no design original, ou seja, é muito importante capturar o Design Rationale. Além disso, o Design Rationale ajuda a manter a consistência da interface com o usuário sobre sucessivas versões produzidas.

Finalmente, o principal objetivo do trabalho de usabilidade após a liberação do produto é 


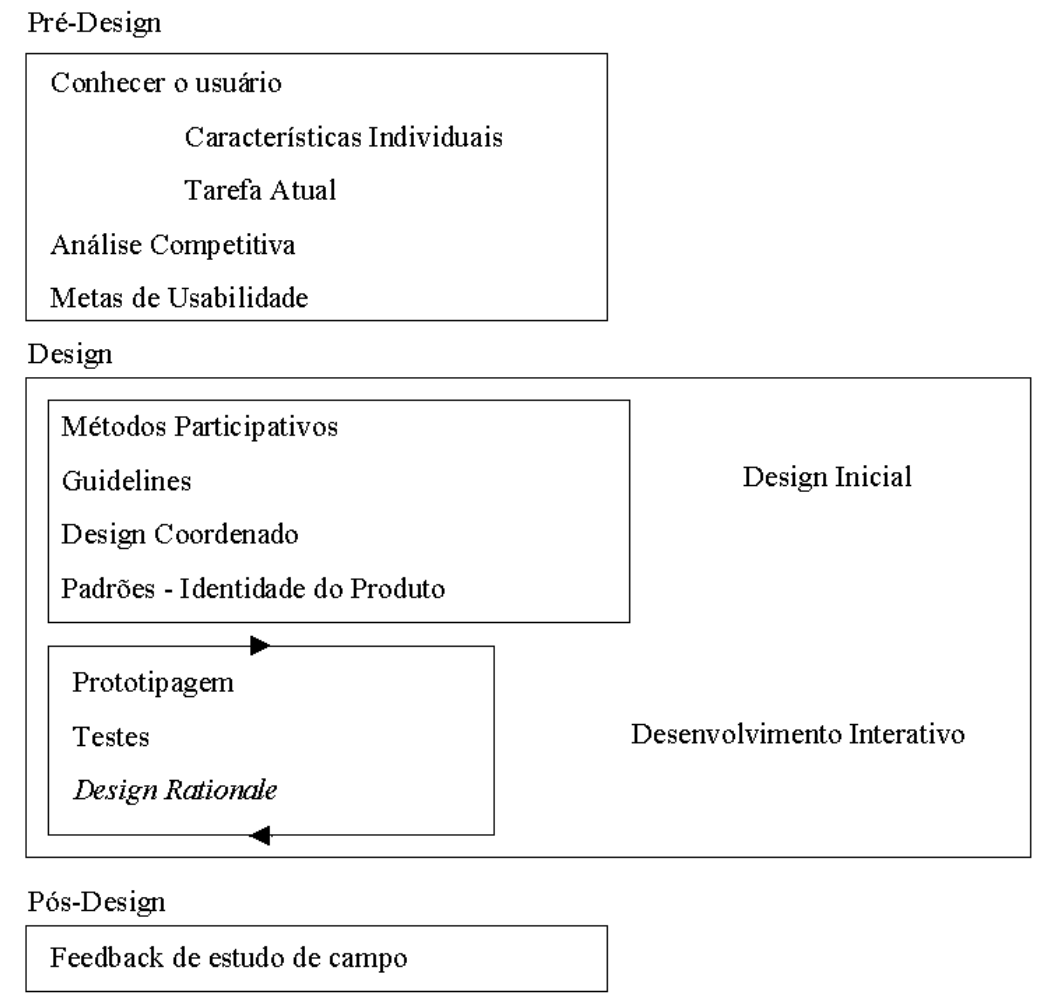

Figura 4.1: Fluxo de execução das atividades no modelo de Engenharia de Usabilidade Rocha and Baranauskas, 2003

coletar dados de usabilidade para a próxima versão e futuros produtos. Da mesma forma que os produtos existentes e concorrentes são os melhores protótipos para a fase de análise de um novo produto, a mais nova versão de um produto liberado pode ser vista como um protótipo para as versões seguintes.

Na Figura 4.1 é ilustrado o fluxo dessas atividades no processo de Engenharia de Usabilidade, sumarizado por Rocha and Baranauskas, 2003.

\subsection{Avaliação de Usabilidade}

A avaliação de um sistema tem como objetivos principais avaliar o seu design e verificar se o mesmo atende os requisitos da especificação, comportando-se de acordo com as expectativas dos usuários.

A etapa de avaliação deveria ser aplicada durante todo o ciclo de vida do design, ao invés de ser aplicada como uma única fase durante o processo, que geralmente é realizada apenas no final do processo de design, isso se ainda existir algum tempo disponível [Dix et al., 2003].

O principal objetivo ao se efetuar uma avaliação é conhecer o que os usuários querem e os problemas que eles experimentam, pois quanto melhor informados sobre seus usuários os 
designers estiverem, melhor serão os design de seus produtos Rocha and Baranauskas, 2003.

Pode-se dizer que a avaliação possui três grandes objetivos: avaliar a funcionalidade do sistema, avaliar o efeito da interface junto ao usuário e identificar problemas específicos do sistema Rocha and Baranauskas, 2003

De forma geral, Rocha and Baranauskas, 2003 classificam os métodos de avaliação em dois grupos:

- inspeção de usabilidade (predictive evaluation): não envolve usuários e pode ser usada em qualquer fase do desenvolvimento de um sistema (implementado ou não);

- testes de usabilidade: métodos de avaliação centrados no usuário que incluem métodos experimentais ou empíricos, métodos observacionais e técnicas de questionamento.

Para a aplicação desses métodos é necessária a existência de uma implementação real do sistema em algum formato que pode ser desde uma simulação da capacidade interativa do sistema, sem nenhuma funcionalidade, um protótipo básico implementado, um cenário, ou até a implementação completa.

\subsubsection{Inspeção de Usabilidade}

Define-se inspeção de usabilidade como um conjunto de métodos baseados em se ter avaliadores inspecionando ou examinando aspectos relacionados à usabilidade de uma interface de usuário. Os avaliadores podem ser especialistas em usabilidade, consultores de desenvolvimento de software, especialistas em um determinado padrão de interface, usuários finais, etc.

Inspeção de usabilidade visa encontrar problemas de usabilidade em um design de interface de usuário e, com base nesses problemas, fazer recomendações no sentido de eliminá-los e melhorar a usabilidade do design. Isso significa que inspeções de usabilidade são feitas em um estágio em que a interface está sendo gerada e sua usabilidade necessita ser avaliada.

Diferentes métodos de inspeção têm objetivos diferentes, mas normalmente a inspeção de usabilidade é proposta como um modo de avaliar design de interfaces baseado no julgamento de avaliadores e são sustentados pela confiança depositada em seus julgamentos. Os métodos variam no sentido de como os julgamentos são efetuados e em quais critérios se espera que o avaliador baseie seus julgamentos Rocha and Baranauskas, 2003.

Dentre os principais métodos de inspeção existentes, pode-se destacar:

- Avaliação Heurística: é feita a inspeção da interface, tendo como base uma pequena lista de heurísticas de usabilidade; 
- Revisão de Guidelines: a interface é analisada no sentido de verificar se está de acordo com uma lista de guidelines de usabilidade. Geralmente essa lista contém uma seqüência de 1000 guidelines, o que torna o uso desse método muito raro, dada a experiência que é exigida de um revisor;

- Inspeção de Consistência: o avaliador verifica a consistência dentro de uma família de interfaces, quanto à terminologia, cores, layout, formatos de entrada e saída, e tudo o mais dentro da interface. Também é avaliado o material on-line de treinamento e de ajuda;

- Percurso Cognitivo: o avaliador simula a ação do usuário, "caminhando" na interface para executar tarefas típicas. Tarefas mais freqüentes são o ponto inicial de análise, mas tarefas críticas, tais como recuperação de erro, também são percorridas. O percurso cognitivo foi desenvolvido para interfaces que podem ser aprendidas de forma exploratória, mas também são úteis em interfaces que exigem muito treinamento.

A partir da análise das principais características dos métodos de inspeção de usabilidade, o método escolhido para avaliar tanto a ferramenta DocRationale quanto a sua nova versão DocRat foi o método de Avaliação Heurística, testes esses que serão detalhados no capítulo seguinte.

A avaliação heurística deve ser vista como parte do processo de design interativo de uma interface. Ela envolve um pequeno conjunto de avaliadores examinando a interface e julgando suas características em face de reconhecidos princípios de usabilidade, denominados heurísticas (ver seção 4.2).

De maneira geral, é raro realizar a Avaliação Heurística com um único avaliador, porque é muito difícil uma única pessoa ser capaz de encontrar todos os problemas de usabilidade em uma interface. A experiência com esse tipo de avaliação tem mostrado que diferentes pessoas encontram diferentes problemas, e portanto os resultados da avaliação heurística melhoram significativamente quando se utiliza múltiplos avaliadores. A recomendação é que se use de três a cinco avaliadores Rocha and Baranauskas, 2003 Nielsen, 1993.

\subsubsection{Testes de Usabilidade}

Teste com usuário é um método fundamental de avaliação de usabilidade. Os desenvolvedores tradicionais resistem à idéia, argumentando que teste de usabilidade sem dúvida alguma é uma boa idéia, mas limitações de tempo e de recursos os impedem de fazê-lo. Mas esse cenário está mudando muito rapidamente. Gerentes de desenvolvimento estão percebendo que o agendamento dos testes de usabilidade é um poderoso incentivo para o término da fase de design. E a surpresa é que os resultados práticos têm demonstrado que testes de usabilidade não somente 
têm acelerado muitos projetos, como também têm produzido uma significativa redução em seus custos Gould and Lewis, 1985, Nielsen, 1994.

Antes de iniciar qualquer teste é preciso estabelecer seus objetivos, pois os mesmos tem um impacto significativo no tipo de teste a ser feito. A principal distinção é se o teste tem como objetivo obter uma ajuda no desenvolvimento ou é um teste que visa avaliar a qualidade global de uma interface. No primeiro caso, interessa saber em detalhes quais aspectos da interface estão bons ou ruins, e como o design pode ser melhorado. É uma forma mais gradual de analisar a interface, e nesse caso usualmente se aplica o teste denominado pensar em voz alta (ThinkAloud test). No segundo caso, como se quer uma visão mais global de uma interface em fase final de definição, geralmente se utiliza testes que dêem medidas de performance. Em qualquer uma das situações, deve ser desenvolvido um plano detalhado de teste onde, dentre outras mais específicas, as seguintes questões devem ser respondidas [Rocha and Baranauskas, 2003]:

- O objetivo do teste: o que se deseja obter?

- Quando e onde o teste irá acontecer?

- Qual a duração prevista de cada sessão de teste?

- Qual o suporte computacional necessário?

- Qual software precisa estar a disposição?

- Qual deverá ser o estado do sistema no início do teste?

- Quem serão os experimentadores?

- Quem serão os usuários e como serão conseguidos?

- Quantos usuários serão necessários?

- Quais tarefas serão solicitadas aos usuários?

- Qual critério será utilizado para definir que os usuários terminam cada tarefa corretamente?

- Quanto o experimentador poderá ajudar o usuário durante o teste?

- Quais dados serão coletados e como serão analisados uma vez que tenham sido coletados?

- Qual o critério para determinar que a interface é um sucesso?

Deve-se estar sempre atento a dois problemas vinculados a um teste de usabilidade: a confiabilidade e a validade. Como confiabilidade entende-se o grau de certeza de que o mesmo 
resultado será obtido se o teste for repetido; e como validade, o fato dos resultados do teste refletirem os aspectos de usabilidade que se deseja testar.

É necessário que seja tomado um cuidado especial para escolher adequadamente os usuários que farão o teste, de forma que sejam tão representativos quanto possível com relação aos usuários reais do sistema. Os experimentadores também devem ser preparados no sentido de tomarem conhecimento completo sobre a aplicação e respectiva interface de usuário. Também é necessário que as tarefas a serem feitas durante um teste sejam as mais representativas possíveis e dêem uma cobertura razoável das partes mais significativas da interface Rocha and Baranauskas, 2003.

O teste de usabilidade é composto basicamente por quatro etapas:

- Preparação: nessa etapa prepara-se todo o ambiente para que o usuário possa realizar o teste antes que ele chegue, garantindo que o equipamento e o software estejam preparados adequadamente;

- Introdução: nessa etapa o usuário é apresentado à situação do teste e recebe instruções sobre o propósito da avaliação e sobre os procedimentos utilizados durante o teste;

- Teste: durante o teste, é importante que se evite fazer comentários sobre a performance dos usuários e também não fornecer ajuda, a não ser que ele esteja realmente em dificuldades muito graves;

- Sessão final: depois do tempo definido para completar as tarefas, os participantes são convidados a fazer comentários ou sugestões gerais, ou a responderem um questionário específico.

Uma técnica efetiva durante um teste de usabilidade é solicitar que os usuários pensem em voz alta sobre o que estão fazendo. A atmosfera informal de uma sessão que usa essa técnica é extremamente agradável, e freqüentemente leva a muitas sugestões espontâneas de melhorias.

A técnica de pensar em voz alta (ou Think-Aloud) é uma técnica muito valiosa utilizada originalmente como um método de pesquisa psicológico. Solicita-se ao usuário que verbalize tudo que pensa enquanto usa um sistema e a expectativa é que seus pensamentos mostrem como o usuário interpreta cada item da interface. A principal contribuição dessa técnica é mostrar o que os usuários estão fazendo e porque estão fazendo enquanto estão fazendo, evitando as racionalizações posteriores.

O critério de eficiência de uso é definido como uma das guidelines de usabilidade. Dentro deste contexto, são fundamentais algumas medidas de performance na forma de tomadas de tempo, por exemplo. Como e quando marcar tempos deve ser decidido a priori, de acordo com 
os dados necessários na coleta. Outros tipos de métricas de performance que podem ser tomadas são o número de erros do usuário, a proporção de comentários favoráveis em relação ao número de comentários desfavoráveis, entre outras.

\subsection{Computação Ubíqua}

Os recentes avanços nas tecnologias de computação têm facilitado a construção de sistemas com alto grau de usabilidade. A proliferação de dispositivos computacionais denominados "ubíquos", tais como: PDA's (Personal Digital Assistants), tablets PCs e laptops têm impulsionado o surgimento de novas aplicações computacionais que explorem o uso desses novos dispositivos. Pode-se definir a computação ubíqua com sendo o uso da tecnologia integrada ao ambiente de forma não intrusiva Weiser, 1991.

Essa proliferação de dispositivos computacionais ubíquos já havia sido prevista por Weiser em 1991 Weiser, 1991. Além dos dispositivos de pequeno (inch-scale) e médio porte (footscale), dispositivos maiores, tais como lousas eletrônicas, passaram a fazer parte de ambientes comuns, tais como salas de reuniões, salas de aula e laboratórios. Hoje em dia, utilizam-se também dispositivos com medidas que ultrapassam muito as escalas anteriores, denominados wall-sized, que podem ocupar paredes inteiras sendo suas superfícies monitoradas por sensores, tais como os mimios. Alguns exemplos desses dispositivos são mostrados na Figura 4.2 .

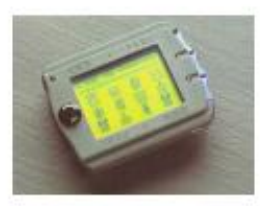

(a)

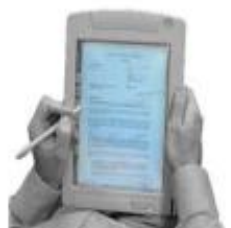

(b)

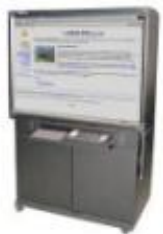

(c)

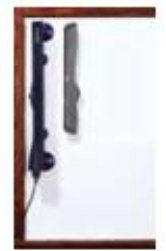

(d)

Figura 4.2: Alguns dispositivos atuais de computação ubíqua: (a) um pda, (b) um tablet, (c) uma lousa eletrônica e (d) um mimio [Pimentel et al., 2003].

Um outro aspecto vislumbrado por Weiser também se confirmou: novas aplicações computacionais surgiriam para explorar o uso desses novos dispositivos. O desenvolvimento de tais aplicações está diretamente associado a três temas: interfaces naturais ou interação transparente, aplicação ciente de contexto e captura automática das experiências humanas Abowd, 1999b Abowd and Mynatt, 2000.

Segundo Abowd Abowd, 1999b, a interação transparente ou interfaces naturais têm 
como objetivo apresentar uma interface que remova a barreira física entre o usuário e o computador. Embora já se tenha conseguido grandes avanços em termos de usabilidade, provenientes do desenvolvimento de técnicas que permitem o desenvolvedor construir sistemas baseados na modelagem de tarefas e modelos mentais do usuário, as pessoas continuam ainda muito presas aos mesmos dispositivos de entrada: teclado, mouse e monitor. Este tipo de interface física não é nada transparente e viola a visão da computação ubíqua no que diz respeito à computação sem intrusão, uma vez que a premissa básica da computação ubíqua é adaptar as interfaces de forma que os usuários não tenham que mudar seus hábitos para realizarem suas tarefas.

A computação ciente de contexto envolve o desenvolvimento de aplicações que admitam uma coleção de contextos e possuam comportamento dinâmico, que é ditado pelo conhecimento do ambiente ou do contexto propriamente dito Abowd, 1999b. Os serviços computacionais devem ser capazes de inferir noções de espaço e tempo, usando facilidades providas pelo sistema GPS - Global Positioning System, por exemplo. Outra forma de explorar a informação contextual está nas técnicas de reconhecimento de objetos. Entretanto, há muitas outras informações contextuais, além de localização e identificação de pessoas e objetos, que não são exploradas. A maioria dos sistemas conscientes de contexto ainda não incorpora noções de tempo, história, outras pessoas além do próprio usuário, e muitas outras informações disponíveis nos ambientes. Abowd \& Mynatt Abowd and Mynatt, 2000 descrevem como obter informações contextuais analisando cinco aspectos primordiais, os quais são chamados de "cinco W's":

- Who (quem): deve-se prover informações contextuais de todas as pessoas envolvidas em uma dada atividade assistida por computador. As pessoas, em geral, lembram-se de eventos do passado baseados na presença de pessoas que os vivenciaram;

- What (o quê): tem como função identificar o que o usuário está fazendo. Sistemas onde atividades muito variadas podem ser desenvolvidas, identificar o que o usuário está fazendo em um determinado momento pode ser uma tarefa complexa;

- Where (onde): como já foi mencionado, o contexto de localização é o mais utilizado pelos sistemas sensíveis a contexto. Pesquisas apontam a utilização dessa informação contextual associada a outras como, por exemplo, quando, indicando que é interessante mesclar os contextos temporais e espaciais no sentido de prover novas funcionalidades às aplicações;

- When (quando): o contexto temporal tem sido usado para indexar um registro capturado ou para informar por quanto tempo um usuário esteve em um determinado local (onde + quando); 
- Why (porquê): mais complexo que perceber o que o usuário está fazendo é entender o porquê de sua ação. Obter informações contextuais que possam caracterizar o raciocínio de uma pessoa é talvez o maior desafio da computação ciente de contexto.

O terceiro tema também importante, de captura e acesso, é um dos mais estudados na área da computação ubíqua Abowd, 1999a. Seu propósito é capturar as experiências diárias das pessoas, registrá-las e torná-las disponíveis para uso posterior. O ser humano gasta muito tempo ouvindo e registrando os fatos, mais ou menos de forma precisa, dos eventos que o cerca, para posteriormente conseguir lembrar apenas dos pontos mais importantes, ou seja, diante da impossibilidade de registrar tudo o que se passa ao seu redor, o ser humano tenta preservar memórias utilizando anotações, gravações de áudio e vídeo, etc. Nos últimos anos, sobretudo em função da difusão da multimídia nos ambientes computacionais, o homem passou a utilizar o computador como forma de capturar e armazenar memórias, seja através de documentos tradicionais, hiperdocumentos ou arquivos de áudio e vídeo.

Uma vez provada a eficiência da utilização de recursos computacionais para o registro de memórias, aplicações surgiram no sentido de tornar mais eficiente a captura e o posterior acesso à informação capturada. Tais aplicações permitem o registro simultâneo de diversos fluxos de informação, preservando as inter-relações existentes entre cada um deles, o que possibilita uma série de facilidades de acesso ao conteúdo capturado, preservando, assim, todo o conteúdo da experiência e ao mesmo tempo proporcionando que esse conteúdo possa ser seletivamente acessado.

Na seção seguinte são apresentadas algumas aplicações que exploram o uso das facilidades proporcionadas pela computação ubíqua, tais como: os projetos eClass e iClass, e ainda outros projetos relacionados.

\subsection{Projetos Relacionados}

A seguir são apresentadas algumas aplicações que fazem uso de conceitos de computação ubíqua e usabilidade, e que serviram de base para o desenvolvimento do trabalho proposto.

\subsubsection{Projetos eClass \& iClass}

O Projeto eClass, desenvolvido originalmente no GATECH, em Atlanta nos EUA, anteriormente chamado de "Classroom 2000" Abowd, 1999a, investiga a utilização de computação ubíqua em ambientes convencionais (salas de aula e salas de reuniões) para a captura de informações. O ambiente eClass é equipado com dispositivos de captura e permite a produção automática de 
documentos hipermídia, que refletem o conteúdo capturado, e a apresentação desse material através da Web Abowd et al., 1998 Abowd, 1999a.

Em uma sala de aula, existem muitas informações apresentadas aos estudantes que são complementadas por discussões e demonstrações visuais. Para a captura de material utiliza-se uma sala de aula equipada com câmeras de vídeo, microfones, projetores e uma lousa eletrônica. O professor geralmente apresenta o conteúdo da aula através de projetores ou de uma lousa eletrônica (whiteboard), que é uma tela sensível ao toque e que, conectada a um computador, permite armazenar as interações do usuário com a tela.

Além disso, tornou-se comum o professor complementar as informações em classe através da Web. A combinação de todas essas informações constitui uma experiência intensiva de captura de informações que está além da capacidade do aluno de registrar tudo precisamente, principalmente no caso do aluno que está tentando prestar atenção e compreender a aula ao mesmo tempo. Assim sendo, quando a aula termina, o aluno consegue preservar apenas uma pequena reflexão sobre o que realmente aconteceu. A grande vantagem do uso de equipamentos eletrônicos e softwares de computação ubíqua é a habilidade de preservar o registro de toda a experiência ocorrida na sala de aula.

O eClass é constituído por duas infra-estruturas, sendo uma de hardware e outra de software. A sala de aula instrumentada com a infra-estrutura de hardware possui basicamente uma lousa eletrônica, projetores, microfones e câmeras de vídeo. Na Figura 4.3 é apresentada a sala protótipo inicial, em operação desde janeiro de 1997 no Georgia Tech, com uma lousa eletrônica (A), câmera de vídeo (B), microfones (C) e projetores (D e E).

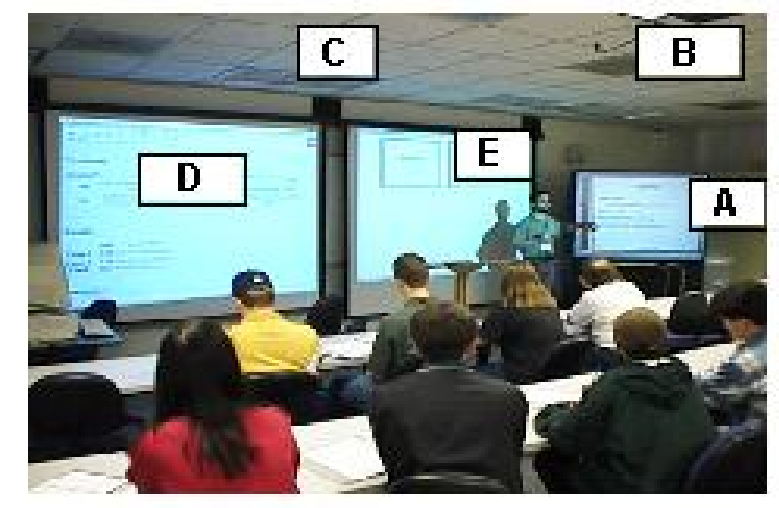

Figura 4.3: Sala de aula instrumentada do sistema eClass Abowd, 1999a

A infra-estrutura de software é responsável pela captura e sincronização dos fluxos (streams) de informação durante cada sessão ao vivo. Suas tarefas incluem ainda a geração dos documentos 
associados quando a sessão é encerrada. Como resultado desse processo, poucos minutos após a conclusão da sessão, um hiperdocumento $W e b$ é automaticamente gerado e disponibilizado para acesso.

No ICMC-USP, numa iniciativa apoiada pela transferência de conhecimentos adquiridos por meio da parceria com o GATECH, foi desenvolvido o sistema iClass Cattelan et al., 2003, para captura e acesso de sessões em ambiente de sala de aula. O objetivo desse sistema, assim como com o eClass, é determinar o impacto da tecnologia de computação ubíqua na educação.

As informações capturadas durante a experiência em sala de aula pelo sistema iClass fazem parte de um contexto que abrange informações produzidas antes e depois da aula em si, e que encontram-se em constante evolução Pimentel et al., 2001a]:

- pré-produção: o professor prepara o material a ser apresentado e/ou discutido e carrega os slides;

- gravação ao vivo: gravação da aula, período em que os slides carregados na fase anterior são apresentados em uma lousa eletrônica e o professor pode fazer anotações neste material ou produzir novo material. Os strokes, o áudio e o vídeo são armazenados utilizando o serviço StRES (Storing, Retrieving and Extending Service) Baldochi, 2002;

- pós-produção: após a aula, um documento XML é gerado e várias folhas de estilo processam esse documento, produzindo outros documentos em diferentes formatos (HTML, SMIL, XHTML) Andrade, 2002;

- acesso: nesta fase os documentos gerados na fase anterior podem ser visualizados (Figura 4.4 .

Atualmente no ICMC-USP, as informações capturadas em salas de aula são armazenadas em um repositório de aulas e disponibilizadas para acesso através da $W e b$.

Existem vários projetos no contexto educacional e de apoio a reuniões que utilizam recursos de computação ubíqua, tais como:

- no contexto educacional: os projetos eClass Abowd, 1999a e iClass Cattelan et al., 2003, Authoring on the Fly Müller and Ottmann, 2000, Smart Classroom Shi et al., 2003 e Lecture Browser Mukhopadhyay and Smith, 1999;

- no apoio a reuniões: Tivoli Pedersen et al., 1993, Dolphin Streitz et al., 1994 e o TeamSpace Richter et al., 2001. 


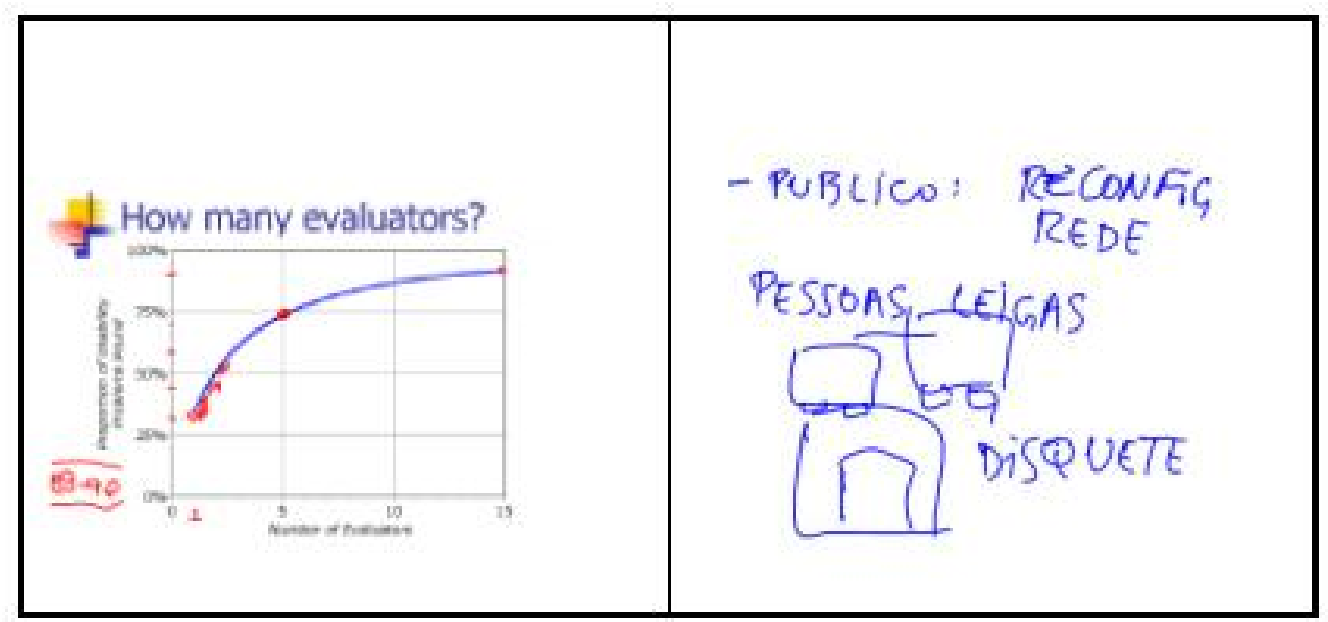

(a)

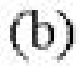

Figura 4.4: Hiperdocumentos gerado automaticamente pelo iClass: (a) slide anotado pelo professor e (b) slide de acompanhamento de curso Pimentel et al., 2003

\subsubsection{Outros Projetos Relacionados}

Além de projetos que visam capturar todo o tipo de interação em salas de aulas e reuniões, existem outros projetos que exploram conceitos de usabilidade e características de computação ubíqua para facilitar a execução e o registro de pequenas tarefas, tais como as tarefas de análise e design de um projeto de software, por exemplo.

Desenhos e esboços são artefatos importantes da fase de design de um software. Desenvolvedores de software fazem uso de desenhos e esboços para ajudá-los a expressar suas idéias, visualizar a organização de um programa ou mesmo compreender os requisitos de um sistema de software. Infelizmente tais artefatos, que constituem uma rica fonte de Design Rationale, são deixados de lado quando os desenvolvedores passam para a fase de modelagem e codificação do sistema.

O Tahuti é um ambiente para o reconhecimento de esboços de diagramas UML com visão dupla Hammond and Davis, 2002. O sistema é baseado em um framework de reconhecimento que realiza o reconhecimento de objetos multi-stroke (objetos compostos por mais de um traço) por meio de suas propriedades geométricas, permitindo que o usuário desenhe seus esboços naturalmente utilizando interações com caneta, como se estivesse utilizando papel e caneta, ao invés de exigir que o usuário desenhe objetos de uma forma pré-definida. Nesse sistema, os usuários podem desenhar e editar tanto em seus strokes originais quanto na versão interpretada (Figura 4.5). 


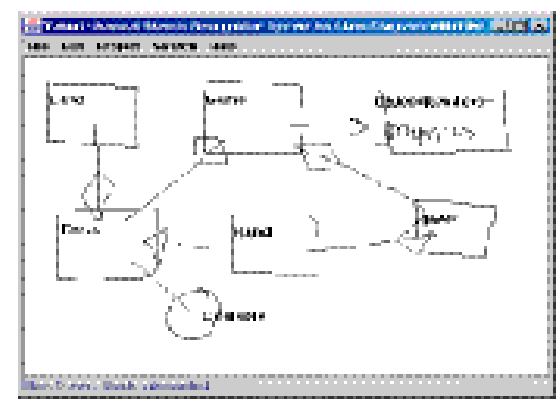

(a)

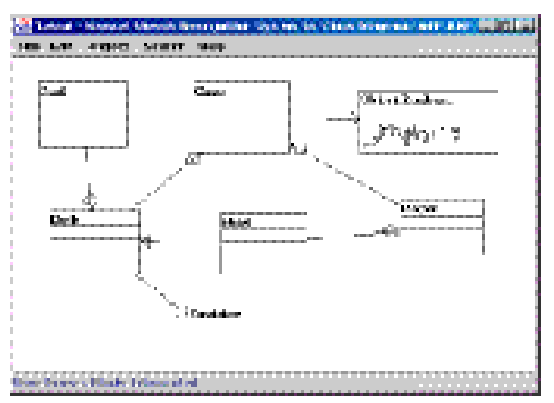

(b)

Figura 4.5: Visões do Tahuti: (a) slide anotado pelo desenvolvedor e (b) slide com diagrama reconhecido pelo sistema Hammond and Davis, 2002.

Uma outra aplicação, desenvolvida por Alvarado Alvarado, 2004, realiza o reconhecimento de desenhos e esboços para a criação de diagramas em Microsoft Power Point. Diferente das interfaces baseadas em caneta tradicionais, a classe de interfaces denominada Sketch Recognition User Interfaces ou SkRUIs executa um processo de reconhecimento robusto, permitindo que enquanto o usuário desenha livremente, o sistema reconhece os diagramas e os importa para a aplicação Power Point. A aplicação construída para explorar as SkRUIs permite que usuários criem diagramas compostos de formas geométricas (quadriláteros e elipses) e conectores (linhas e setas) desenhando-os em um tablet $P C$, por exemplo. O sistema reconhece as diferentes formas desenhadas, sem que o usuário tenha que executar nenhuma ação adicional para indicar qual forma ele está desenhando. A ferramenta apresenta também a opção do não-reconhecimento, permitindo ao usuário acrescentar anotações aos diagramas já desenhados e transformados em objetos do Power Point, de modo que eles aparecem no slide exatamente como foram escritos, visto que a ferramenta não apresenta o reconhecimento de escrita, como pode ser visualizado na Figura 4.6 .

\subsection{Considerações Finais}

Neste capítulo foram apresentados os principais conceitos de usabilidade, o processo de reengenharia de usabilidade proposto por Nielsen Nielsen, 1993 e algumas formas de avaliação de interface. Os conceitos explorados pela Computação Ubíqua também foram apresentados, no sentido de que se utilizados em conjunto com as guidelines de usabilidade podem contribuir efetivamente com o desenvolvimento de aplicações com alto grau de usabilidade. 


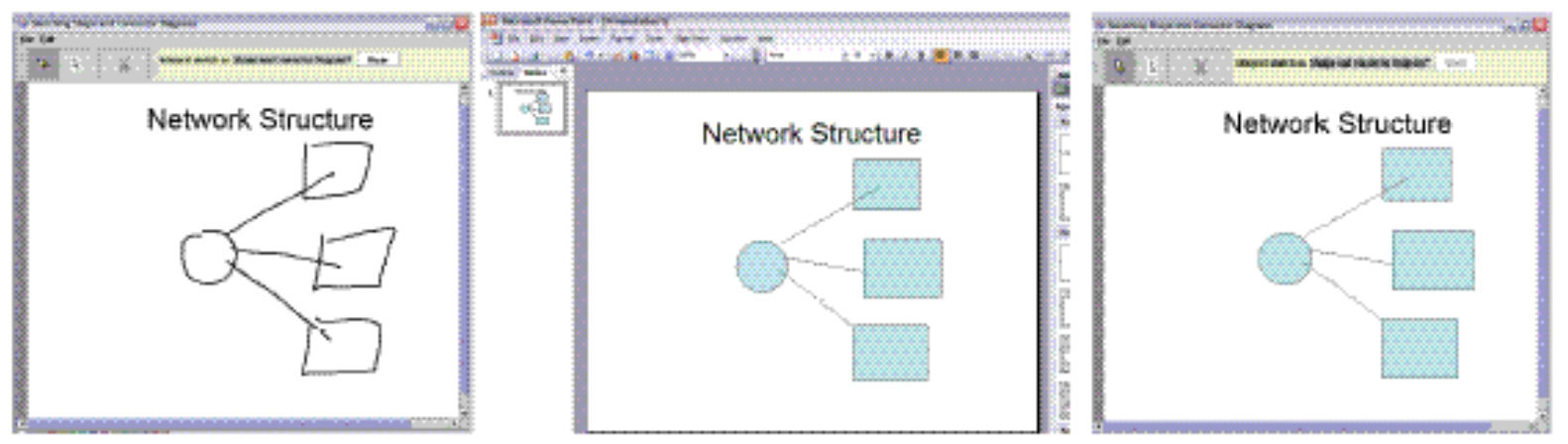

Figura 4.6: Diagramas e objetos importados para o Microsoft Power Point: (a)esboço de um diagrama (b)os objetos gerados a partir dos esboços são automaticamente importados para o Power Point (c)os objetos reconhecidos substituem os esboços do usuário Alvarado, 2004.

Os trabalhos apresentados visam explorar interações naturais em dispositivos ubíquos para a realização de tarefas habituais dos usuários, tais como: a realização de uma aula por um professor, a criação de um diagrama desenhado por um desenvolvedor, entre outras. Os objetivos principais de tais aplicações são: fazer com que o usuário interaja de maneira natural e espontânea com a aplicação sem que para isso tenham que modificar os seus hábitos; registrar todo o conteúdo produzido por tal interação; disponibilizar o conteúdo registrado para posterior acesso.

O trabalho proposto tem como objetivo o desenvolvimento de uma aplicação para apoiar as fases de análise e design de projetos de software, visando facilitar a captura de Design Rationale. Para que a interação com a aplicação seja a mais natural possível deve-se utilizar um dispositivo do tipo tablet $P C$, que permite interações com caneta, de modo que o usuário possa escrever e desenhar livremente. 


\section{Capítulo 5}

\section{DocRat: Reengenharia da}

\section{Ferramenta DocRationale}

\subsection{Considerações iniciais}

No início do desenvolvimento das atividades referentes ao projeto de mestrado, a primeira tarefa consistiu em identificar quais os pontos ideais para a integração de uma interface ubíqua para a captura de Design Rationale. O objetivo principal era definir quais os pontos favoráveis para a integração de um editor gráfico com reconhecimento de escrita manual, de modo a tornar mais natural o uso da ferramenta e a respectiva captura de $D R$.

Durante o estudo das funções e da implementação já existentes na ferramenta foi constatado o primeiro problema: a DocRationale, que era uma ferramenta Web, apresentava uma interface não compatível com o padrão de interface $W e b$. Pode-se dizer que padrão de interface $W e b$ é um conjunto de aspectos comuns de interface com o usuário, encontrado em várias aplicações Shneiderman, 1998.

Problemas de usabilidade da ferramenta também foram detectados, tanto por alunos que a tinham utilizado durante o desenvolvimento de trabalhos em disciplinas oferecidas pelo departamento, como por pessoas que a estudaram com o intuito de utilizá-la como apoio para o desenvolvimento de seus próprios projetos.

Além dos problemas de usabilidade, havia também a dificuldade de manutenção do código da ferramenta, visto que da forma como estava implementada não havia a separação entre o código escrito em linguagem PHP (lógica) e o código HTML (camada de apresentação) e nem a utilização de folhas de estilo. Além disso, havia duplicação de funções relativas à integração com a CoTeia e com o GroupNote, o que tornava o processo de manutenção ainda mais complicado.

Diante de todos esses fatores, e tendo como principal objetivo facilitar o uso da ferramenta, 
foi constatado que não adiantaria prover um meio de captura de dados mais ubíquo (interface para escrita manual) sem antes resolver os problemas de usabilidade já existentes. Neste capítulo são descritas as atividades desenvolvidas no contexto da engenharia reversa, da reengenharia da interface e da reimplementação do código da ferramenta, atividades essas que deram origem a uma nova versão da ferramenta, denominada DocRat.

O estudo e o entendimento da ferramenta DocRationale foi realizado seguindo, de forma simplificada, o método de engenharia reversa FUSION-RE/I [Costa, 1997]. A reengenharia da interface foi realizada com o objetivo de atender aos requisitos de usabilidade identificados durante o uso da ferramenta e seguiu os passos do ciclo de vida de Engenharia de Usabilidade Nielsen, 1993. A reimplementação do código tornou-se necessária para atender aos requisitos da nova interface e com isso aproveitou-se para realizar a separação entre a lógica da aplicação e a sua apresentação, por meio da utilização de templates.

As seções seguintes estão organizadas da seguinte forma: na Seção 5.2 são apresentados os principais conceitos sobre a engenharia reversa e os artefatos produzidos durante a aplicação do método FUSION-RE/I na ferramenta DocRationale. Na Seção 5.3 são apresentadas as atividades realizadas de acordo com o modelo do ciclo de vida da Engenharia de Usabilidade. Na Subseção 5.3 .3 são apresentadas as técnicas de avaliação que foram aplicadas na ferramenta, bem como os seus resultados. A Seção 5.4 descreve as dificuldades e limitações encontradas durante o desenvolvimento do trabalho. Finalmente, são apresentadas as considerações finais a respeito da reengenharia da ferramenta, na Seção 6.5.

\section{$5.2 \quad$ Engenharia Reversa}

O processo tradicional de engenharia de software caracterizado pelas atividades progressivas do ciclo de vida, que partem de um alto nível de abstração para um baixo nível de abstração é conhecido como engenharia progressiva Chikofsky and Cross, 1990. O processo inverso à engenharia progressiva, caracterizado pelas atividades retroativas do ciclo de vida, é conhecido como engenharia reversa (Figura 5.1.

Um dos objetivos principais da engenharia reversa é a recuperação de informações para serem utilizadas na fase de manutenção do software. Pode-se observar que a facilidade de manutenção (manutenibilidade), caracterizada principalmente pelo entendimento do sistema, está fortemente relacionada à disponibilidade de informações sobre o sistema. Essas informações podem ser produzidas pela engenharia reversa facilitando, primeiramente, o entendimento e, posteriormente, a modificação e revalidação do sistema, aumentando assim a manutenibilidade do mesmo Chikofsky and Cross, 1990. 


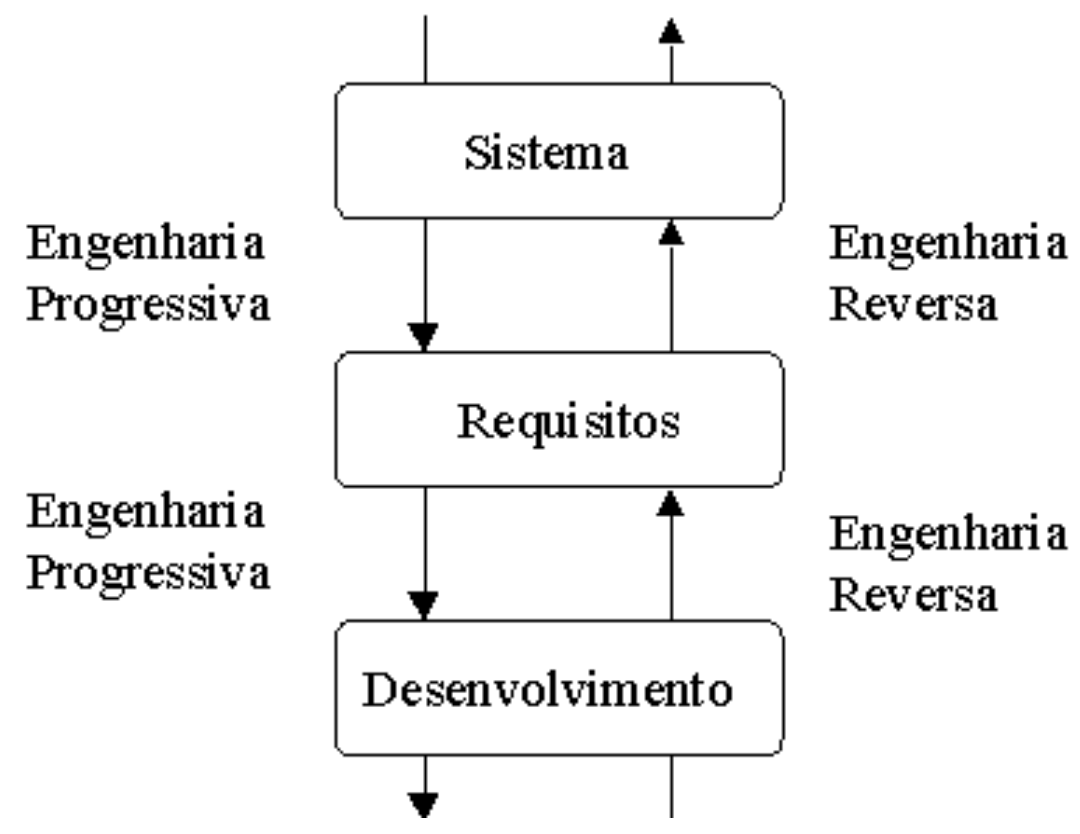

Figura 5.1: Engenharia Progressiva/Engenharia Reversa

Segundo [Chikofsky and Cross, 1990], a aplicação da engenharia reversa não envolve mudanças ou criação de um novo software. Trata-se do processo de exame e compreensão do sistema existente, a fim de recuperar ou recriar o projeto e decifrar os requisitos atualmente implementados, apresentando-os em um grau, ou nível, mais alto de abstração. Para Pressman Pressman, 1995, a engenharia reversa é o processo de analisar um software num esforço de criar uma representação do mesmo, em um nível de abstração mais alto do que o código fonte.

Assim sendo, pode-se dizer que o objetivo da engenharia reversa é a produção de informações que possam aumentar o conhecimento geral de sistemas de software. Essas informações podem ser utilizadas em atividades como manutenção, reuso, teste e controle de qualidade de software.

Por meio da engenharia reversa, um software pode ser visualizado em diferentes níveis de abstração, os quais são detalhados a seguir.

\subsubsection{Níveis de Abstração no Ciclo de Vida}

As fases do ciclo de vida podem ser agrupadas em três atividades fundamentais:

- Sistema (engenharia de sistemas): envolve o contexto em que o sistema está operando, ou seja, o porquê do sistema ser desenvolvido;

- Requisitos (análise): são estabelecidos os serviços a serem fornecidos pelo sistema e as 
restrições sob as quais ele deve operar, ou seja, o que o sistema deve fazer e sob quais circunstâncias;

- Desenvolvimento (projeto, codificação e testes): cria-se um planejamento da solução, ou seja, como o sistema cumprirá o que foi estabelecido na atividade de requisitos e a implementação dessa solução, incluindo a codificação, os testes, a depuração e a entrega do sistema. A fase de manutenção é vista como reiteração das atividades prévias.

As atividades consideradas fundamentais no ciclo de vida (Figura 5.2) possuem uma nítida diferença nos níveis de abstração. Com base nos níveis de abstração, as visões obtidas do software são classificadas em quatro categorias: visão em nível implementacional, visão em nível estrutural, visão em nível funcional, visão em nível de domínio Harandi and Ning, 1990.

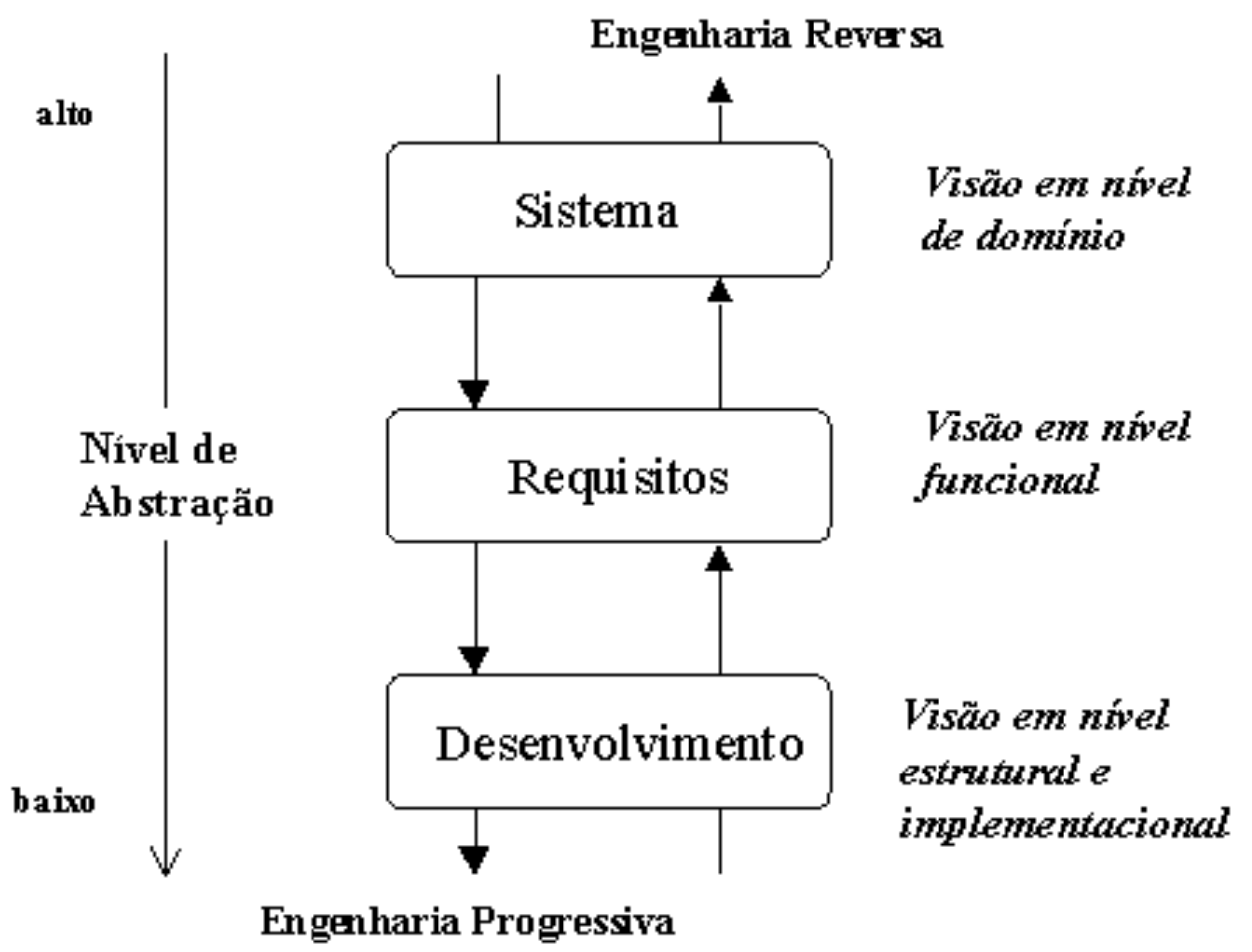

Figura 5.2: Níveis de entendimento do software de acordo com o ciclo de vida

Visão em nível implementacional: abstrai características da linguagem de programação e especificamente da implementação. Exemplos de visões em nível implementacional são informações a respeito da sintaxe e da semântica da linguagem, e informações de implementação.

Visão em nível estrutural: abstrai detalhes da implementação para revelar sua estrutura a partir de diferentes perspectivas. O resultado é uma representação explícita das dependências entre os componentes do sistema. 
Visão em nível funcional: abstrai a função de um componente do sistema, isto é, identifica o que o componente faz. Relaciona partes do programa às suas funções a fim de revelar as relações lógicas entre elas.

Visão em nível de domínio: abstrai o contexto em que o sistema está operando, ou seja, relata o porquê do sistema ter sido desenvolvido.

Para obter as diversas visões do software, usualmente é necessário acrescentar às informações contidas no código outras informações provenientes de conhecimento e de experiência humana. Baseado no nível de entendimento obtido do sistema e no escopo das informações fornecidas, há uma categorização das técnicas de engenharia reversa: redocumentação e recuperação de projeto Chikofsky and Cross, 1990. Na Figura 5.3, são apresentadas as categorias de engenharia reversa, relacionadas às fases do ciclo de vida.

\section{Engenharia Reversa}

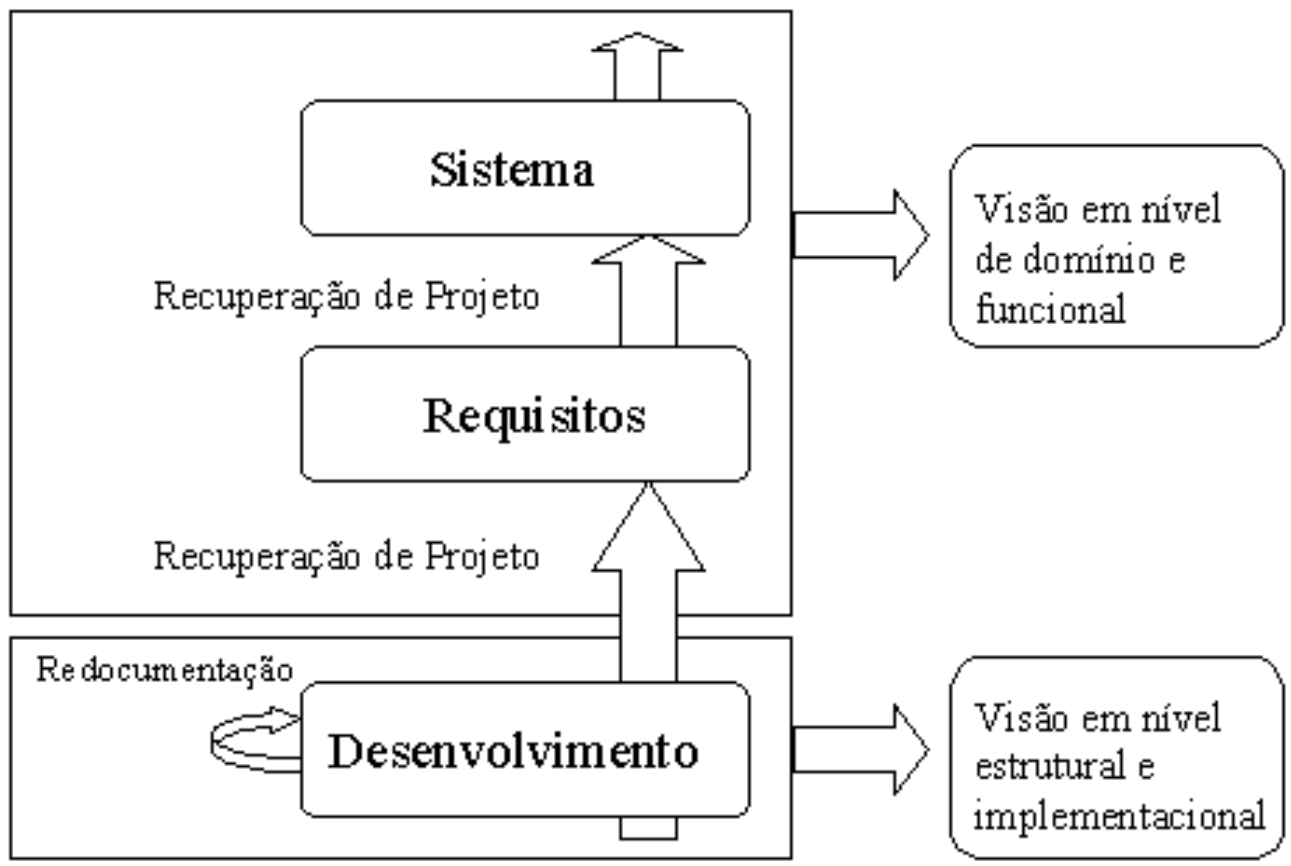

Figura 5.3: Categorias da engenharia reversa relacionadas ao ciclo de vida

Redocumentação: É a criação ou revisão de representações semanticamente equivalentes em um mesmo nível de abstração. O processo de redocumentação cria as representações a partir de informações obtidas apenas da análise do código fonte. Por exemplo: a partir do código fonte, pode-se analisar e extrair a arquitetura do programa, a estrutura de controle, a estrutura de dados, etc. As formas obtidas das representações são consideradas visões alternativas, tendo como objetivo melhorar a compreensão do sistema de maneira global. 
Recuperação de Projeto ou Entendimento do Programa: Tem como objetivo entender o sistema ao invés de simplesmente fornecer visões alternativas para auxiliar o usuário a entendê-lo, distinguindo-se, porém, da redocumentação. Esse entendimento vai além do escopo do conhecimento em nível implementacional e estrutural. A ênfase é obter conhecimento em nível funcional e até mesmo em nível de domínio (ambiente de operação do sistema).

Para auxiliar a atividade de manutenção de software, Costa Costa, 1997 desenvolveu o método de engenharia reversa FUSION-RE/I que, partindo do código fonte, de aspectos operacionais do sistema e de dados da interface, recupera visões funcionais e estruturais do sistema. As visões funcionais são recuperadas partindo-se de informações apresentadas na interface e de aspectos operacionais; as visões estruturais são recuperadas utilizando as visões funcionais produzidas e o código fonte do sistema. Na subseção a seguir são detalhadas as etapas do método de engenharia reversa FUSION-RE/I, que foi utilizado neste trabalho de mestrado.

\subsubsection{O Método de Engenharia Reversa FUSION-RE/I e sua aplicação na ferramenta DocRationale}

O método FUSION-RE/I [Costa, 1997] é um método para a realização de engenharia reversa que, partindo do código fonte, de aspectos operacionais do sistema e de dados da interface, recupera as visões funcionais e estruturais do sistema. As visões funcionais são recuperadas partindo-se de informações apresentadas na interface e de aspectos operacionais; as visões estruturais são recuperadas utilizando as visões funcionais produzidas e o código fonte do sistema. O método FUSION-RE/I é constituído de duas etapas:

- na primeira, parte-se de considerações "lógicas", obtidas por meio de aspectos operacionais e visões de dados disponíveis via interface, para a recuperação de visões funcionais do sistema, ou seja, essa primeira etapa tem como objetivo a abstração da funcionalidade do sistema, representada por meio dos modelos de ciclo de vida, de operações e de objetos do sistema, segundo o método FUSION [Coleman et al., 1994];

- na segunda etapa, parte-se de considerações "físicas", obtidas por meio do código-fonte, e das visões funcionais, para a recuperação de visões estruturais do sistema, sendo que o objetivo dessa fase é a identificação dos procedimentos que implementam as operações da interface do sistema, representados através dos quadros de chamadas de procedimentos e de operações-procedimentos de implementação.

Na Figura 5.4 é esquematizada uma síntese do método de engenharia reversa FUSION-RE/I. 


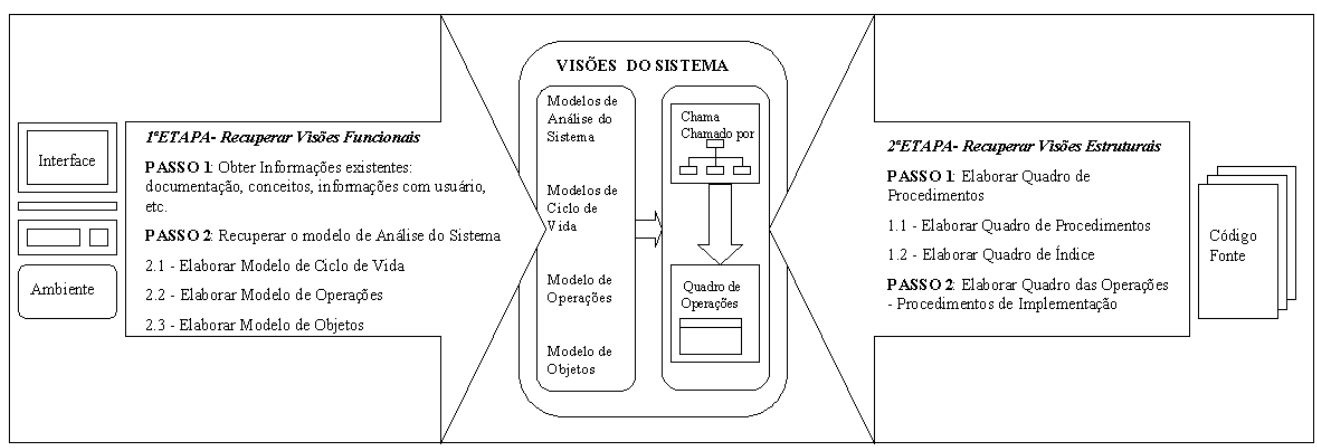

Figura 5.4: Síntese do método de engenharia reversa FUSION-RE/I Costa, 1997

Conforme ilustrado na Figura 5.4, a etapa de recuperação de visões funcionais é subdividida em dois passos: o primeiro envolve a reunião de todas as informações existentes sobre o sistema em estudo e o segundo envolve a recuperação de informações da fase de análise do sistema.

No primeiro passo deve-se:

- reunir toda a documentação envolvendo a informação textual existente sobre o sistema (manuais, livros, artigos, listagem do código-fonte, etc.) e a informação técnica relacionada aos conceitos pertinentes (domínio do sistema, aplicação, linguagem de implementação do sistema, da interface, etc.);

- identificar os usuários do sistema, pois informações importantes podem não estar documentadas e um modo de recuperá-las é a partir do conhecimento dos desenvolvedores e usuários. Esses conhecedores do sistema também são requeridos para auxiliar na validação dos modelos obtidos no processo de aplicação do método FUSION-RE/I;

- analisar os dados a fim de identificar informações relacionadas aos requisitos do sistema, ao projeto arquitetural, de dados e procedimental, ao ambiente onde o sistema é executado, à linguagem de implementação do sistema, à organização dos arquivos no disco, etc.

A realização desse primeiro passo para a recuperação de visões funcionais da ferramenta DocRationale envolveu a realização das seguintes atividades:

- leitura da dissertação do trabalho de mestrado que deu origem à ferramenta Francisco, 2004 e artigos relacionados à ferramenta Francisco et al., 2003;

- nova revisão da literatura sobre os modelos de representação de $D R$ e entendimento do modelo utilizado na ferramenta;

- uso intensivo da ferramenta para familiarização com a interface; 
- elaboração do roteiro "Como usar o software", que se encontra inserido no relatório técnico Documentação do Software DocRationale Lara and Fortes, 2004a;

- estudo da linguagem PHP para entendimento do código-fonte;

- análise de avaliações de interface produzidas por alunos do ICMC-USP e por usuários independentes que utilizaram a ferramenta como apoio ao desenvolvimento de seus projetos particulares;

- identificação dos requisitos funcionais da ferramenta Lara and Fortes, 2004a;

- identificação dos atores e elaboração do diagrama de casos de uso Lara and Fortes, 2004a.

O segundo passo da etapa de recuperação de visões funcionais do método FUSION-RE/I, envolve a recuperação das informações da fase de análise do sistema. Para representar essas informações são utilizados os modelos da fase de análise do método FUSION Coleman et al., 1994 de desenvolvimento de software orientado a objeto. A fase de análise do método FUSION gera dois modelos: (1) o modelo de objetos, que descreve a estrutura do sistema e (2) o modelo de interface, que descreve o comportamento do sistema. O modelo de interface é composto de dois modelos que capturam diferentes aspectos do comportamento: o modelo de ciclo de vida, o qual caracteriza seqüências permitidas de operações e eventos do sistema, e o modelo de operações, o qual caracteriza o efeito de cada operação do sistema em termos de mudanças de estado e eventos gerados. Esse segundo passo consiste em:

- elaborar o modelo de ciclo de vida do sistema. Para tanto, se faz necessário possuir um bom conhecimento do domínio e da aplicação do sistema submetido à engenharia reversa, incluindo estudo da documentação existente e entrevistas com os usuários do sistema. A partir disso, e principalmente do uso do sistema, é possível definir as seqüências de operações permitidas e os eventos de entrada e de saída que o sistema aceita;

- elaborar o modelo de operações do sistema, partindo-se do modelo de ciclo de vida, obtido anteriormente. O modelo de ciclo de vida apresenta uma visão geral da funcionalidade das operações do sistema, as quais, para elaboração do modelo de operações, devem ser melhor estudadas, por meio do uso intensivo do sistema, de modo que possam ser especificadas detalhadamente;

- desenvolver o modelo de objetos do sistema definindo, primeiramente, assuntos com os quais a funcionalidade do sistema se relaciona. O objetivo da definição de assuntos é identificar os diferentes níveis de abstração da funcionalidade do sistema e os possíveis agrupamentos de operações de um mesmo assunto. 
A realização desse segundo passo do método FUSION-RE/I na ferramenta DocRationale compreendeu a realização das seguintes atividades [Lara and Fortes, 2004a]:

- identificação dos objetos da ferramenta e elaboração de uma tabela de termos e definições a respeito desses objetos;

- identificação da arquitetura da ferramenta, seus módulos e as interdependências entre eles;

- elaboração dos casos de uso da ferramenta, detalhando o fluxo principal de eventos e os fluxos alternativos;

- elaboração do modelo de ciclo de vida da ferramenta;

- identificação dos requisitos de interface externa, com a especifição dos campos de entrada, descrição, valores válidos, formato, tipo e restrições;

- identificação dos objetos do sistema e as operações a eles relacionadas, como por exemplo, ao objeto Artefato pode-se relacionar as seguintes operações: inclusão, alteração, remoção, consulta, listagem e assim por diante.

Quanto à etapa de recuperação de visões estruturais do método FUSION-RE/I, os passos a serem desenvolvidos são subdivididos em:

1. elaborar o quadro de procedimentos;

2. elaborar o quadro das operações/procedimentos de implementação.

O primeiro passo da etapa de recuperação das visões estruturais envolve o entendimento da implementação do sistema, por meio da identificação dos procedimentos de implementação, da funcionalidade de cada procedimento identificado e da seqüência de chamadas desses procedimentos. A apresentação dos procedimentos de cada arquivo do sistema é realizada por meio de um conjunto de quadros de chamadas, que vem acompanhado por um índice geral dos procedimentos do sistema. Esse passo, então, consiste em:

- elaborar o quadro de chamadas de procedimentos. Para cada arquivo do sistema, deve ser elaborado um quadro de chamadas dos procedimentos de implementação. Nesse quadro de chamadas devem ser apresentados todos os procedimentos contidos no arquivo, fazendo-se referência aos procedimentos utilizados (CHAMA) e utilizadores (CHAMADO POR);

- elaborar o quadro índice de procedimentos. Para isso, utilizam-se os quadros de chamadas de procedimentos de todos os arquivos. 
Para o entendimento da implementação da DocRationale, optou-se por realizar a documentação das bases de dados e tabelas utilizadas pela ferramenta. Ao invés de elaborar o índice geral de procedimentos e o quadro de chamadas, atividades que demandariam grande quantidade de tempo, foi realizada a identificação dos procedimentos que implementavam as operações da interface da ferramenta, por meio da observação do código-fonte da página Web gerada, de onde era possível extrair qual o arquivo que era chamado para a execução da operação, construindo assim o modelo mental da estrutura do sistema.

O segundo passo da etapa, que trata da recuperação de visões estruturais do método FUSION-RE/I, consiste em identificar, entre todos os procedimentos considerados no quadro de chamadas, aqueles que implementam as operações da interface do sistema (identificadas na primeira etapa), e alocá-los, de acordo com sua funcionalidade, à interface ou a um dos assuntos do sistema (identificados na primeira etapa). Nesse passo, um quadro de operações/procedimentos de implementação deve ser elaborado. Nesse quadro, as duas primeiras colunas são referentes às opções e às operações da interface do sistema. A terceira coluna referese aos procedimentos que implementam as opções e as operações do sistema. As demais colunas são utilizadas para indicar a funcionalidade de cada procedimento, associando-os à interface ou a algum dos assuntos do sistema (identificados na etapa anterior).

Além da identificação dos procedimentos que implementavam as operações da interface, por meio do código-fonte da página $W e b$, a realização do segundo passo para recuperar as visões estruturais da ferramenta DocRationale envolveu também a elaboração de uma tabela para cada uma das telas da ferramenta, contendo o elemento da interface que aciona a operação, a descrição da ação que tal operação produz e as restrições relacionadas à execução da operação Lara and Fortes, 2004a].

Vale ressaltar que, além do estudo realizado, foram necessários alguns encontros com a aluna responsável pela implementação da DocRationale para o esclarecimento de dúvidas. Foi realizada também a documentação do procedimento de instalação da ferramenta, cujo roteiro se encontra no relatório técnico "Documentação do Software DocRationale" Lara and Fortes, 2004a.

\subsection{A Reengenharia da interface da Ferramenta DocRationale}

A reengenharia da interface da ferramenta DocRationale foi realizada seguindo o modelo de ciclo de vida da Engenharia de Usabilidade proposto por Nielsen Nielsen, 1993 e classificado em fases de Pré-Design, Design e Pós-Design Rocha and Baranauskas, 2003. Dentre as atividades realizadas em cada uma dessas fases, de modo resumido, pode-se destacar: 
- a análise de dados de uso obtidos previamente por meio dos registros da ferramenta e por meio da realização de testes com usuários, com o objetivo de conhecer o perfil dos usuários, verificar a forma com que eles executam as tarefas e detectar os principais problemas de usabilidade de modo que, a partir deles, um novo protótipo de interface para a ferramenta pudesse ser elaborado;

- a análise das tarefas atuais, das sugestões fornecidas pelos usuários e levantamento de novos requisitos;

- a definição das metas de usabilidade: correção dos problemas existentes, padronização da interface e da navegação, de modo a facilitar o aprendizado e o uso da ferramenta;

- a elaboração de um novo projeto navegacional da ferramenta, de acordo com o modelo OOHDM (Object Oriented Hypermedia Design Model) [Schwabe and Rossi, 1995] com a finalidade de corrigir os problemas de usabilidade encontrados e adequação da interface da ferramenta aos padrões de interface $W e b$;

- o estudo sobre as vantagens da separação de interesses (lógica e apresentação) e escolha de um sistema de templates (modelos de documentos) que facilitasse tal separação;

- a implementação dos templates de apresentação de conteúdo e reimplementação do código da lógica da aplicação, eliminando as partes referentes à apresentação e gerando as saídas necessárias aos templates, além da correção dos problemas já identificados;

- a validação da melhoria da usabilidade da ferramenta por meio da avaliação de usabilidade, utilizando testes com usuários e Avaliação Heurística;

- a análise do feedback dos usuários após a realização dos testes e realização de novas alterações na ferramenta, dando continuidade à fase de Design Interativo.

Nas subseções seguintes são descritas de forma detalhada as atividades realizadas durante a execução da reengenharia da interface da ferramenta DocRationale, as quais deram origem a uma nova ferramenta denominada DocRat.

\subsubsection{Atividades da Fase de Pré-Design}

Para a elaboração do protótipo de interface da ferramenta DocRat foram efetuadas as atividades do modelo de Engenharia de Usabilidade de Nielsen Nielsen, 1993, classificadas por Rocha and Baranauskas, 2003 como atividades de Pré-Design. Tais atividades consistem: no conhecimento do usuário, na análise competitiva e no estabelecimento de metas de usabilidade. 
Os principais usuários da ferramenta são os alunos de graduação do ICMC-USP. Com o objetivo de conhecer as necessidades de usabilidade dos usuários foi efetuada a análise de alguns dados de uso disponíveis e uma coleta informal de informações com usuários da ferramenta DocRationale. Após a realização da Avaliação Heurística da interface da DocRationale, também foi possível verificar a existência de vários problemas de usabilidade.

Como atividades de Pré-Design foram analisadas as tarefas atuais da ferramenta, como também os principais problemas encontrados pelos usuários e a gravidade dos mesmos, principalmente aqueles que prejudivam a adoção da ferramenta pelos usuários.

Os primeiros dados analisados foram obtidos a partir de um questionário aplicado aos alunos do curso de Hipermídia em 2003, no qual a ferramenta foi utilizada como apoio ao desenvolvimento do projeto da disciplina. O questionário foi respondido por 20 dos 27 alunos matriculados.

Como o questionário foi aplicado somente no final da disciplina, não foi possível identificar problemas muito específicos, mas a partir dele foi possível identificar problemas com a navegação e com a demora na realização de tarefas. Quando perguntados se a interface da ferramenta auxilia na realização de atividades/objetivos, $12 \%$ dos alunos responderam que a interface não auxilia, 54\% responderam que auxiliam parcialmente, pois os recursos não são satisfatórios, e $34 \%$ responderam que a interface auxilia e que os recursos são satisfatórios.

Além disso, foram identificados problemas com a visualização de projetos e artefatos. Em resposta ao questionamento sobre este quesito, $12 \%$ dos alunos responderam que a visualização é ruim, e só conseguiram entender depois de algum tempo; $54 \%$ responderam que a visualização é boa, mas o espaço é muito curto, e $34 \%$ disseram que era muito boa, com pequenos detalhes a serem melhorados.

Também foram efetuadas entrevistas informais com usuários da ferramenta, de forma a esclarecer alguns dos principais problemas identificados por eles. Os problemas mais citados pelos usuários estavam relacionados com a dificuldade de criação de projetos, artefatos, e com a falta do uso de elementos de interface que são padrões em outras aplicações. Os usuários também consideraram o caminho para se alcançar os objetivos longos, confirmando os dados obtidos pelos questionários.

A exibição de uma lista pequena (apenas 4 elementos por página) de itens de dados (projetos, artefatos, questões) na tela também foi criticada, pois exigia diversas interações até se alcançar o item desejado.

Após a análise dos dados do questionário e das entrevistas informais com usuários realizadas no segundo semestre de 2003, na disciplina SCE225-Hipermídia ${ }^{1}$, também foi efetuada uma

\footnotetext{
${ }^{1}$ http://coweb.icmc.usp.br/coweb/mostra.php?ident=116
} 
avaliação heurística Nielsen, 1993 da interface da ferramenta. A avaliação foi efetuada pela própria autora deste trabalho e por mais cinco alunos de pós-graduação especialistas em design de interfaces durante o primeiro semestre de 2004.

Por meio da Avaliação Heurística foi possível levantar diversos outros problemas com a interface da ferramenta DocRationale, dentre os quais pode-se citar:

- a ferramenta não indica o caminho percorrido na navegação;

- uso de botões ao invés de links (não compatível com padrão de interface $W e b$ );

- navegação confusa, necessitando de muitos cliques para alcançar informação desejada;

- falta de clareza nas mensagens de erro;

- mau aproveitamento do espaço da tela;

- design muito carregado;

- inconsistência da interface da ferramenta com as interfaces da CoTeia e do GroupNote;

- a ferramenta não previne o usuário contra possíveis erros.

Além dos problemas de âmbito geral listados acima, diversos problemas pontuais também foram encontrados em locais específicos da interface. Um dos problemas ocorria quando o link presente no nome de um projeto era acionado, e ao invés de exibir as informações referentes aos dados cadastrais do projeto, era exibida a lista de artefatos relacionados a ele. E somente nesta tela (tela com a lista dos artefatos do projeto) é que os botões para acesso aos dados cadastrais do projeto e para acesso à lista de usuários que formavam a equipe do projeto eram exibidos ao usuário. Ou seja, as informações relativas ao projeto eram apresentadas em telas hierarquicamente inferiores, e assim sucessivamente para artefatos e questões.

Outro grande problema encontrado foi com relação à seqüência de interações para a criação de um novo projeto com suas respectivas fases e atividades. Tal seqüência era confusa e fazia com que a navegação tivesse que ser refeita várias vezes para que a tarefa fosse concluída. Esse problema ocorria devido ao fato de que, para um projeto ser cadastrado, ele necessitava possuir ao menos uma fase e uma atividade, e o cadastramento efetivo do projeto só se concretizava no final das interações. Assim, a cada tentativa incorreta de cadastrar alguma das informações, ou caso o usuário clicasse no botão "Cancelar", quando estivesse cadastrando uma atividade por exemplo, todas as informações sobre o projeto, as fases e as atividades eram perdidas e o usuário era obrigado a reiniciar o preenchimento de todas as informações novamente. Além disso, não 
havia nenhuma relação lógica entre fases e atividades, o que causava confusão aos usuários, pois eles sempre tentavam cadastrar uma atividade relacionada a alguma fase.

O processo de importação de modelos de projeto (processamento de arquivos XML) foi outro problema constatado. O processo de criação de projeto baseado em um modelo escrito em XML era muito demorado e não fornecia feedback apropriado ao usuário, incentivando-o muitas vezes a interromper o processamento pela falta de resposta do sistema.

Outros problemas relacionados ao uso de metáforas e padrões também foram muito citados. Na Figura 5.5 é ilustrado um exemplo de uma página onde podem ser identificados alguns exemplos de problemas de usabilidade relacionados ao uso de metáforas e agrupamentos de itens de navegação na ferramenta:

- Item 1: Título ocupando espaço considerável sem expressar informação;

- Item 2: Itens dispostos sem agrupamento lógico;

- Item 3: Título com informação redundante;

- Item 4: Itens dispostos sem agrupamento lógico, e usando padrões pouco usuais para aplicações $W e b$ (botões, ao invés de links);

- Item 5: Falta de opções de navegação para efetuar operações de editar e excluir, as quais tornariam a navegação mais eficiente.

Desta forma, como parte da fase de Pré-Design do processo de Engenharia de Usabilidade, os dados coletados por meio de questionários, aplicados aos usuários nas disciplinas em que a ferramenta foi utilizada, assim como entrevistas informais com usuários que utilizavam a ferramenta como apoio ao desenvolvimento de seus próprios projetos, puderam contribuir para a obtenção de um bom conhecimento sobre os usuários da ferramenta.

Além da avaliação de usabilidade, também foram efetuadas avaliações de acessibilidade, visando identificar os principais problemas contidos na ferramenta, de acordo com as guidelines do WCAG 1.0 W3C, 1999]. Foram identificados problemas como a falta de textos alternativos para imagens, o uso de cores como única forma de identificação de informações, o uso de tamanho absoluto para largura, o uso de tabelas somente para layout, entre outros.

Por meio da avaliação heurística e da avaliação de acessibilidade realizadas na ferramenta DocRationale, também foi possível definir algumas das metas de usabilidade e acessibilidade esperadas para a nova versão da ferramenta. As principais metas a serem atingidas eram: correção dos problemas de usabilidade existentes na ferramenta, padronização da interface e 


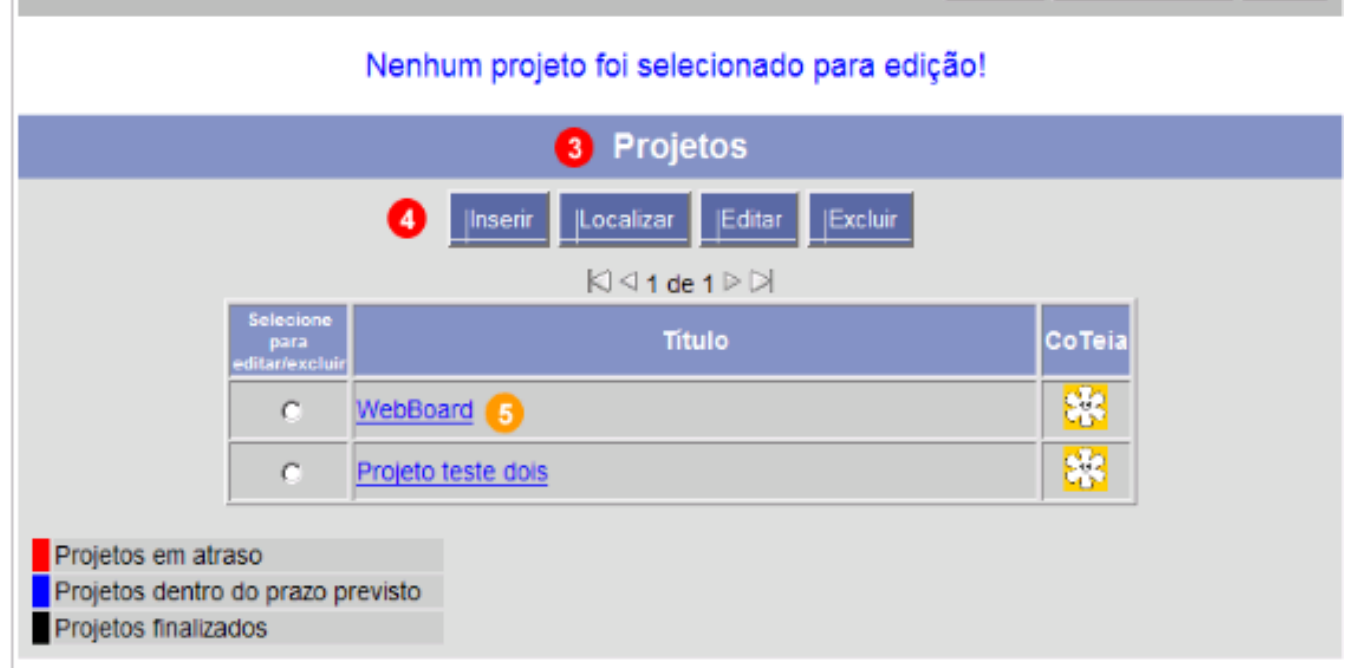

Usuário: luciano

Figura 5.5: Tela de exibição de projetos na primeira versão de DocRationale

aplicação de guidelines de acessibilidade, reestruturação da navegação, entre outras, com o objetivo de facilitar o aprendizado, o uso da ferramenta e a recuperação após erros.

\subsubsection{Atividades da Fase de Design}

A fase de Design pode ser dividida em duas etapas: Design Inicial e Desenvolvimento Interativo Rocha and Baranauskas, 2003.

As primeiras atividades realizadas no início da fase de Design Inicial foram a elaboração de um novo esquema navegacional e a elaboração dos protótipos de interface da nova versão da ferramenta.

A elaboração do novo esquema navegacional da ferramenta em sua nova versão, denominada DocRat, teve como principal objetivo solucionar alguns problemas relacionados à navegação encontrados na versão anterior da ferramenta, referentes à dificuldade de realização de tarefas/objetivos devido ao grande número de interações necessárias para se alcançar as informações procuradas.

O novo esquema navegacional foi elaborado de acordo com a notação do método OOHDM (Object Oriented Hypermedia Design Model) Schwabe and Rossi, 1995. Na Figura 5.6 é ilustrado um trecho do novo esquema navegacional elaborado para a ferramenta, no qual foi 
priorizado a inclusão de links a partir de diversos pontos da navegação, de forma a facilitar a interação do usuário com a ferramenta.

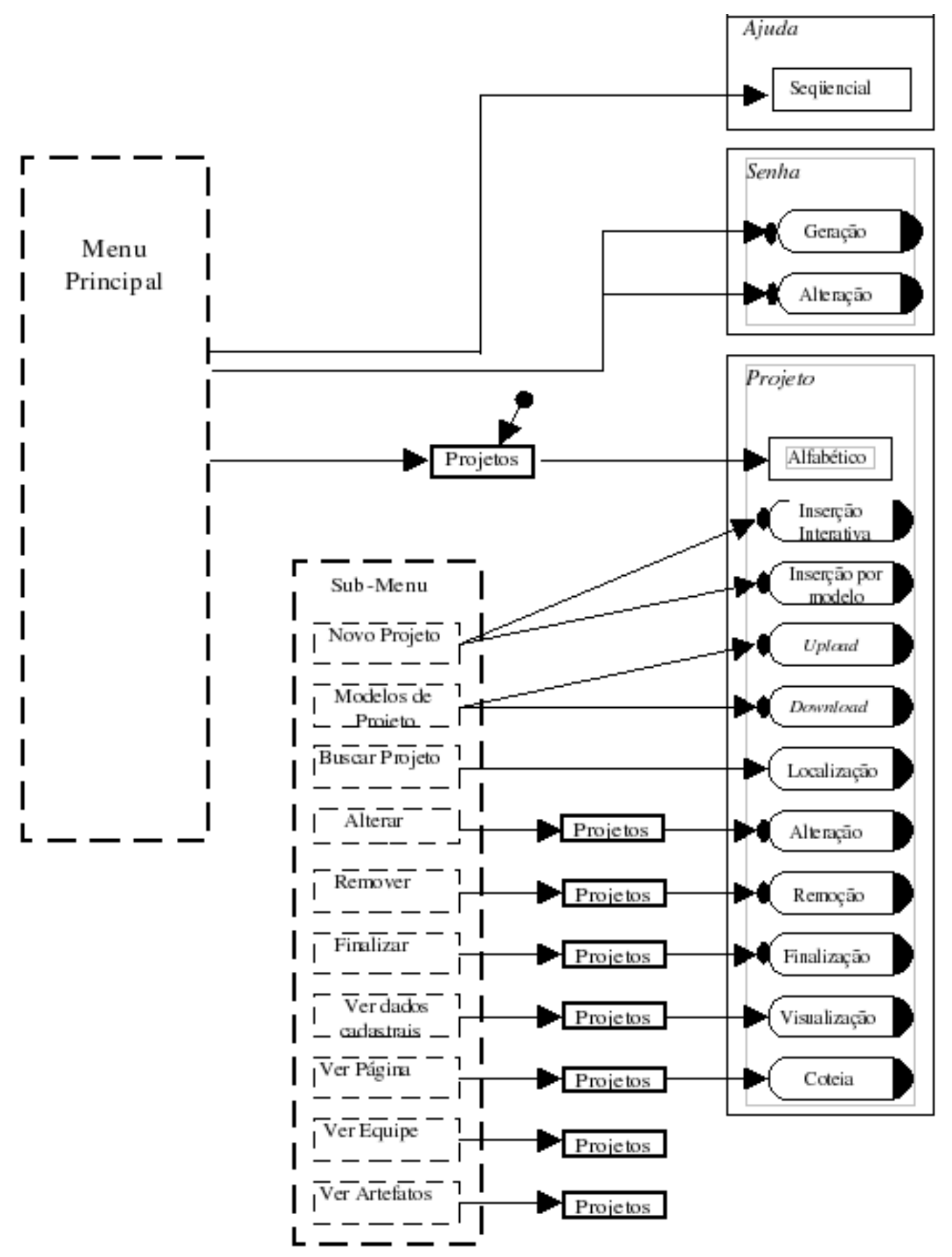

Figura 5.6: Novo esquema navegacional da ferramenta DocRat

Este trecho corresponde à navegação pelas funcionalidades referentes ao contexto de projetos. Os retângulos tracejados representam estruturas de acesso. Os retângulos cheios representam um contexto de navegação. Os contextos representados pela elipse indicam que são contextos protegidos, ou seja, que somente usuários autorizados podem acessá-los. A seta com um círculo sobre um contexto indica que o mesmo pode ser acessado a partir de qualquer ponto da 
navegação.

Uma das principais alterações realizadas na navegação foi o agrupamento das operações possíveis em um determinado contexto numa mesma tela, substituindo a funcionalidade do link do nome do projeto e apresentando explicitamente o acesso à lista de artefatos do projeto. Por exemplo, ao acessar a tela "Projetos", para cada projeto listado, o usuário pode: acessar os dados cadastrais (link presente no nome do projeto), visualizar os membros da equipe, visualizar os dados na CoTeia, imprimir, alterar, remover ou finalizar o projeto escolhido, acessar a lista de artefatos ou ainda criar um novo projeto. Assim, em uma única tela de acesso o usuário pode optar pela realização de todas as operações disponíveis no contexto de Projetos, conforme representado na figura 5.7. Na versão anterior, o link presente no nome do projeto apresentava a tela contendo a lista de artefatos do projeto escolhido e era somente nessa tela (em nível hierarquicamente inferior) que as opções de visualização dos dados cadastrais e da equipe do projeto eram apresentadas ao usuário, havendo, desse modo, a mistura entre informações dos artefatos e informações do projeto. O mesmo problema e a mesma correção se aplica com relação a artefatos e questões.

Uma outra alteração da navegação foi necessária para refletir a alteração realizada no modelo conceitual referente a projeto, fases e atividades. De acordo com a primeira implementação, um projeto era constituído por título, data de início, data de previsão do término, por um conjunto de fases e um conjunto de atividades, sendo que não havia o conceito de que uma fase era composta de atividades. Na nova versão da ferramenta foi decidido que toda fase seria composta de uma ou mais atividades. Sendo assim, a criação de um projeto foi dividida em duas telas, sendo que na primeira o usuário deve informar o título do projeto, sua data de início, a data prevista para o término e o número de fases. Na segunda tela é mostrado o número de campos referente ao número de fases e os seus respectivos campos de atividades, sendo que não há limite para o número total de atividades em cada fase, flexibilizando a eventual necessidade do aumento do número de atividades conforme o projeto ocorre.

Também procurou-se manter um padrão para a estrutura de navegação da ferramenta, de forma que o aprendizado pudesse ser facilitado.

Em paralelo com a elaboração do esquema navegacional foi especificado um protótipo da interface da ferramenta, visando estabelecer os padrões para as telas, definindo as posições para menus, informações de contexto e exibição de dados. Na Figura 5.7 é exibido um protótipo de uma tela da ferramenta. Nesse protótipo, procurou-se elaborar uma interface que estivesse de acordo com padrões normalmente utilizados em interfaces de aplicações $W e b$, tais como a utilização de menu lateral, barra de localização e mecanismos de navegação claros. 


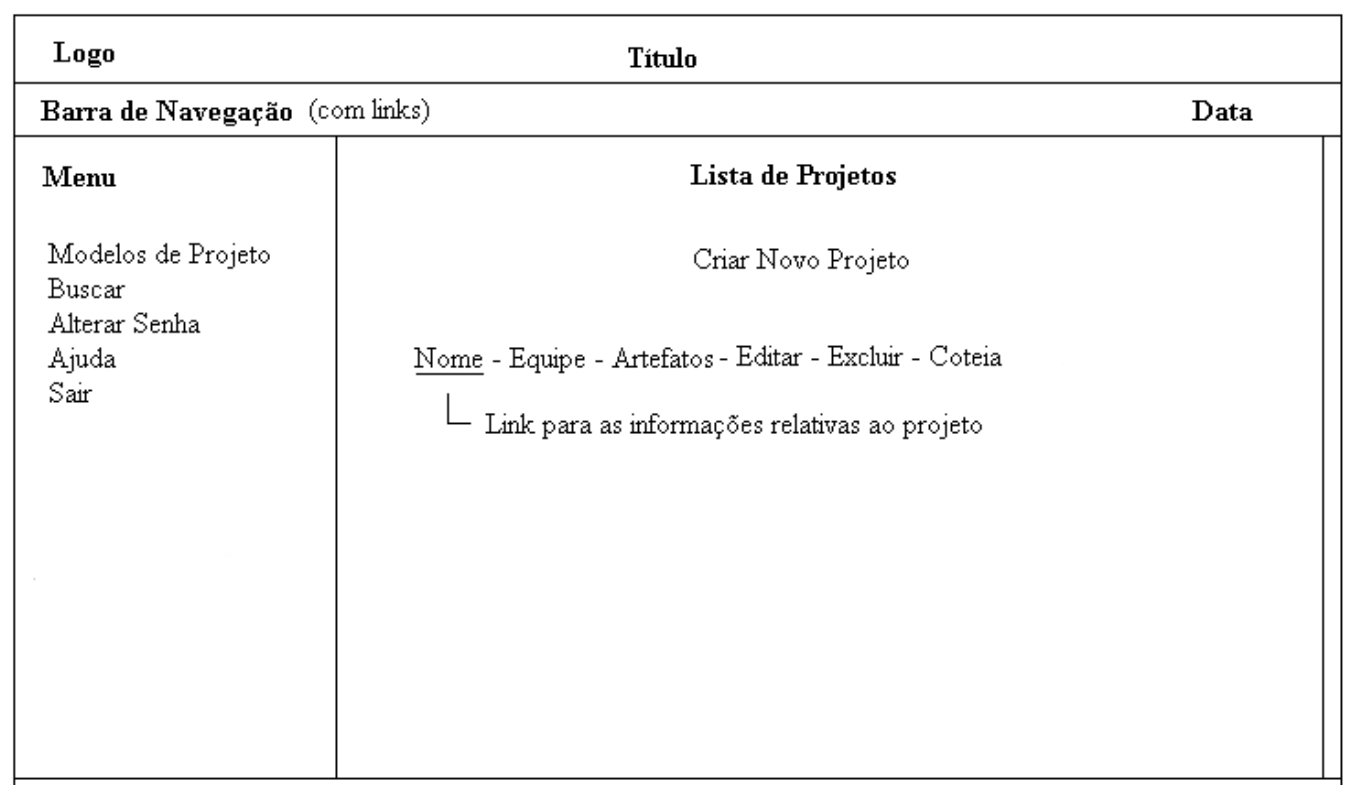

Figura 5.7: Protótipo de tela da ferramenta DocRat

A reimplementação do código da ferramenta DocRationale que deu origem a uma nova versão da ferramenta, denominada DocRat, foi a primeira atividade realizada na etapa de Desenvolvimento Interativo (ver seção 4.3), e corresponde à atividade de prototipagem. A etapa de Desenvolvimento Interativo compreende também as atividades de testes e Design Rationale Rocha and Baranauskas, 2003.

Em aplicações baseadas na $W e b$ é difícil de se realizar a separação entre a apresentação e a lógica de processamento Aberer et al., 2003. O princípio da separação de interesses é um dos princípios essenciais na engenharia de software e diz que o software deve ser decomposto de modo que diferentes "questões" ou aspectos do problema sejam resolvidos em módulos bem separados ou em partes distintas do software Win et al., 2002.

A separação de interesses tem como objetivo controlar a complexidade em sistemas que apresentam crescimento contínuo. Assim sendo, a separação de interesses promove a identificação de diferentes interesses em um problema e propõe que estes sejam resolvidos separadamente, onde a solução de uma parte não requer o conhecimento envolvido na solução de outras partes, e combinando-se a todas as soluções, obtém-se o resultado final.

Na prática, esse princípio corresponde à modularização de um problema e, portanto, pode-se contar com todos os benefícios provenientes da decomposição do problema em módulos independentes. As principais vantagens da modularização são Win et al., 2002:

- maior agilidade no desenvolvimento e na manutenção;

- facilidade de escalabilidade; 
- melhoria na compreensão do sistema.

O princípio da separação de interesses visa a geração de uma solução melhor e mais flexível para o problema. As aplicações desenvolvidas com base neste princípio implementam cada interesse em uma entidade separada Ebraert and Tourwe, 2004. Estas entidades podem ser adaptadas e substituídas sem afetar o restante da aplicação. Dependendo do paradigma de programação utilizado, uma entidade pode ser uma função, um componente, os requisitos funcionais e não-funcionais, ou até mesmo a interface de um sistema.

Durante o processo de reimplementação do código da ferramenta DocRationale decidiuse por realizar a separação entre o processamento da informação (lógica) e apresentação das informações. Para separar esses dois interesses foi adotado o uso de templates para a camada de apresentação, de forma que em cada arquivo escrito em PHP contivesse apenas a lógica do processamento do conteúdo. Dessa forma, as mudanças realizadas na interface não afetariam a lógica do processamento e alterações na lógica do processamento poderiam ser realizadas sem interferirem no layout da apresentação.

A implementação da interface da ferramenta DocRat, ainda na fase de Design do modelo de Engenharia de Usabilidade [Nielsen, 1993, foi efetuada utilizando ciclos iterativos de prototipação e testes.

A partir do projeto navegacional elaborado, deu-se prosseguimento à reengenharia da interface da ferramenta, por meio da implementação dos templates (modelos de documentos) em XHTML e da reimplementação do código escrito em PHP, para a sua adequação ao uso dos templates, com a finalidade de realizar a separação entre a lógica de processamento e a lógica da apresentação da ferramenta, de forma que o código-fonte não ficasse misturado ao XHTML a ser gerado pelas páginas. Web Standards e normas de acessibilidade também foram consideradas durante a elaboração da nova interface. Além disso, foram realizadas alterações na lógica de processamento da aplicação para a correção de problemas de usabilidade encontrados durante os testes realizados com os usuários (seção 5.3).

A separação do conteúdo XHTML a ser gerado foi efetuada utilizando templates, na forma de documentos semi-prontos com partes variáveis. Durante a execução de cada código PHP da aplicação são efetuadas consultas à base de dados e todo o processamento da lógica de negócio. Ao término do processamento, os dados resultantes são passados a um módulo, denominado Smarty ${ }^{2}$, que efetua o processamento do respectivo template com os dados processados e retorna o resultado final.

O Smarty Smarty, 2005 é um sistema de templates para PHP que fornece uma rica variedade

\footnotetext{
${ }^{2}$ http://smarty.php.net
} 
de ferramentas para automatizar tarefas que normalmente estão relacionadas com a camada de apresentação de uma aplicação escrita em PHP. Alguns exemplos da lógica da apresentação são: a inclusão de outros templates, alternância de cores nas linhas das tabelas, colocação o texto de uma variável em maiúsculo, exibição de uma matriz de dados, entre outras. Isto não significa que o Smarty exija a separação entre a lógica de negócios e a lógica de apresentação. O Smarty não tem conhecimento do que é o que em uma aplicação, portanto colocar a lógica de negócio no template é um problema que deve ser avaliado pelo programador.

Um outro aspecto importante do Smarty é seu sistema de compilação de templates. O Smarty lê os arquivos de templates e cria scripts PHP a partir deles. Uma vez criados, eles são executados sem a necessidade uma outra compilação do template. Com isso, os arquivos de template não são "parseados" (analisados) toda vez que um template é solicitado Smarty, 2005.

As principais características do Smarty são:

- é extremamente rápido;

- não realiza inúmeras interpretações do template pois compila apenas uma vez, possuindo mecanismos capazes de só recompilar os arquivos de template que foram modificados;

- permite a criação de funções customizadas e modificadores de variáveis customizados, de modo que a linguagem de template se torne extremamente extensível;

- permite o aninhamento ilimitado de sections, ifs, etc;

- possui modificadores de variáveis, permitindo que o conteúdo das variáveis dos templates possam ser facilmente ajustadas em tempo de apresentação, por meio do uso de modificadores. Existem modificadores para a apresentação de conteúdo em letras maiúsculas e minúsculas, formatação de datas, caracteres de escape do HTML, adição de espaços entre caracteres, entre outras, sem precisar de nenhuma intervenção dos programadores;

- permite a inclusão de código PHP diretamente nos arquivos de template (não recomendado);

- possui arquitetura de plugin;

Dentre os benefícios obtidos com o uso do Smarty vale ressaltar que os mais importantes são:

- Segurança: templates não deve conter código PHP, o que garante que os designers não irão interferir no código da programação da aplicação; 
- Facilidade de uso e manutenção: os designers não precisam conhecer a sintaxe do código PHP para utilizar os templates, pois a sintaxe dos templates é muito próxima do HTML.

Os templates são uma representação muito próxima da apresentação final, o que diminui drasticamente o ciclo de Design.

A seguir é mostrado um trecho do código do template Smarty para a visualização dos dados de um projeto na DocRat, com suas respectivas fases e atividades:

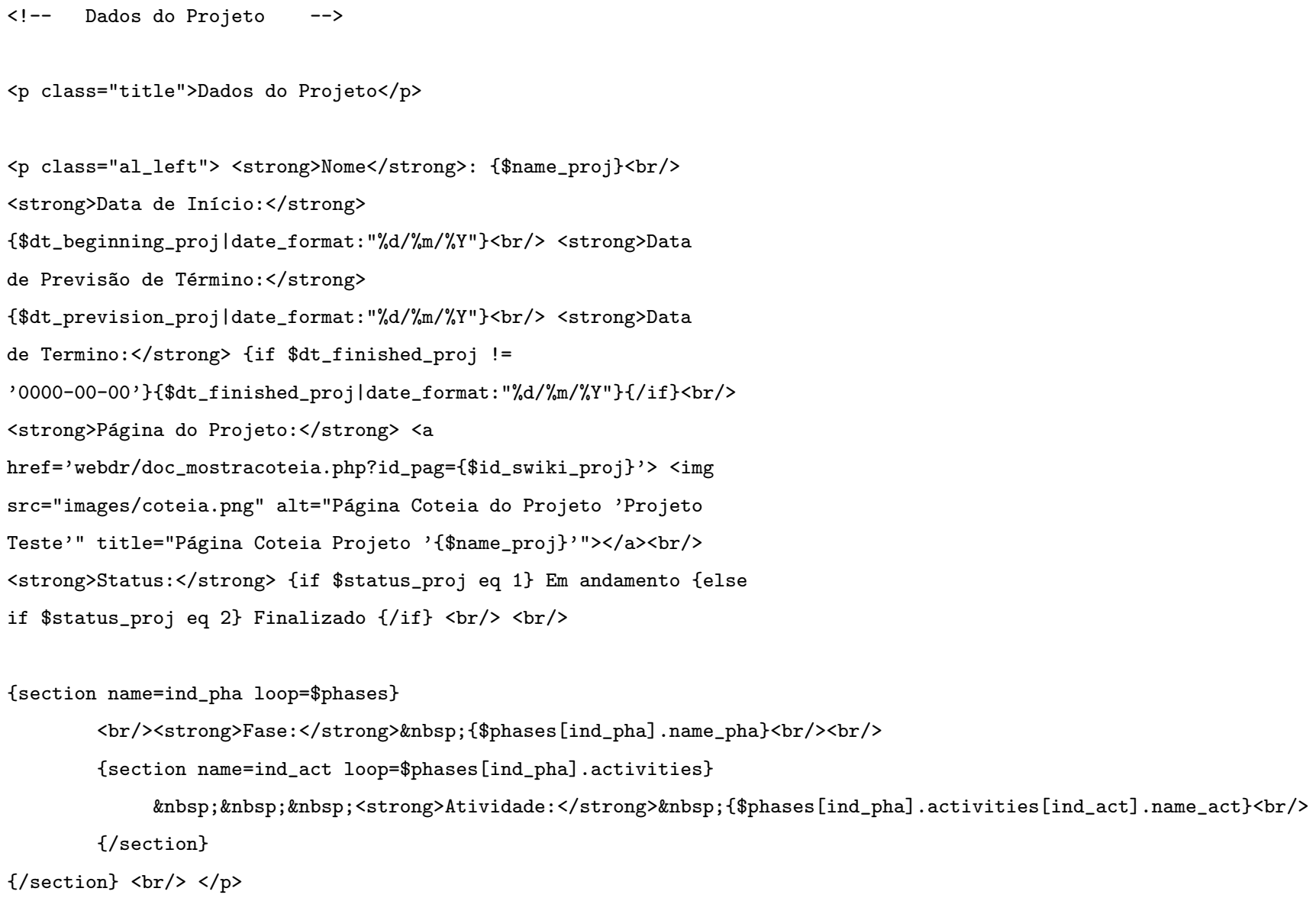

Dentre as alterações realizadas para a correção de problemas de usabilidade, deve-se destacar a alteração realizada no modelo conceitual referente a projeto, fases e atividades. De acordo com a primeira implementação, um projeto era constituído por título, data de início, data de previsão do término, fases e atividades, sendo que não havia relacionamento nenhum entre fases e atividades. O conceito de que uma fase era composta por atividades não existia e confundia muito os usuários, que sempre tentavam inserir uma atividade dentro de uma fase. Na nova versão da ferramenta foi decidido que toda fase seria composta de uma ou mais atividades, o que gerou modificações no modelo de dados persistentes e no modelo navegacional da ferramenta. Sendo assim, a lógica para criação de um projeto foi dividida em dois passos conforme mencionado na subseção 5.3 .2 
Outra alteração significativa realizada na ferramenta foi a substituição do módulo de processamento de arquivos XML. Inicialmente a ferramenta utilizava-se de uma aplicação escrita em JAVA e que rodava como um outro processo na máquina servidora para criar um projeto baseado em um modelo de projeto escrito em XML. O problema desse tipo de solução era o tempo gasto para a realização de tal atividade. A nova solução utiliza-se de funções do Módulo Pear Pear, 2005, que são escritas em PHP e demoram menos tempo do que o processo JAVA para executar a mesma tarefa.

Além das correções citadas acima, no decorrer da implementação da ferramenta DocRat, procurou-se utilizar algumas das guidelines do WCAG 1.0 [W3C, 1999 para o desenvolvimento de páginas acessíveis. As principais recomendações utilizadas foram:

- fornecer alternativas ao conteúdo sonoro e visual: fazer com que o conteúdo apresentado ao usuário transmita as mesmas funções e tenha a mesma finalidade que o conteúdo sonoro ou visual. Na implementação da DocRat foi fornecido um equivalente textual a cada elemento não textual, com a utilização do atributo "ALT" para elementos IMG e APPLET. Além disso, em todos os campos de formulário, também foi utilizada marcação adequada para relacionar os labels e os campos (não só de forma visual);

- não associar semântica a cores: assegurar que as informações relacionadas com as cores estejam também disponíveis sem cor, como por exemplo, a partir do contexto ou de marcações. Na ferramenta DocRat foi utilizada a informação de contexto status para indicar o estado de um projeto com relação ao prazo previsto para o seu término, sendo que na versão anterior o nome do projeto era escrito nas cores azul, preto e vermelho para indicar os estados "em andamento", "finalizado" e "atrasado" respectivamente (Figura 5.5 ;

- utilizar folhas de estilo: controlar a apresentação por meio de folhas de estilo em vez de elemento de apresentação e atributos, facilitando qualquer alteração na apresentação das informações;

- criar tabelas passíveis de transformação harmoniosa: garantir que as tabelas têm as marcações necessárias (TH - para identificar cabeçalhos e TD - para identificar células) para que possam ser transformadas harmoniosamente por navegadores acessíveis e outros agentes do usuário. Não utilizar tabelas para obter efeitos de formatação visual. Na ferramenta DocRat optou-se pelo uso de tags div com CSS para organização do layout, ao invés de tabelas;

- fornecer informações de contexto e orientações: fornecer orientações para ajudar os usuários 
a compreenderem páginas ou elementos complexos. Em todas as páginas da ferramenta DocRat existe o link "Ajuda" que fornece o acesso às páginas de orientação ao usuário;

- fornecer mecanismos de navegação claros: fornecer informações com a finalidade de aumentar as chances de uma pessoa encontrar o que procura em um site, como por exemplo, informações gerais sobre o site, barras de navegação e mapa do site. Na ferramenta DocRat foi implementada a barra de navegação que indica o caminho percorrido pelo usuário.

Toda a codificação do XHTML gerado foi efetuada utilizando Web Standards recomendados pelo W3C (World Wide Web Consortium). De acordo com as recomendações de [Nielsen, 2000, as informações de conteúdo foram separadas das informações de layout. As informações de layout foram denotadas através do uso de CSS (Cascading Style Sheets), de forma que o XHTML representa somente o conteúdo. A separação de conteúdo e layout também é uma guideline de acessibilidade do WCAG 1.0 [W3C, 1999].

Os elementos de interface foram criados de acordo com os protótipos de interface desenvolvidos, sendo que a cada conjunto de telas desenvolvido eram realizados testes simples com usuários para obter feedback sobre a elaboração da interface.

Na Figura 5.8 é ilustrada uma página com a lista de projetos de um usuário em DocRat. É possível notar que diversos problemas de usabilidade encontrados na versão anterior da ferramenta foram solucionados, como por exemplo, a inclusão de links para a edição, exclusão e finalização de elementos de forma mais intuitiva e direta para o usuário, a inclusão de um menu de mais fácil manipulação, a inclusão de barra de localização e a utilização de padrões de interface mais compatíveis com aplicações $W e b$, entre outras.

Durante os ciclos de implementação, os usuários que já haviam utilizado a ferramenta $D o c R a-$ tionale em disciplinas ou em seus próprios projetos eram consultados com o objetivo de se obter feedback sobre a nova implementação, visto que as sugestões dos usuários guiaram muitas das modificações realizadas na interface. Também foram consideradas as heurísticas de usabilidade propostas por Nielsen, 1993 e princípios de usabilidade, bem como as guidelines de acessibilidade do WCAG 1.0 [W3C, 1999].

Diversas recomendações para design de interfaces para Web propostas por Nielsen, 2000 foram utilizadas, como o uso de layout líquido (especificação de largura por tamanhos relativos, não absolutos), a priorização do conteúdo na exibição, utilizando um espaço menor para menus, links e atalhos para encurtar a navegação, além do uso de um padrão de layout mais "leve" para o usuário.

A utilização de templates facilitou de forma considerável a tarefa de implementação da interface da ferramenta DocRat, na medida em que facilitou também a reimplementação do 


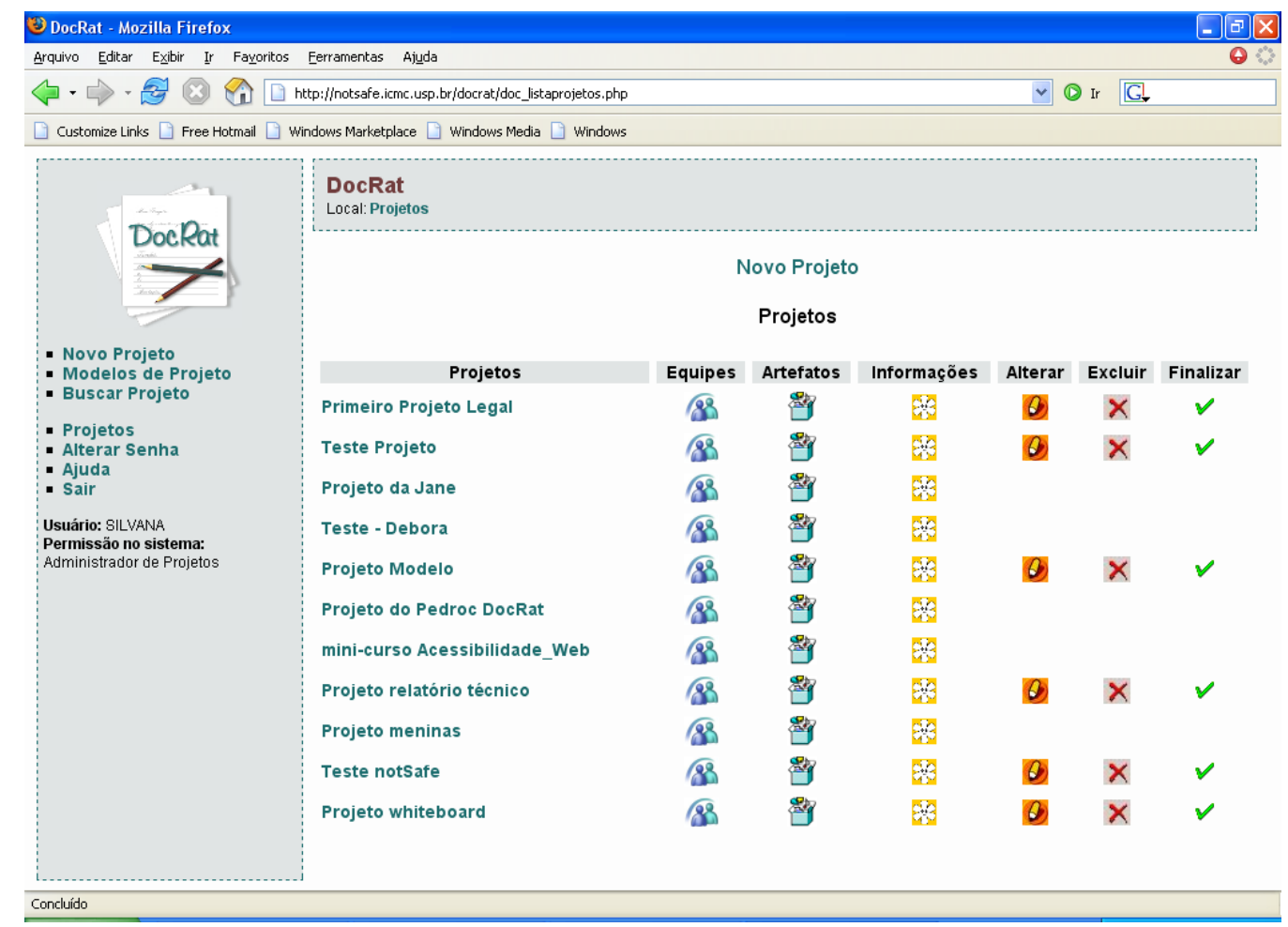

Figura 5.8: Página com a lista de projetos na ferramenta DocRat

código-fonte, visto que as principais alterações consistiram em eliminar os elementos de apresentação, organizar a lógica de programação (anteriormente misturada ao código HTML) e gerar as informações necessárias para o processamento do template. As atividades de composição dos templates em XHTML e de confecção das folhas de estilo em CSS foram realizadas em conjunto com um aluno de graduação e fazem parte de seu projeto de conclusão de curso Freire, 2005.

Neste projeto foi alterada somente a interface das páginas da aplicação DocRat. As interfaces das ferramentas integradas CoTeia e GroupNote não sofreram alterações.

\subsubsection{Atividades de Pós-Design}

Durante todo o processo de desenvolvimento da interface da ferramenta DocRat foram efetuadas avaliações informais visando obter feedback dos usuários com a finalidade de detectar problemas de usabilidade o mais breve possível.

Após o término do primeiro ciclo de implementação da interface da ferramenta DocRat, foi realizada uma avaliação de usabilidade, compreendendo uma inspeção de usabilidade, através de Avaliação Heurística, e um teste de usabilidade com usuários finais. Estas atividades correspondem à última fase do ciclo de vida de Engenharia de Usabilidade proposto por Nielsen, 1993.

Antes do início da avaliação foi efetuado um planejamento, de forma a definir os objetivos da inspeção e dos testes, assim como a definição dos procedimentos a serem utilizados para 
a realização da avaliação, a seleção dos avaliadores, as tarefas a serem realizadas e o tipo de avaliação a ser realizada.

O método escolhido para efetuar a inspeção de usabilidade foi a Avaliação Heurística, por apresentar um custo menor e por ser indicado pela literatura Nielsen, 1993 Rocha and Baranauskas, 2003 como um método eficiente para a detecção de problemas de usabilidade no design de interfaces.

No planejamento da avaliação da ferramenta DocRat foi definido que ela seria efetuada pelos mesmos cinco avaliadores (com exceção da autora) que efetuaram a avaliação da ferramenta DocRationale e com as mesmas tarefas. As heurísticas utilizadas foram aquelas definidas por Nielsen, 1993, listadas na Seção 4.2. O objetivo dessa inspeção foi verificar se a nova interface continha problemas com princípios de usabilidade apontados pelas heurísticas, e também verificar se os problemas identificados na Avaliação Heurística da ferramenta DocRationale haviam sido solucionados efetivamente.

Da mesma forma que na Avaliação Heurística realizada anteriormente, os avaliadores percorreram a interface da ferramenta de modo a executar as tarefas propostas (Apêndice A), e registravam em um questionário cada um dos problemas encontrados relacionando-os com suas respectivas heurísticas.

De forma geral, a maioria dos problemas identificados na Avaliação Heurística da ferramenta DocRationale não foram apontados na avaliação da ferramenta DocRat. Problemas presentes na versão anterior como dificuldade de navegação, falta de informações sobre localização, problemas com design carregado e caminho de navegação longo, que haviam sido solucionados, não foram apontados pelos avaliadores, de forma que se pôde detectar uma melhora efetiva da interface na nova versão da ferramenta.

Alguns problemas de usabilidade pontuais ainda foram detectados, como a falta de um link para a página principal a partir do logo da ferramenta, a falta de links para seções já visitadas na barra de localização, e alguns problemas de consistência de nomenclatura entre os links e as opções de menus e textos exibidos em mensagens de conclusão de operações. Estes problemas foram corrigidos após a avaliação.

Contudo, notou-se que problemas com a falta de consistência da interface da DocRat com a interface da CoTeia e GroupNote ainda foram detectadas na Avaliação Heurística. Identificou-se também problemas com a forma como as ferramentas estão integradas, apontada como ponto de confusão durante o uso da ferramenta, devido a abertura de muitas janelas.

Decidiu-se então, após a avaliação, pela reimplementação da interface de cadastramento de posições e argumentos, ou seja, da parte relativa ao GroupNote. Para a reimplementação 
dessa interface foram adotados os mesmos padrões e estrutura de navegação utilizados pela ferramenta DocRat, permanecendo inalteradas a base de dados e as tabelas utilizadas, de modo que o usuário não percebe a alteração. Quanto aos problemas referentes à CoTeia, esses deverão ser solucionados em trabalhos futuros.

De acordo com Dix et al., 1998, as técnicas utilizadas para avaliar a usabilidade de sistemas em estágios finais de desenvolvimento são denominadas técnicas de avaliação de implementação. Como exemplo de tais técnicas pode-se citar: Métodos Empíricos (ou Avaliação Experimental), Think Aloud e Métodos de Questionamento. Além da avaliação heurística, os avaliadores também responderam a um questionário (Apêndice B), que tinha por finalidade avaliar o grau de facilidade com que os usuários executavam as principais tarefas da ferramenta, tais como a criação de projetos, artefatos, questões, bem como avaliar a sensação do usuário com relação à sua localização, apoio para a realização das tarefas (help) e a satisfação do usuário com relação à interface. Também foi objetivo deste teste a obtenção de uma comparação de usabilidade da nova versão da ferramenta DocRat com a versão anterior DocRationale.

Durante a realização dos testes, foi solicitado aos usuários que eles fossem verbalizando seus pensamentos a respeito de como realizar as tarefas, permitindo que a técnica de Think Aloud também fosse aplicada. A técnica de avaliação Think Aloud consiste numa maneira simples de se obter informações a respeito da utilização do sistema através da observação da interação dos usuários com o mesmo. Essa técnica requer que os usuários elaborem suas ações "pensando alto", descrevendo o que eles acreditam que está acontecendo no sistema, o porquê eles tomaram uma ação, o que eles estão tentando fazer, etc. O principal objetivo do Think Aloud é verificar como o sistema é usado pelos seus potenciais usuários e quais os mecanismos de recuperação de erros disponíveis. Como durante a avaliação o projetista não pode falar com o usuário, o usuário tende a cometer mais erros, fazendo com que o projetista identifique falhas na recuperação de erros.

Alguns dados de uso da ferramenta DocRationale já haviam sido obtidos durante a utilização da ferramenta em disciplinas ministradas no ICMC-USP. Contudo, os critérios utilizados para avaliar o seu uso na disciplina não foram os mesmos que deveriam ser avaliados no teste comparativo a ser realizado. Desta forma, também foi efetuado um novo teste com a ferramenta em sua versão anterior e com a nova ferramenta, utilizando as mesmas tarefas e os mesmos critérios de avaliação.

Durante o planejamento dos testes foi definido que o mesmo seria aplicado a oito desenvolvedores, sendo quatro alunos de graduação e quatro alunos de pós-graduação. Como os resultados dos testes também seriam utilizados para efetuar uma comparação entre as ferramentas, foi 
definido que metade dos usuários deveriam fazer o teste primeiro com a versão anterior da ferramenta, e em seguida com a nova, e a outra metade deveria fazer o teste na ordem contrária, para diminuir o "efeito aprendizado" 3 sobre os resultados.

O conjunto de tarefas foi definido de forma que o usuário percorresse a maioria das funcionalidades básicas do sistema. A lista de tarefas utilizada no teste encontra-se disponível no Apêndice A.

Para a realização dos testes foram utilizados microcomputadores com acesso a Web. Antes da execução do teste era realizada uma apresentação da ferramenta para o usuário, assim como os objetivos do teste e o procedimento de realização. Só eram respondidas perguntas do usuário se o nível de dificuldade para realização de uma tarefa fosse realmente grande, e a não realização dessa tarefa impossibilitasse o prosseguimento do teste. Durante a execução dos testes eram realizadas anotações sobre as dificuldades encontradas pelos usuários, sobre o modo com que as tarefas eram realizadas, bem como sobre as sugestões dadas pelos usuários.

Após a realização das tarefas em cada uma das ferramentas, solicitava-se que o usuário respondesse a um questionário onde deveria classificar o nível de dificuldade encontrado para efetuar algumas tarefas, e também para classificar alguns outros aspectos da sua impressão com a interface. O questionário utilizado encontra-se disponível no Apêndice B.

Na Tabela 5.1 estão listados o grau de formação dos usuários (aluno de graduação ou pósgraduação), a ordem em que o teste foi realizado (denotando por 1 - 2 a sequência DocRationale - DocRat, e vice-versa) e o tempo gasto com a realização das tarefas em cada uma das versões da ferramenta.

Analisando os dados de tempos da Tabela 5.1, verifica-se que o tempo de realização do teste com a nova versão da ferramenta foi em média 8,87 min mais rápido do que o teste com a versão anterior, com desvio padrão de 10,68 min. Assim, pode-se afirmar com nível de significância de 10\%, que há indícios de uma melhora no tempo de realização de tarefas com a nova implementação da interface.

A partir da análise do avaliador sobre a execução das tarefas do usuário, também foi possível verificar a quantidade de erros cometidos pelos usuários durante a realização do teste. Na Tabela 5.2 está listada a quantidade de erros cometidos pelos usuários no teste com cada uma das versões da ferramenta.

Observa-se que, em média, houve uma redução de 2,38 erros cometidos com a nova interface, quando comparada com a interface da versão anterior de DocRationale, com desvio padrão de 1,3 erros. Com base nesses dados pode-se afirmar, com nível de significância de 10\%, que há

\footnotetext{
${ }^{3}$ Após fazer o teste com a primeira ferramenta, o usuário já aprende vários conceitos envolvidos com as tarefas, o que pode influenciar na realização das tarefas na segunda ferramenta Nielsen, 1993.
} 
Tabela 5.1: Tempo gasto pelos usuários para efetuar o teste em cada versão da ferramenta

\begin{tabular}{|c|c|c|c|c|}
\hline Usuário & Aluno de & Ordem & Tempo na DocRat & Tempo na DocRationale \\
\hline Usuário 1 & Graduação & $2-1$ & $25 \mathrm{~min}$ & $20 \mathrm{~min}$ \\
Usuário 2 & Pós-graduação & $2-1$ & $20 \mathrm{~min}$ & $20 \mathrm{~min}$ \\
Usuário 3 & Graduação & $1-2$ & $19 \mathrm{~min}$ & $40 \mathrm{~min}$ \\
Usuário 4 & Pós-graduação & $1-2$ & $17 \mathrm{~min}$ & $32 \mathrm{~min}$ \\
Usuário 5 & Graduação & $1-2$ & $30 \mathrm{~min}$ & $40 \mathrm{~min}$ \\
Usuário 6 & Pós-graduação & $1-2$ & $30 \mathrm{~min}$ & $55 \mathrm{~min}$ \\
Usuário 7 & Graduação & $2-1$ & $18 \mathrm{~min}$ & $21 \mathrm{~min}$ \\
Usuário 8 & Pós-graduação & $2-1$ & $18 \mathrm{~min}$ & $21 \mathrm{~min}$ \\
\hline & & Média: & $21,38 \mathrm{~min}$ & $30,25 \mathrm{~min}$ \\
\hline
\end{tabular}

Tabela 5.2: Número de erros cometidos pelos usuários ao efetuar o teste em cada uma das versões da ferramenta

\begin{tabular}{|c|c|c|}
\hline Usuário & Erros na DocRat & Erros na DocRationale \\
\hline Usuário 1 & 1 & 4 \\
\hline Usuário 2 & 0 & 3 \\
\hline Usuário 3 & 2 & 4 \\
\hline Usuário 4 & 1 & 4 \\
\hline Usuário 5 & 1 & 2 \\
\hline Usuário 6 & 1 & 5 \\
\hline Usuário 7 & 3 & 3 \\
\hline Usuário 8 & 1 & 4 \\
\hline Média: & 1,25 & 3,63 \\
\hline
\end{tabular}


Tabela 5.3: Graus de dificuldade para realização de operações, entendimento da hierarquia, e navegação pelo sistema a partir das respostas de questionários pelos usuários

\begin{tabular}{|r|c|c|c|c|}
\hline Item & DocRat & DocRationale & Média Diferença & Desv. Padrão Diferença \\
\hline Novo projeto & 0 & 3,44 & $-3,44$ & 2,65 \\
Novo artefato & 1,24 & 3,44 & $-2,19$ & 2,48 \\
Nova questão & 1,25 & 3,44 & $-2,19$ & 2,09 \\
Nova página & 3,44 & 4,69 & $-1,25$ & 1,89 \\
Hierarquia & 2,81 & 5,63 & $-2,81$ & 3,12 \\
Navegação & $3,4,4$ & 6,88 & $-3,44$ & 3,52 \\
\hline
\end{tabular}

indícios de uma redução no número de erros cometidos pelos usuários com a implementação da nova interface.

Durante o preenchimento dos questionários, verificou-se que alguns usuários não possuiam parâmetros de comparação adequados para classificar o grau de dificuldade na realização das tarefas no teste. Apesar disso, pôde-se verificar pelas opiniões dos usuários nos questionários, que diversas tarefas puderam ser realizadas de forma mais fácil por meio da nova interface.

Nas seis primeiras perguntas do questionário, pediu-se que os usuários classificassem o grau de dificuldade para se efetuar as operações de criar de um novo projeto, criar um novo artefato, criar uma nova questão e criar uma nova página, o grau de dificuldade para abstrair a estrutura hierárquica do sistema e o grau de dificuldade encontrado para localizar informações nas aplicações (número de cliques necessários). Os níveis de dificuldade foram colocados em uma escala de "muito fácil" - "fácil" - "razoável" - "difícil" - "muito difícil". Na Tabela 5.3 são exibidas as médias de dificuldade para cada item, e a média e desvios-padrão das diferenças entre os níveis em cada ferramenta. Os graus de dificuldades foram colocados em uma escala de 0 a 10, onde 0 equivale a "muito fácil" e 10 equivale a "muito difícil".

A partir da análise dos dados de cada um dos itens da Tabela 5.3, é possível afirmar com nível de significância de 10\% que há indícios de que cada um dos itens analisados possui grau de dificuldade menor na nova interface, quando comparados com os graus de dificuldade da interface da ferramenta em sua versão anterior. Pode-se notar que a melhora na facilidade de se criar uma nova página não foi significativa. Isso se deve ao fato de que essa operação é acessada a partir da interface da CoTeia, que não foi alterada durante a reengenharia da interface.

Nas duas perguntas seguintes do questionário, pediu-se que os usuários classificassem o auxílio a localização corrente fornecido pelo sistema e a qualidade das informações de orientação sobre a realização de tarefas fornecidas pelo sistema. O usuário deveria classificar cada uma 
Tabela 5.4: Classificação da localização corrente e qualidade das informações de orientação, a partir das respostas de questionários pelos usuários

\begin{tabular}{|r|c|c|c|c|}
\hline Item & DocRat & DocRationale & Média Diferença & Desv. Padrão Diferença \\
\hline Localização corrente & 6,56 & 2,5 & 4,06 & 3,99 \\
Orientação & 8,44 & 3,13 & 5,31 & 3,88 \\
\hline
\end{tabular}

dessas informações em uma escala de "muito ruim" - "ruim" - "razoável" - "bom" - "muito bom". Na Tabela 5.4 são exibidos as médias obtidas na classificação de cada item, e a média e desvios-padrão das diferenças entre as classificações em cada ferramenta. As classificações foram colocadas em uma escala de 0 a 10, onde 0 equivale a "muito ruim" e 10 equivale a "muito bom".

A partir da análise dos dados de cada um dos itens da Tabela 5.4, é possível afirmar, com nível de significância de 10\%, que há indícios de que cada um dos itens analisados obteve uma classificação melhor na nova interface do que na interface da versão anterior. O item localização corrente foi apontado por diversos usuários como uma melhoria, mas vários deles comentaram que seria interessante que os itens do "caminho percorrido" fossem na forma de links para o local visitado, para facilitar a navegação.

Na última pergunta do questionário foi solicitado para que os usuários respondessem se consideravam suficiente a quantidade de informações exibidas por página, em cada uma das versões da ferramenta. Cem por cento dos usuários consideraram que a quantidade de informações disponíveis na DocRat era suficiente, enquanto somente $25 \%$ responderam que a quantidade de informações era suficiente na versão anterior da DocRationale.

Assim, verifica-se que houve uma melhora considerável com a eliminação do limite de exibição de somente quatro itens por página, existente na versão anterior da ferramenta.

Durante a realização dos testes, diversos problemas novos, que não haviam sido identificados na avaliação heurística, também foram encontrados. Por exemplo, muitos usuários não conseguiam localizar as opções para a criação novos artefatos e de novas questões a partir do menu lateral, pois eles sempre procuravam primeiro na área central da página.

\section{Avaliação de Acessibilidade}

No contexto deste projeto, o principal objetivo em relação à acessibilidade da interface da ferramenta DocRat foi estar em conformidade com as principais guidelines do WCAG 1.0 (Web Content Accessibility Guidelines) W3C, 1999.

Uma das formas de se efetuar a avaliação de acessibilidade é através do uso de ferramentas de avaliação automática. As ferramentas de avaliação automática são capazes de identificar 
diversos problemas referentes às guidelines de acessibilidade. Além dos problemas que podem ser determinados de forma automática, as ferramentas também são capazes de apontar alguns possíveis problemas para serem verificados de forma manual. Alguns exemplos de ferramentas de avaliação automática de acessibilidade são o Bobby ${ }^{4}$ e o daSilva ${ }^{5}$.

A avaliação de acessibilidade da nova interface confeccionada foi efetuada utilizando a ferramenta daSilva. Diversos problemas com textos alternativos, com a identificação de rótulos de campos e outros problemas recorrentes foram identificados com o auxílio da ferramenta de avaliação automática. Outros problemas como dificuldades de navegação ou falta de clareza nos textos tiveram que ser verificados de forma manual.

Uma das principais dificuldades para se realizar a avaliação de acessibilidade foi o fato de as páginas da aplicação serem geradas dinamicamente. Diversas páginas tiveram que ser avaliadas mais de uma vez, de forma a verificar as diferentes possibilidades de saídas que poderiam ser geradas. A avaliação automática de páginas dinâmicas tem sido alvo de trabalhos de pesquisa, mas ainda é um problema não solucionado [Stone and Dhiensa, 2004, Freire and Fortes, 2005.

\section{Considerações sobre os resultados da avaliação}

Com a realização da avaliação de usabilidade e acessibilidade, pôde-se verificar que diversos problemas levantados no início deste capítulo puderam ser solucionados com a implementação da nova interface da ferramenta DocRat.

Além disso, diversos outros problemas que não haviam sido encontrados no início do desenvolvimento puderam ser identificados e solucionados após a realização dos testes.

Contudo, alguns problemas de usabilidade ainda existem na nova implementação, principalmente problemas no que se refere a integração da DocRat com a ferramenta CoTeia, os quais deverão ser resolvidos em trabalhos futuros.

\section{Considerações sobre o plano de avaliação}

A utilização da Avaliação Heurística foi de extrema valia para a identificação de problemas por outros especialistas em interfaces, com diferentes opiniões e experiências, que contribuíram de maneira bastante eficaz.

Verificou-se também que o teste com usuários foi de extrema importância, e que por mais problemas que possam ser identificados, através da avaliação por especialistas, muitos problemas só são realmente identificados quando o sistema é utilizado por usuários reais.

\footnotetext{
${ }^{4}$ Disponível em http://bobby.watchfire.com

${ }^{5}$ Disponível em http://www.acessobrasil.org.br
} 
Caso houvesse tempo e recursos disponíveis, outros métodos de captura (como a gravação de vídeo) poderiam ter sido utilizados, para analisar o comportamento dos usuários durante os testes, num momento posterior, pois, a realização de anotações durante o teste impossibilitava a análise do comportamento do usuário de forma detalhada.

Outros métodos de teste poderiam ter sido utilizados para efetuar a inspeção de usabilidade, contudo, isso aumentaria consideravelmente o custo da avaliação.

Durante o preenchimento de algumas perguntas do questionário pelos usuários, verificouse que algumas delas não eram respondidas de forma adequada. Por exemplo, usuários que tiveram que repetir a criação de um novo projeto três ou mais vezes na antiga versão da $D o c R a$ tionale classificaram a dificuldade em criar um projeto como "muito fácil" ou "fácil". Talvez um detalhamento maior na elaboração das questões poderia ter evitado esse tipo de resposta.

\subsection{Dificuldades e Limitações}

Durante a execução deste trabalho foram encontradas dificuldades para integrar as ferramentas CoTeia e Groupnote à nova versão da DocRationale.

A versão da CoTeia que foi integrada à nova DocRat era diferente da versão integrada anteriormente. Esta nova versão da CoTeia possui recursos para efetuar o controle de versões de páginas, e estava em desenvolvimento uma nova versão que também permitia o controle de versões de arquivos anexos. Como essas funcionalidades eram de grande interesse para o contexto de armazenamento de $D R$, foi necessário adequar a DocRat para também interagir com esses recursos da CoTeia.

Como no início havia sido decidido integrar o Groupnote, da forma como ele estava implementado, à ferramenta DocRat, também foram encontrados alguns problemas, pois foi necessário verificar toda a estrutura da $A P I$ novamente para verificar os pontos de integração com a nova ferramenta. Na versão anterior da DocRationale, os pontos de integração com a CoTeia e com o GroupNote não estavam bem documentados, o que dificultou bastante o trabalho de integração durante a codificação da nova versão.

Por meio da avaliação de usabilidade, foram identificados diversos problemas relacionados às ferramentas CoTeia e GroupNote, principalmente no que se refere aos pontos de integração da DocRat com essas ferramentas. E, após a realização dos testes, apesar do esforço de integração do GroupNote à DocRat ter sido grande, optou-se por desenvolver as funcionalidades de armazenamento de posições e argumentos na própria ferramenta DocRat, seguindo os padrões e estrutura de navegação já definidos para a nova versão. Após a realização da reengenharia da ferramenta DocRationale, a nova arquitetura da ferramenta DocRat pode ser visualizada na 


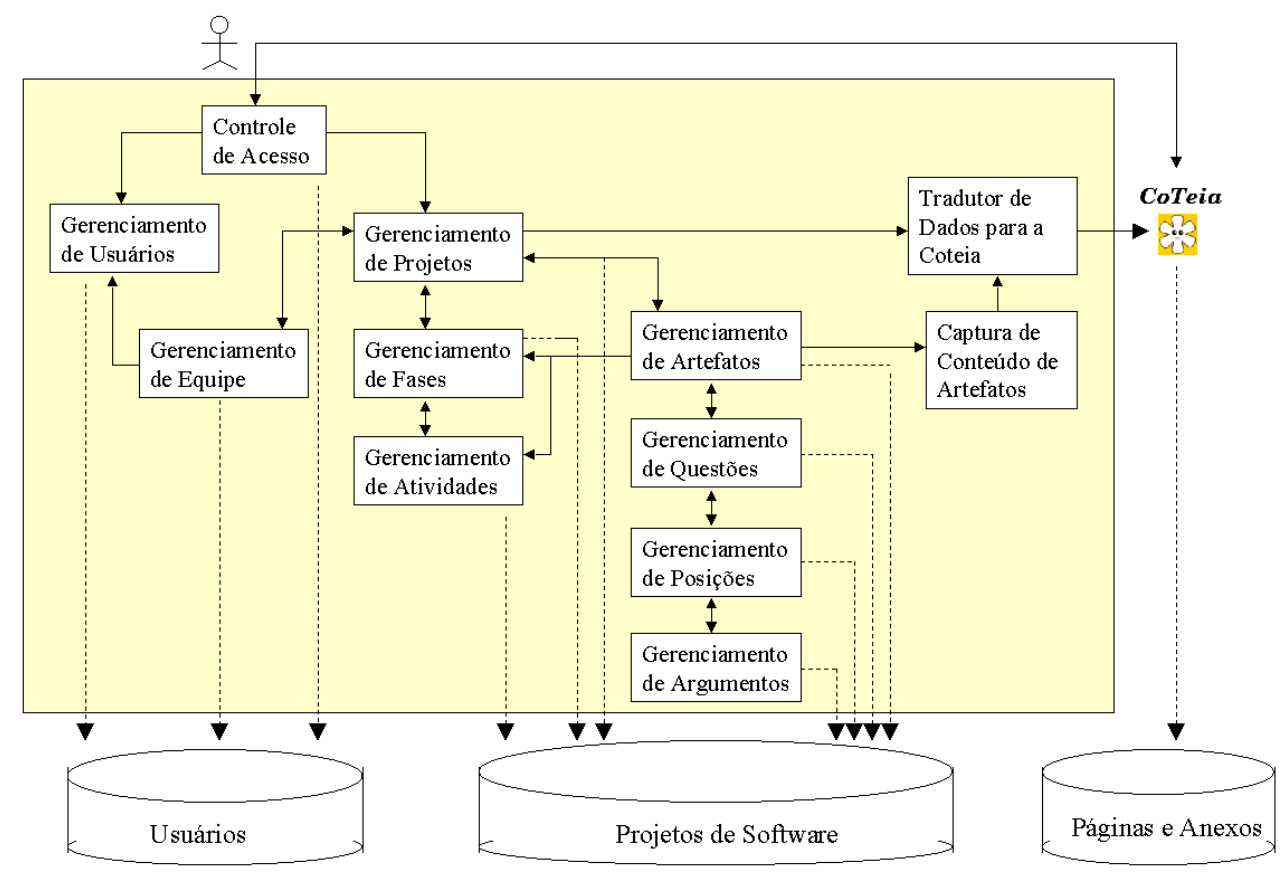

Figura 5.9: Arquitetura da ferramenta DocRat

Figura 5.9 .

Infelizmente, não foi possível solucionar todos os problemas por limitações de tempo. Para solucionar os problemas da CoTeia, seria necessário efetuar alterações consideráveis na sua interface, bem como alterações relativas à segurança de acesso às páginas, problemas esses que devem ser resolvidos em trabalhos futuros.

\subsection{Considerações Finais}

O principal resultado obtido com a realização da reengenharia da interface foi a implementação da nova interface da ferramenta DocRat, com melhorias no quesito de usabilidade. Essa melhoria pôde ser verificada pelos resultados favoráveis da avaliação de usabilidade.

Com o uso da ferramenta em disciplinas de graduação e pós-graduação, pôde-se verificar a existência de diversos problemas de usabilidade, e, com isso, forte resistência por parte dos alunos em utilizar a ferramenta.

Para solucionar ou minimizar tais problemas foi realizada uma reengenharia da interface da ferramenta, culminando em uma nova versão denominada DocRat. O processo de reengenharia foi realizado seguindo o ciclo de vida de Engenharia de Usabilidade proposto por [Nielsen, 1993.

Durante o trabalho de reengenharia foram realizadas diversas entrevistas informais com os usuários, tanto antes quanto durante o desenvolvimento, para conhecer os principais problemas de usabilidade enfrentados por eles. Também foi realizada uma Avaliação Heurística na 
versão anterior da ferramenta DocRationale com o objetivo de levantar problemas e guiar o desenvolvimento da nova interface.

A nova interface da ferramenta foi desenvolvida de forma que a apresentação e a lógica fossem separadas, por meio do uso de templates; também foram seguidas as principais guidelines de acessibilidade contidas no WCAG 1.0 W3C, 1999. Diversos problemas apontados estavam relacionados com a navegação da ferramenta, de forma que um novo esquema navegacional foi elaborado para a nova interface.

Após a implementação da nova interface foi realizada uma avaliação de usabilidade, que consistiu em uma inspeção de usabilidade utilizando Avaliação Heurística, efetuada com cinco especialistas, e um teste com oito usuários, realizado com as duas versões da ferramenta para a obtenção de dados comparativos. A partir dos resultados da avaliação de usabilidade, pôde-se observar uma real melhoria de usabilidade na ferramenta DocRat.

Com a nova implementação da ferramenta e com as melhorias de usabilidade, espera-se a redução da resistência por parte dos usuários com o seu uso, e que a usabilidade da ferramenta não seja mais um obstáculo para o processo de captura e armazenamento de Design Rationale de artefatos de software.

As melhorias de usabilidade alcançadas com a realização desse trabalho também contribuirão para o projeto SAFE Fortes et al., 2004, um framework de ferramentas CASE livres, com o qual a ferramenta DocRat deverá ser integrada.

Foi elaborado um relatório técnico: "DocRat: Produto da Re-engenharia da Ferramenta DocRationale" Lara et al., 2005a, contendo os resultados obtidos com a reengenharia da ferramenta DocRationale, onde foram publicados em detalhes os aspectos da nova implementação (das funcionalidades e da interface), assim como os resultados da avaliação de usabilidade.

A reengenharia foi uma atividade relevante nesta pesquisa, pois possibilitou que os pontos de interação mais propícios a serem providos com suporte à escrita manual, por meio de interface ubíqua, fossem identificados. No próximo capítulo é descrito o desenvolvimento realizado para a incorporação de interface ubíqua à ferramenta DocRat. 


\section{Capítulo 6}

\section{Evolução da Ferramenta DocRat}

\subsection{Considerações iniciais}

Como a tarefa de registro de Design Rationale na ferramenta DocRationale era considerada onerosa pelos desenvolvedores, visto que esses eram obrigados a interromper suas atividades habituais de desenvolvimento de projeto para registrarem suas decisões e cadastrarem os artefatos produzidos, o objetivo desse trabalho foi investigar uma maneira de tornar o uso da ferramenta o mais natural possível, de forma que a ferramenta se tornasse um instrumento de auxílio durante o desenvolvimento das atividades de projeto, capturando o conteúdo dos artefatos produzidos e gerando automaticamente o $D R$ dos artefatos de software, sob as perspectivas de comunicação e documentação.

Os recentes avanços nas tecnologias de computação têm tornado os dispositivos baseados em caneta cada vez mais populares. Dispositivos como lousas eletrônicas, tablet PCs e PDAs (Personal Digital Assistants) possibilitam interações mais naturais por meio do uso de caneta e provêm uma maneira mais eficiente para a entrada de dados via escrita manual.

A Java Ink API (JInk) Júnior, 2004 consiste de uma biblioteca de classes e interfaces implementada em linguagem Java que possibilita integrar as funcionalidades de reconhecimento on-line de traços manuais a diferentes tipos de aplicações.

Com o propósito de auxiliar os desenvolvedores nas fases de análise e de design de um projeto de software foi realizada a evolução da ferramenta DocRat por meio da sua integração com mecanismos de interfaces naturais da JInk, adicionando características de uma aplicação ubíqua à ferramenta. Esse mecanismo de interface natural provê um meio de captura da escrita manual, que envolve interações por meio de caneta e o reconhecimento automático da escrita.

Na seção 6.2 é apresentada uma visão geral do método de reconhecimento de escrita utilizado, apresentando um breve resumo sobre os passos necessários para a realização do reconhecimento 
de escrita. Na seção 6.3 são mostrados os principais requisitos atendidos pela API JInk. Na seção 6.4 é descrito o processo de integração da ferramenta DocRat com a API JInk e na seção 6.5 são apresentadas as considerações finais.

\subsection{Visão Geral do Método de Reconhecimento de Escrita}

Um dos problemas ainda em aberto das interfaces baseadas em caneta é a transcrição das entradas manuais em caracteres manipuláveis por computadores, sendo esse um tópico de pesquisa ativo há mais de trinta anos Tappert et al., 1990. Diferentes abordagens têm sido propostas na tentativa de se obter sistemas de reconhecimento mais precisos, as quais incluem desde o uso de modelos matemático-estatísticos e métodos baseados em análise estrutural, até técnicas envolvendo inteligência artificial [Plamondon and Srihari, 2000].

Basicamente, o reconhecimento de caracteres pode ser classificado em dois tipos: off-line e on-line Plamondon and Srihari, 2000. O reconhecimento off-line foca no processamento de imagens previamente obtidas, nas quais são analisadas as disposições e níveis de cores dos pixels, sem levar em conta informações de tempo ou de direção de escrita dos traços. No reconhecimento on-line o processamento ocorre durante a escrita, sendo fornecida a seqüência exata dos pontos que compõem os traços, possibilitando calcular sua direção.

Algumas estratégias são utilizadas para facilitar o processo de reconhecimento, como a demarcação de áreas de escrita, a definição de conjuntos de caracteres permitidos ou a restrição da maneira como os mesmos devem ser escritos. Em alguns casos, os reconhecedores são específicos para algum domínio, como caracteres de música Forsberg et al., 1998 ou associados ao projeto de interfaces Lin et al., 2000. Atualmente, existem sistemas comerciais que fazem uso de alfabetos próprios, como o Palm Graffiti, que possui um conjunto de caracteres similar ao alfabeto romano. Embora possua taxa de precisão acima de 99\%, esse sistema restringe a escrita do usuário a um estilo pré-definido, aumentando a curva de aprendizado e tornando a interação com o dispositivo menos natural.

O método de reconhecimento de escrita proposto por Chan and Yeung, 1999 é dividido em três estágios principais: Extração e Reconstrução da Estrutura, Casamento Estrutural Flexível e Pós-Processamento, como representado na Figura 6.1 .

Basicamente, o que existe após a escrita do caractere é apenas uma seqüência de pontos, representados por suas respectivas coordenadas. O primeiro passo é identificar as primitivas que compõem cada caractere, através da extração da estrutura, sendo que neste estágio algumas formas de reconstrução podem ser empregadas. Com a estrutura obtida, os caracteres podem então ser comparados com os modelos pré-fornecidos, na tentativa de encontrar alguma 


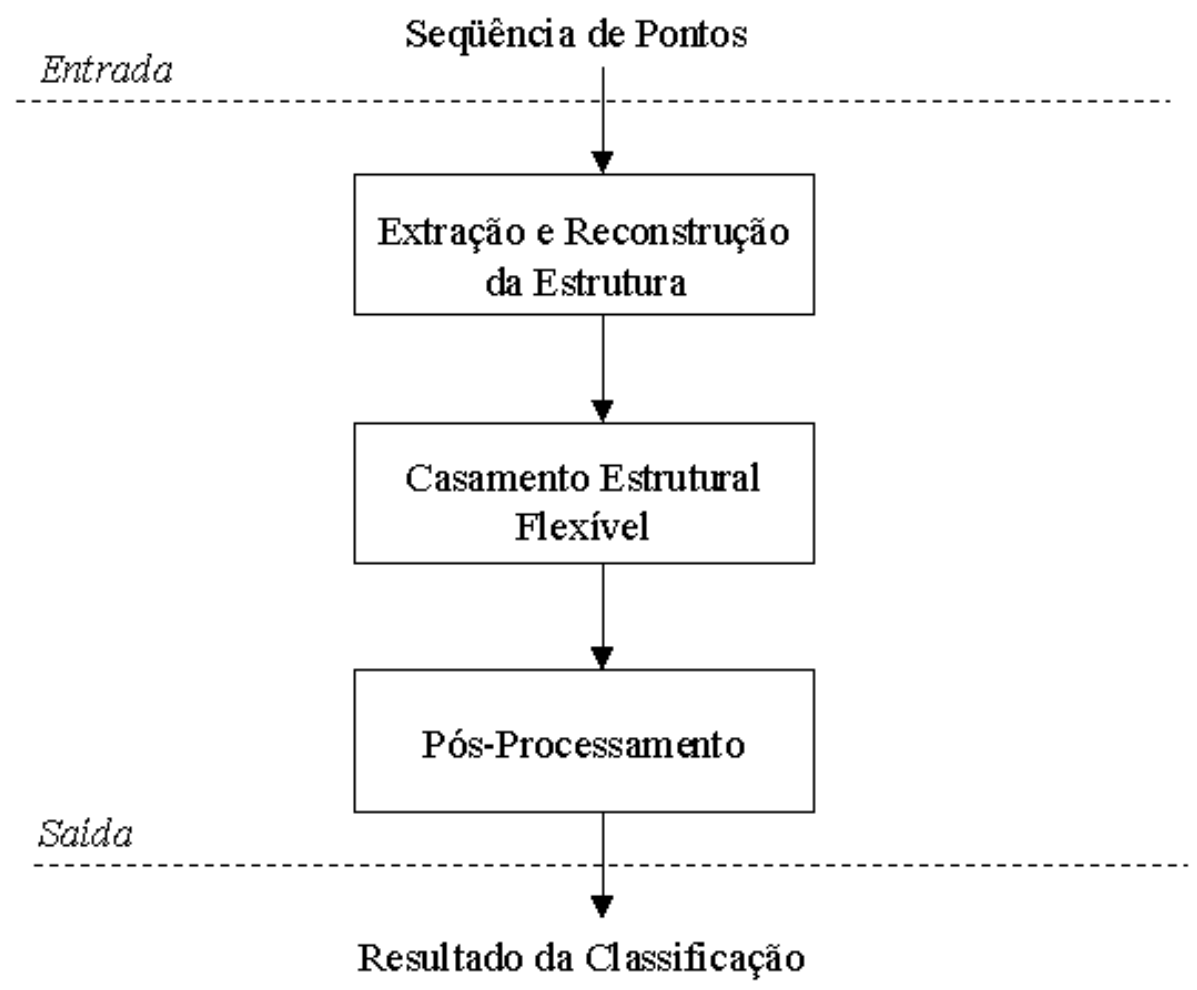

Figura 6.1: Passos do reconhecimento de escrita

equivalência. É então aplicado o algoritmo de Casamento Estrutural Flexível, que executa uma série de transformações na estrutura do caractere de modo a facilitar o reconhecimento. Finalmente, no último passo do reconhecimento, operações de pós-processamento são realizadas, para que ambigüidades ou possíveis erros de classificação sejam corrigidos.

\subsubsection{Extração e Reconstrução da Estrutura}

O método de reconhecimento proposto por Chan and Yeung, 1999 considera cada caractere como sendo um conjunto de linhas e curvas, organizadas sobre uma estrutura bi-dimensional. Os elementos que formam esse conjunto são denominados primitivas estruturais, e são identificados a partir da seqüência de segmentos que compõem cada traço do caractere. São definidos cinco tipos de primitivas: linha, curva acima (sentido anti-horário), curva abaixo (sentido horário), loop e ponto. Os segmentos são fragmentos de reta que interpolam os pontos gerados pela discretização do traço, sendo que cada segmento possui uma direção de escrita (facilmente obtida no reconhecimento on-line). Essa direção segue o modelo de codificação de [Freeman, 1974, pelo qual os $360^{\circ}$ de movimento no plano são reduzidos a oito direções, representadas por valores inteiros de 0 a 7, como mostrado na Figura 6.2. Assim, um valor inteiro é associado para cada segmento do traço, representando a direção aproximada na qual este se enquadra. Os valores 
obtidos são concatenados em uma cadeia de caracteres, sendo que segmentos consecutivos com direções iguais são unidos em um só segmento (Figura 6.2b). Uma direção também é associada a cada primitiva identificada, sendo calculada através do segmento obtido entre os pontos inicial e final da primitiva (Figura 6.2.).

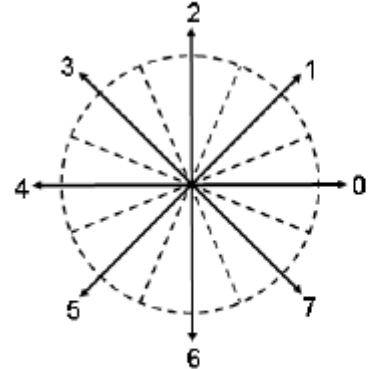

(a)

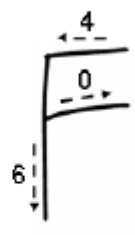

460

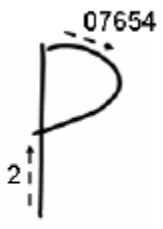

207654

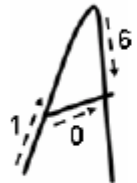

160

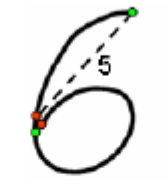

\{CurvaAcima, 5\}, \{Loop, -1\}

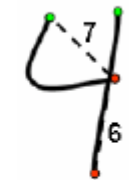

$\{$ CurvaAcima, 7$\}$ $\{$ Linha, 6\}

(b)

(c)

Figura 6.2: (a) Direções e valores utilizados na codificação de Freeman, 1974. (b) Exemplos de caracteres e concatenação de segmentos e traços. (c) Identificação das primitivas e cálculo da direção, onde os pontos representam o início e o fim de cada primitiva.

Assim sendo, cada segmento possui uma direção de escrita, codificada em um valor inteiro de 0 a 7 . Essas direções são armazenadas seqüencialmente em uma cadeia de caracteres, partindo do ponto inicial ao ponto final de cada traço do caractere. A extração da estrutura de um traço começa pela identificação de conjuntos de segmentos que correspondem a uma mesma primitiva. Pequenas variações de direção entre segmentos consecutivos são mantidas e representadas em um único traço, ao passo que variações bruscas de direção implicam na quebra do traço. Posteriormente, cada traço dará origem a uma primitiva. Além disso, segmentos consecutivos com direções iguais são agrupados em um único segmento, reduzindo o tamanho da cadeia.

\section{Remoção de Zig-Zag}

Uma outra operação realizada durante a extração da estrutura é a remoção de zig-zag. Esse tipo de problema ocorre geralmente devido à baixa qualidade do dispositivo de captura ou à estilos ruins de escrita. Para resolvê-lo pode-se simplesmente extrair os pontos médios de cada segmento e conectá-los novamente, de modo a "suavizar"a trajetória do traço, reduzindo o conjunto de pontos de sua estrutura. Entretanto, isso pode fazer com que a posição dos pontos mude e, dependendo de quantas vezes essa operação for executada, pode deformar o caractere e prejudicar o reconhecimento. 


\section{Identificação de Loops}

Depois de obter a estrutura preliminar é necessário verificar a ocorrência de determinadas subestruturas, tais como loops, e testar a possibilidade de combinação entre primitivas. Uma das maneiras de se identificar loops é por meio da análise da distância dos pontos do traço em relação a um ponto fixo. Sempre que esta distância for menor que um limitante e os pontos não pertençam ao mesmo segmento, é retornado um valor -1 indicando que um loop foi encontrado.

Em geral, um loop pode se localizar em três diferentes posições no traço: no começo, no meio e no fim. Quando o loop está no começo, o ponto inicial é fixado e o método acima pode ser utilizado para detectar sua ocorrência. O mesmo pode ser utilizado quando o loop está no fim, com a diferença que o ponto a ser fixado é o final. Já quando o loop está no meio, são utilizadas as duas extremidades do traço. Estas vão sendo deslocadas uma em direção à outra e o teste vai sendo executado conforme a distância entre elas diminui.

\section{Combinação de primitivas}

Algumas vezes um traço pode ser quebrado devido à baixa qualidade da escrita ou do dispositivo de captura. Desse modo, faz-se necessário checar cada par de primitivas consecutivas no conjunto de primitivas do caractere. Se algumas condições forem satisfeitas, é possível combiná-las em uma única nova primitiva.

\subsubsection{Casamento Estrutural Flexível}

Após extrair a estrutura final do caractere é possível então compará-lo ao conjunto de modelos. Entretanto, devido aos diferentes estilos e à variabilidade natural que ocorre durante a escrita, a probabilidade do caractere apresentado ser exatamente igual à algum dos modelos pré-fornecidos é baixa. O método de Casamento Estrutural Flexível tenta resolver esse problema executando uma série de deformações na estrutura do caractere, por meio de alterações na sua forma e direção, garantindo assim robustez e eficácia no reconhecimento. O algoritmo em alto nível do método de Casamento Estrutural Flexível desenvolvido por Chan and Yeung, 1999 pode ser visto na Figura 6.3

\section{Níveis de Deformação}

Há quatro níveis de deformação, sendo que o processo termina assim que um modelo equivalente (resultante de deformação ou não) é encontrado ou terminam os níveis e o caractere é rejeitado. A seguir é apresentada uma descrição sobre esses níveis: 


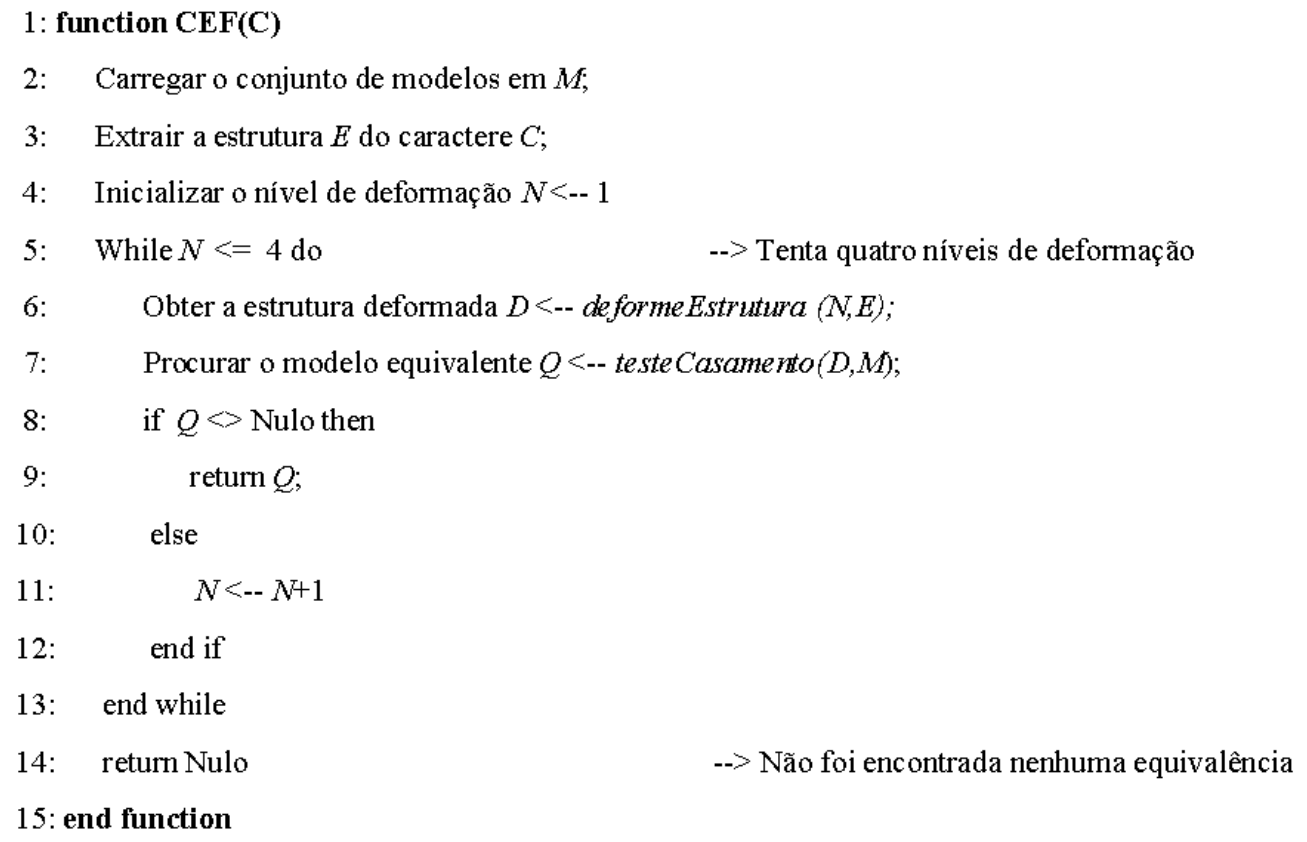

Figura 6.3: Algoritmo Casamento Estrutural Flexível

- Nível 1: Nenhuma deformação. A estrutura do caractere não é modificada, sendo que para uma equivalência ser encontrada o caractere deve ter estrutura idêntica à de um dos modelos;

- Nível 2: Deformação no tipo das primitivas. A estrutura do caractere sofre alterações no tipo de suas primitivas. Por exemplo, uma Linha se torna um de seus tipos vizinhos, isto é, uma CurvaAcima ou CurvaAbaixo, já que o tipo Linha é o meio-termo entre eles. Os tipos CurvaAcima e CurvaAbaixo podem apenas se transformar numa Linha, pois esses tipos não são vizinhos. A direção de cada primitiva é mantida sem alterações. Um exemplo é apresentado na Figura 6.4(a), no qual são geradas oito variações distintas do caractere "T";

- Nível 3: Deformação na direção das primitivas. Nesse caso, cada primitiva tem sua direção alterada para suas direções vizinhas, ou seja, uma primitiva $\{$ Linha, 5$\}$ pode se tornar $\{$ Linha, 4$\}$ ou $\{$ Linha, 6\}. Como exemplo, o mesmo caractere "T" é apresentado na Figura 6.4(b) ao lado de suas oito variações. Primitivas como Loop e Ponto, cuja direção é inválida, não sofrem o efeito dessas deformações;

- Nível 4: Deformação simultânea no tipo e direção. Quando nenhum modelo é encontrado 
nos passos anteriores, é então utilizada a deformação simultânea no tipo e na direção de cada primitiva do caractere. Como resultado, um número muito maior de variações é gerado. O mesmo "T", nesse passo, gera 80 variações, sendo que cada uma será testada com o conjunto de modelos.

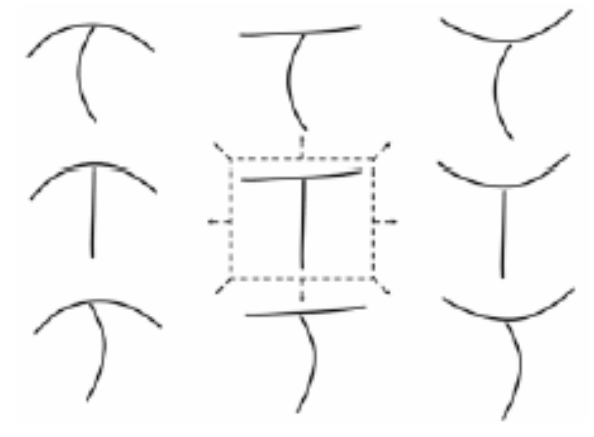

(a)
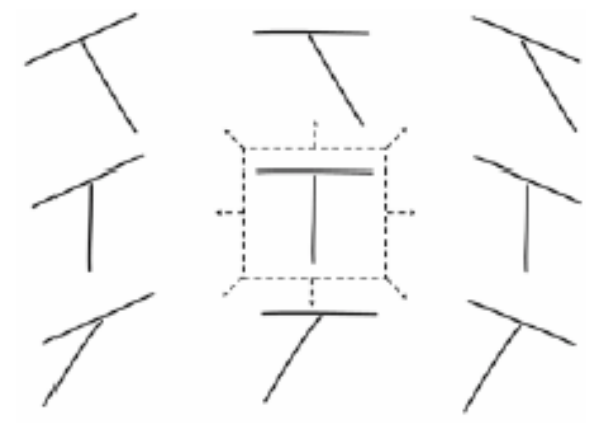

(b)

Figura 6.4: Versões deformadas do caractere "T" resultantes de alteração no tipo (a) e na direção (b) das primitivas (adaptado de [Chan and Yeung, 1999.

\subsubsection{Pós-Processamento}

Utilizando o Casamento Estrutural Flexível, caracteres que não encontrariam equivalência direta com os modelos pré-definidos podem ser reconhecidos. Entretanto, ao mesmo tempo que o método diminui a taxa de rejeição, ele pode gerar muitos resultados equivocados, visto que a flexibilidade dada ao caractere é cada vez maior conforme aumenta o nível de deformação. Assim, torna-se necessário executar passos adicionais para verificar a adequação do resultado e desfazer ambigüidades. Um dos principais tipos de ambigüidade é aquele em que caracteres distintos são representados pela mesma estrutura. Por exemplo, os caracteres "L" e "T" podem ser classificados com a mesma estrutura $\{\{$ Linha, 6$\},\{$ Linha, 0$\}\}$. Para resolver essa ambigüidade deve-se considerar a posição relativa dos traços vertical e horizontal: se o traço horizontal estiver acima do ponto médio do traço vertical, este é classificado como "T"; caso contrário, é classificado como um "L".

Devido ao fato de alguns caracteres serem muito parecidos, resultados equivocados são bastante comuns. Como exemplo, temos o caso de caracteres como "1" e "7", "9" e "g", "u" e "y", etc. O algoritmo que possibilita distinguir "u" de "y" por exemplo, que são definidos pelas primitivas $\{\{$ CurvaAcima, 0$\},\{$ Linha, 6$\}\}$, resolve essa ambigüidade através da comparação da altura das duas primitivas. A desvantagem do pós-processamento é que para cada grupo de caracteres suscetível à erro de reconhecimento é necessário escrever uma rotina específica para tratá-lo. Na 
versão atual da JInk a operação de pós-processamento é definida por meio de uma interface, na qual a aplicação que a implementa cuida de executar sua verificação de erros após receber o callback. Para o caso de reconhecimento de letras e dígitos, é fornecida uma implementação default. Em uma avaliação realizada por Chan and Yeung, 1999, o método foi testado com dados obtidos de 150 usuários, e as taxas de reconhecimento foram de $98.60 \%$ para dígitos, 98.49\% para letras maiúsculas e $97.44 \%$ para letras minúsculas. Quando os casos de rejeição foram excluídos do cálculo, as taxas subiram para 99.93\%, 99.53\% e 98.07\%, respectivamente.

Antes do reconhecimento é necessário definir um conjunto básico de modelos para cada classe de caractere. Esses modelos serão posteriormente utilizadas para o teste de casamento, no qual o modelo apresentado será comparado com os modelos pré-definidos. Os modelos devem ser distintos, isto é, não podem possuir o mesmo número de primitivas com os mesmos tipos e direções. Diferentes classes de caracteres também podem ter diferentes números de modelos, dependendo da complexidade da estrutura. Na implementação da JInk são fornecidos métodos que permitem que cada usuário especifique seu próprio conjunto de modelos, melhorando a precisão do algoritmo pela personalização do reconhecedor. Em alguns casos é possível também fazer combinações com os traços dos caracteres e reduzir o número de modelos.

Apesar das pesquisas sobre o reconhecimento da escrita já possuírem um certo amadurecimento, poucas aplicações têm explorado as vantagens dessas tecnologias. A principal razão para isso é o tempo gasto para se implementar uma interface com reconhecimento de escrita. Um programador que deseja construir uma aplicação com tal interface deve começar implementando acesso a componentes de baixo nível, desenvolvendo algoritmos e adaptando funcionalidades. Existem poucas opções de ferramentas não-proprietárias de desenvolvimento que possibilitem integrá-las às aplicações, sendo que muitos dos produtos de reconhecimento de caracteres existentes devem ser utilizados em ambientes controlados para melhor desempenho. Sobretudo, tais produtos não oferecem suporte à extensão do conjunto de caracteres a ser reconhecido, como por exemplo, símbolos definidos pelo usuário, restringindo o escopo das aplicações que podem ser construídas.

\subsection{JInk: A Java Ink API}

A Java Ink API (JInk Application Interface) consiste de uma biblioteca de classes e interfaces implementada em linguagem Java, que possibilita integrar as funcionalidades de reconhecimento on-line de traços manuais a diferentes tipos de aplicações. A JInk foi desenvolvida como software livre e faz parte do projeto de mestrado do aluno Valter dos Reis Inácio Júnior [Júnior, 2004.

A estrutura da API é composta por três pacotes: core, util e demo. O primeiro contém 
as classes e interfaces correspondentes ao núcleo da API, responsáveis pelo reconhecimento e pelo suporte ao tratamento de eventos. O segundo pacote, util, possui as classes utilitárias responsáveis pela configuração da API, gerenciamento de usuários e manipulação de arquivos XML. Por fim, o pacote demo contém algumas aplicações desenvolvidas com a API demonstrando o seu uso.

Os principais requisitos que a Java Ink API atende são [Júnior, 2004]:

- suporta o reconhecimento on-line de caracteres de escrita manual não-cursiva (os caracteres devem estar separados);

- Permite a extensão dos tipos de caracteres suportados. Ex: um programador pode definir os tipos "Gestos", "Formas Geométricas", "Alfabeto Japonês Hiragana", "Letras Gregas", etc;

- Permite que cada usuário treine seu próprio conjunto de modelos de caracteres, de forma a aumentar a precisão do reconhecedor;

- Provê interfaces de programação responsáveis por notificar a ocorrência de eventos relacionados ao reconhecimento;

- Possibilita que o método de reconhecimento utilizado, baseado no algoritmo de Casamento Estrutural Flexível Chan and Yeung, 1999, tenha seus parâmetros e restrições configuráveis;

- Suportar diferentes formas de unificação e/ou segmentação dos caracteres. Ex: algumas aplicações exigem que os traços sejam agrupados de acordo com sua posição relativa; outras demandam que esse processo seja feito de acordo com o tempo de escrita de cada traço;

- O reconhecimento deve poder ser executado de maneira concorrente à aplicação, como um processo independente;

- Suportar a manipulação de arquivos XML com informação de tipos, símbolos, modelos e outras configurações do usuário;

- A configuração da API pode ser feita via uma interface gráfica, por meio de um painel de controle que efetue a geração automática dos arquivos XML.

\subsection{Integração da Ferramenta DocRat com a API JInk}

O processo de integração da Java Ink API à ferramenta DocRat necessitou inicialmente da criação de uma aplicação com interface gráfica para o editor, de modo que permitisse a entrada 
dos símbolos por meio de uma caneta. Tal interface possui os elementos básicos para a escrita, tais como: caneta (fina e grossa), borracha, opção de cores, e a opção de habilitar ou não o reconhecimento dos símbolos escritos pelo usuário, como pode ser verificado na figura 6.5. A interface gráfica possui ainda o botão "JInk" que provê o acesso a outra interface gráfica, interface essa que permite ao usuário treinar os símbolos da sua escrita e associá-los aos seus respectivos caracteres, para que o reconhecedor possa identificá-los durante a realização da escrita no editor.

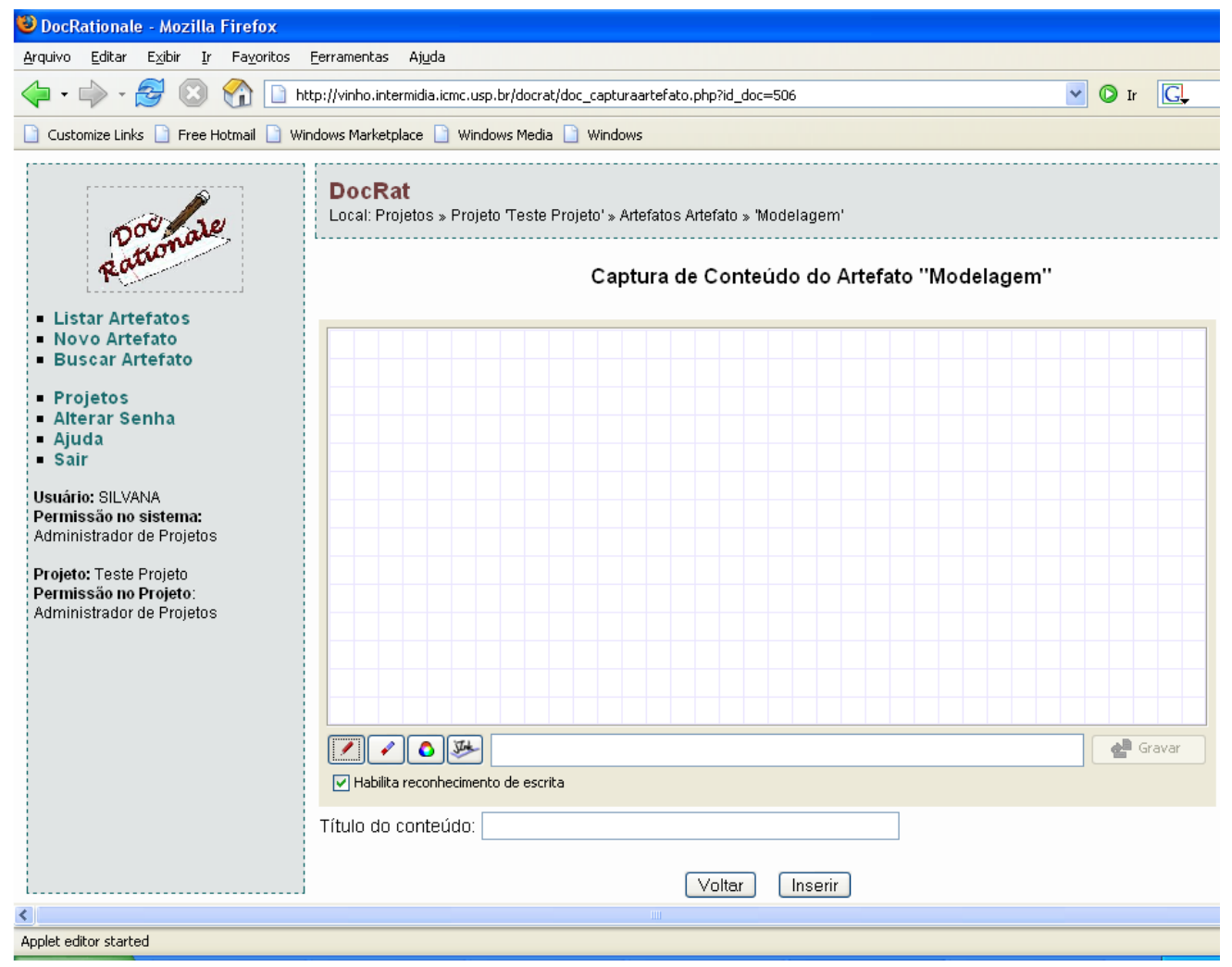

Figura 6.5: Tela do editor de escrita manual

O desenvolvimento da aplicação para a integração com a ferramenta DocRat envolveu três fases:

- Definição dos tipos e símbolos a serem reconhecidos: Por meio da interface gráfica do Painel de Configuração, o programador define o conjunto de tipos e símbolos suportados pela aplicação, que são automaticamente salvos em arquivos XML e acessados por todos os usuários da ferramenta DocRat. As propriedades de cada tipo, como o reconhecimento de caracteres com ordem de escrita ou direção fixa, o nível de variação suportado ou o método de unificação utilizado (posição relativa dos traços ou tempo de escrita), também são configurados através dessa ferramenta. Para a ferramenta DocRat foi configurado um único tipo denominado "caracteres" e associado a esse tipo foi configurado um conjunto de símbolos (letras maiúsculas e minúsculas, dígitos e caracteres especiais); 
- Criação do reconhecedor e adição-remoção de traços: Após a definição dos tipos e símbolos, é necessária a instanciação do(s) reconhecedor(es) na aplicação, sendo isso feito por meio da chamada de um construtor da classe InkRecognizer. É preciso também habilitar a adição e a remoção dos traços do reconhecedor, que pode, por exemplo, ser efetuada dentro dos métodos associados ao tratamento de eventos do mouse, por meio de chamadas aos métodos addStroke() e removeStroke(). O reconhecimento dos traços é implícito dentro da execução de ambos os métodos.

- Notificação e tratamento dos eventos de reconhecimento: Quando um dos métodos de remoção ou adição é executado, o reconhecimento é iniciado e executado em uma thread independente, de maneira concorrente à aplicação. Assim que o caractere é processado pelo sistema, um evento de resultado (implementado pela classe InkResultEvent) é despachado para as classes ouvintes (listeners). Porém, para que uma classe seja notificada da ocorrência desses eventos, é necessário registrá-la no reconhecedor (através do método addResultListener()) e implementar a interface InkResultListener. É dentro dos métodos providos por essa interface que o programador define como cada aplicação irá manipular o resultado do reconhecimento.

A integração da aplicação do editor com a ferramenta DocRat foi realizada por meio da inclusão de applets em páginas PHP e do uso de scripts para a obtenção dos dados gerenciados pelo applet.

Os tipos de caracteres a serem reconhecidos e os modelos treinados pelos usuários ficam armazenados no servidor sob a forma de arquivos XML. O usuário pode treinar novos modelos durante a execução da aplicação, de modo que um arquivo XML é gravado na máquina do cliente e posteriormente transferido para a máquina servidora.

O mecanismo que permite a captura de dados via escrita manual foi integrado em vários pontos relativos ao registro do $D R$ na ferramenta DocRat, sendo que um dos principais pontos foi o da captura de conteúdo de um artefato. Anteriormente, a ferramenta DocRationale não oferecia nenhum tipo de suporte para a geração de documentos além do editor HTML existente na CoTeia. Após a integração com o novo editor, passou-se a permitir a entrada de caracteres e também de desenhos (diagramas, gráficos, etc) como pode ser visto na Figura 6.6. Após o término da interação do usuário com o editor gráfico, uma imagem da tela do editor é capturada e transformada em um arquivo de imagem, e o texto gerado por meio do reconhecimento dos caracteres também é gravado em um arquivo do tipo texto, os quais são anexados como documentos pertencentes ao artefato em questão, na página do artefato na CoTeia, gerando assim a captura de $D R$ sob a perspectiva de documentação e comunicação. 


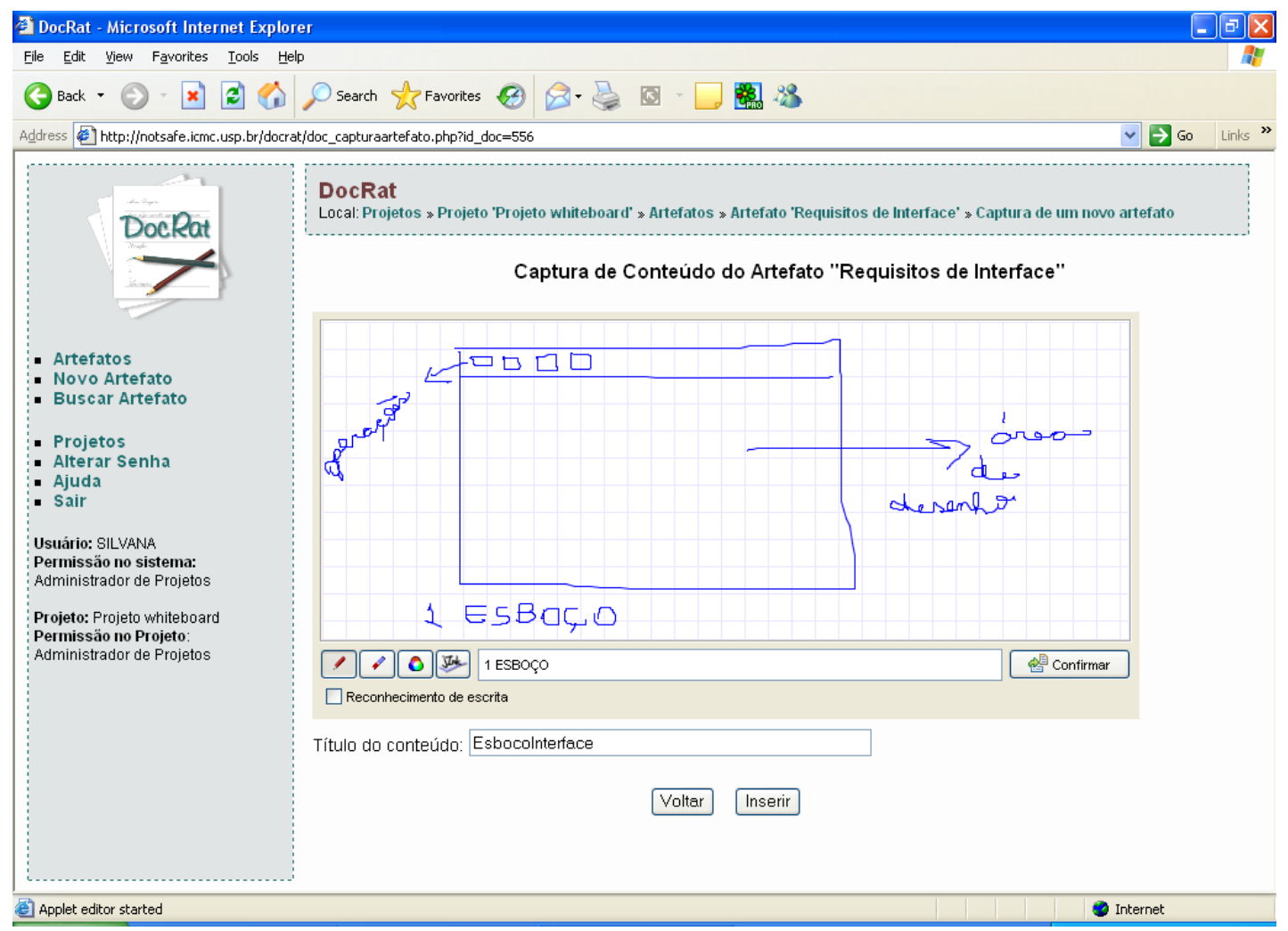

Figura 6.6: Tela do editor para captura de artefatos de software

Além de ser utilizado para a captura de artefatos, o editor também foi integrado para captura de uma nova questão, sendo que nesse caso, somente os caracteres reconhecidos fazem parte do título da questão, como pode ser observado na Figura 6.7.

Para viabilizar a captura de posição, argumento a favor e argumento contra, foi realizada uma modificação na tela do editor, de modo a delimitar as três áreas de reconhecimento, onde somente os caracteres reconhecidos fazem parte do conteúdo do dado em questão, registrando o $D R$ sob a perspectiva de argumentação. Nesse caso, como houve a necessidade da captura de mais de um tipo de informação de uma só vez, foi necessária a divisão da área de escrita em três partes, como pode ser visualizado na Figura 6.8.

A captura de argumentos a respeito de uma determinada posição ocorre de forma semelhante à captura de uma nova questão, onde somente os caracteres reconhecidos fazem parte do título do argumento, como pode ser observado na Figura 6.9, que mostra a tela para a captura de um argumento contra a posição em questão.

É importante ressaltar que para o reconhecimento de caracteres funcionar de forma mais precisa, cada usuário da ferramenta DocRat deve treinar seu conjunto de modelos de caracteres. Isso pode ser feito antes ou durante a execução da aplicação, por meio do Painel de Controle. 


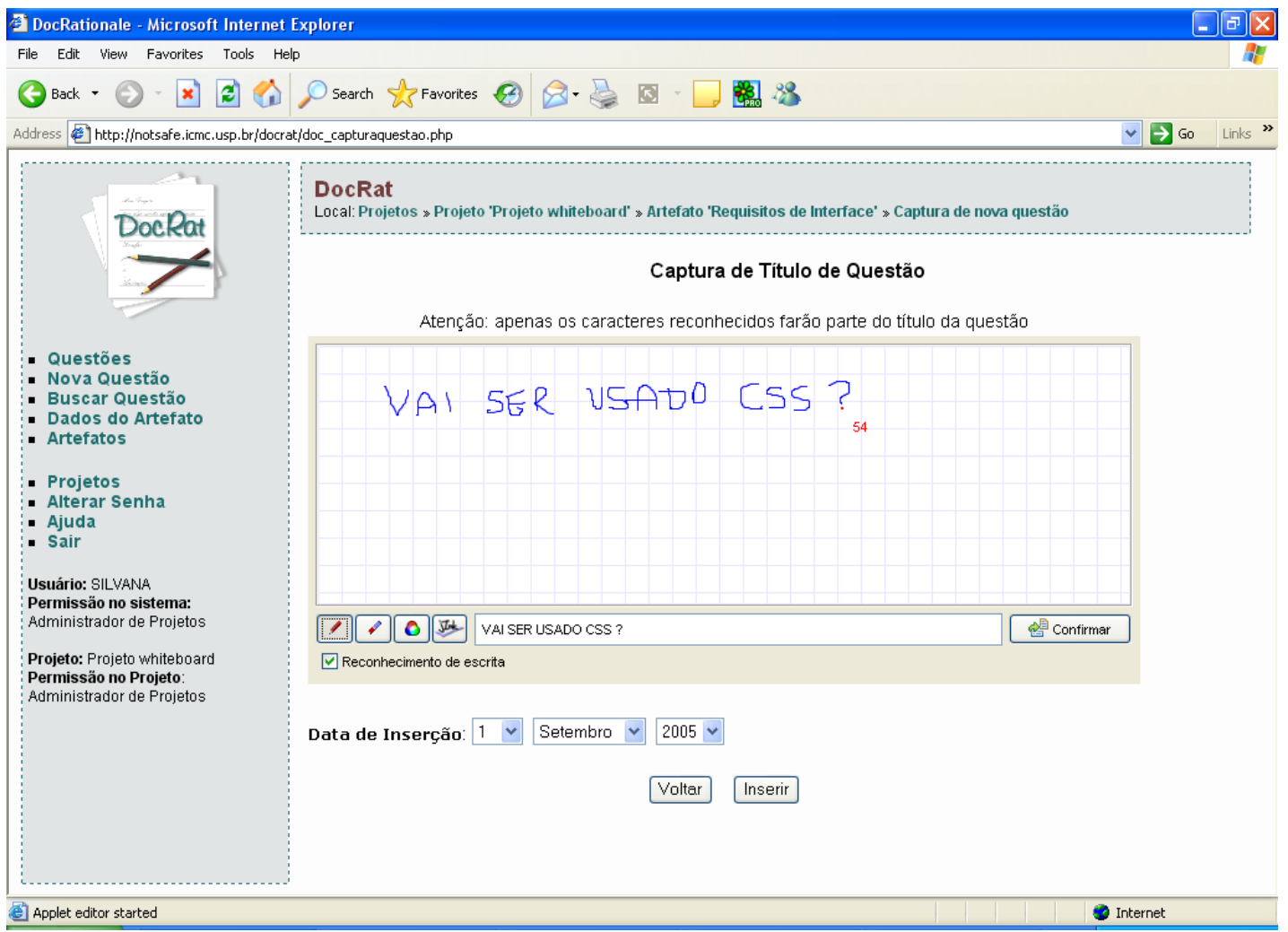

Figura 6.7: Tela do editor para a captura do título de uma questão

DocRationale - Microsoft Internet Explorer

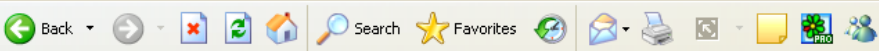

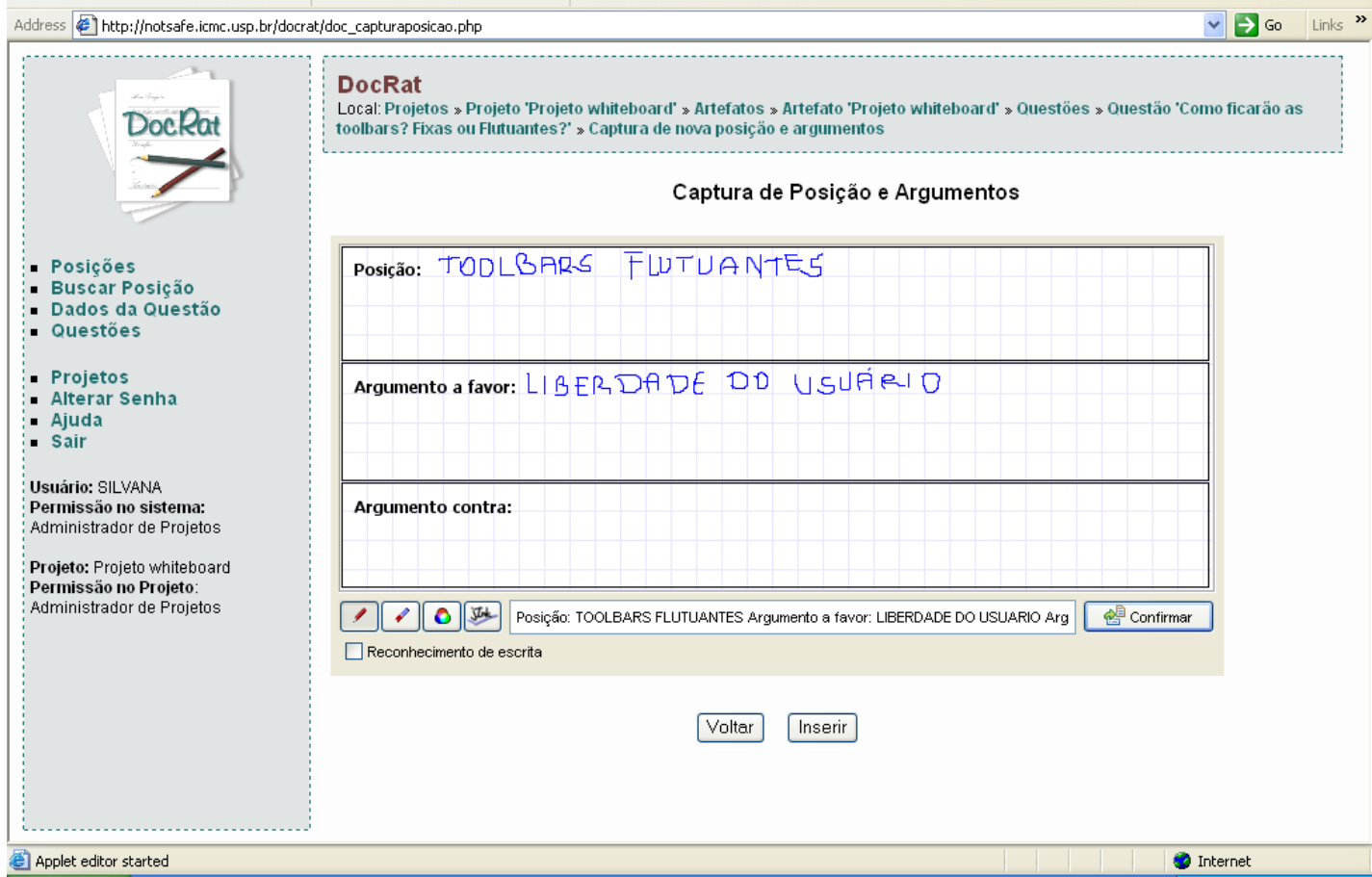

Figura 6.8: Tela do editor para captura de posição e argumentos 


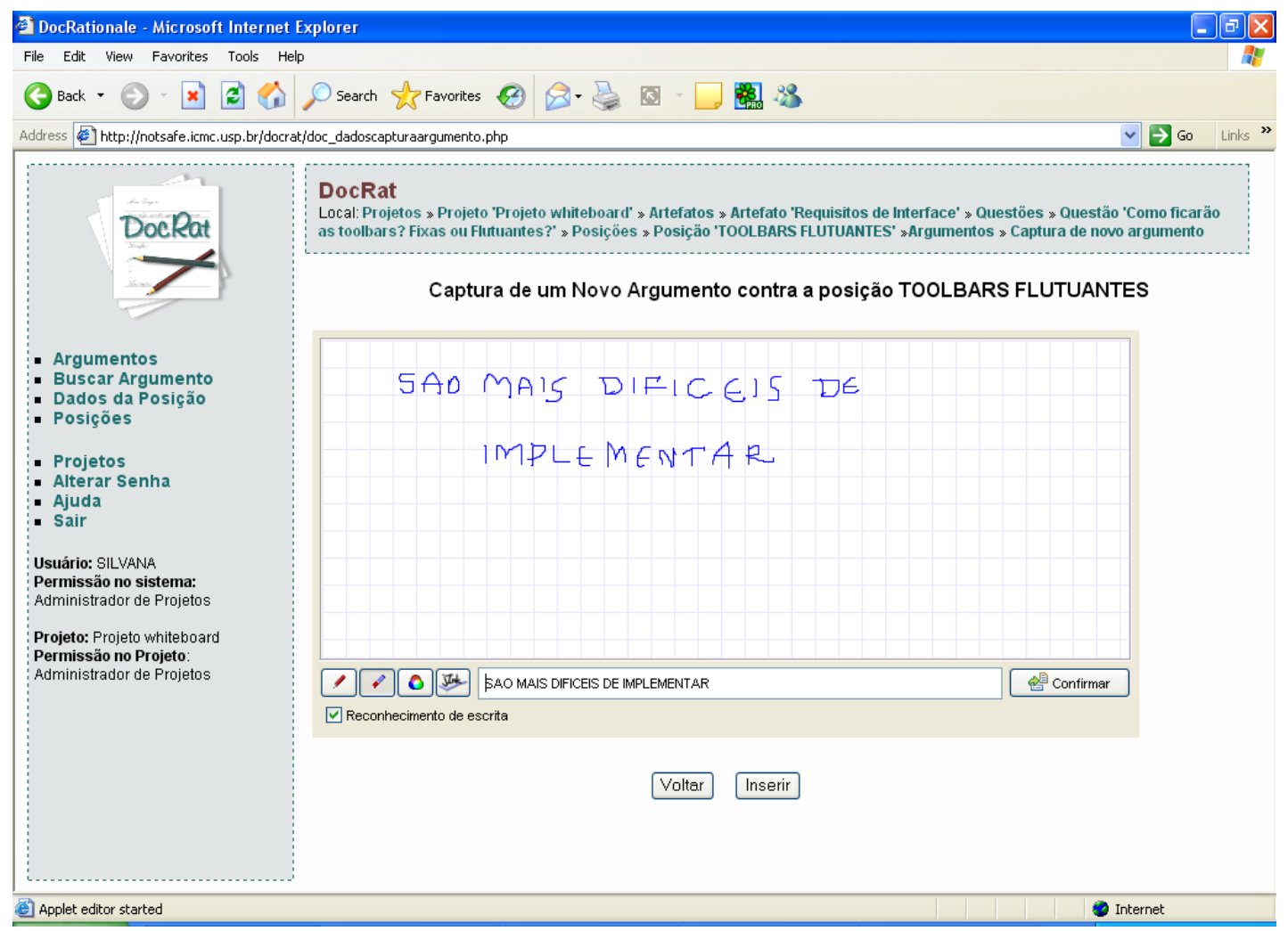

Figura 6.9: Tela do editor para captura argumentos

\subsection{Considerações Finais}

Para integrar o mecanismo de captura ubíquo, que permite a entrada de dados via escrita manual na ferramenta DocRat, foi necessário o estudo da API JInk e a adaptação de um editor gráfico, de modo a atender as necessidades específicas da ferramenta.

As maiores dificuldades concentraram-se na parte de transferência dos dados gerenciados pelo applet para as páginas escritas em PHP.

Além disso, como forma de resolver problemas de usabilidade levantados nos testes realizados após a reengenharia da ferramenta, e de promover a captura de $D R$ sob a perspectiva de argumentação de forma mais consistente, foi necessária a reimplementação das páginas relativas ao registro de posições e argumentos, que anteriormente eram implementadas utilizando a $A P I$ GroupNote. 


\section{Capítulo 7}

\section{Conclusões}

\subsection{Contribuições}

O processo de desenvolvimento de software envolve a geração de uma grande quantidade de documentos que devem ser armazenados de forma organizada, visando facilitar a recuperação dos mesmos em momento posterior.

De modo geral, apenas as decisões finais durante o processo são documentadas. O conjunto de "razões" de projeto ou Design Rationale(DR) consiste das informações adicionais aos documentos padrões do processo de desenvolvimento de software, e visam facilitar sua compreensão, manutenção e reuso.

No entanto, ainda observa-se grande resistência por parte dos usuários ao uso de ferramentas para suporte a DR. Neste trabalho foi realizada uma investigação de mecanismo para facilitar a adoção dessas ferramentas.

Nesse sentido, este trabalho foi iniciado com a realização da reengenharia da ferramenta DocRationale, visando melhorar sua usabilidade. Como resultado, a ferramenta DocRat foi implementada.

A DocRat é uma ferramenta Web que tem como propósito o registro do Design Rationale de artefatos de software, mas que permite também o gerenciamento (equipe e prazos) e a organização da documentação de projetos de software.

Com a reengenharia da ferramenta, procurou-se minimizar os problemas de usabilidade já detectados pelos seus usuários, incorporar conceitos de acessibilidade, facilitar a sua evolução e identificar os pontos favoráveis à integração de um mecanismo ubíquo, que permitisse a entrada de dados via escrita manual, realizando assim a captura do conteúdo dos artefatos de forma automática.

Assim, foi também desenvolvido um mecanismo para a realização da captura das informações 
e decisões relacionadas ao projeto de artefatos de software de forma mais natural na DocRat. O serviço de reconhecimento de escrita manual utilizado nesse mecanismo ainda apresenta resultados inconsistentes ou imprecisos. Tal serviço continua em evolução em outro projeto de mestrado [Júnior, 2004]. O mecanismo de edição ubíquo incorporado à ferramenta DocRat visa reduzir a sobrecarga do uso da ferramenta, para que os desenvolvedores não necessitem de tempo e atenção adicionais para o armazenamento do $D R$, seja durante o processo de tomada de decisões ou depois do mesmo.

A partir dos estudos e resultados obtidos durante o desenvolvimento deste projeto, as seguintes publicações foram elaboradas:

- "Registering Design Rationale in Collaborative Software Projects: a Case Study", poster, I2TS 2005 Lara et al., 2005c.

- "Um Mecanismo de Captura Ubíquo para Registro de Design Rationale de Artefatos de Software", full paper em português, I2TS LLara and Fortes, 2005.

- "Captura de Artefatos de Software e Design Rationale com a Ferramenta DocRat", demonstration, Webmedia 2005 [Lara et al., 2005b].

- "Acessibilidade no Projeto de Aplicações Web", minicurso, Webmedia 2005 Fortes et al., 2005a.

- "Universalização do Acesso a Conteúdo Educacional em Aplicações Web", minicurso, SBIE 2005 Fortes et al., 2005b.

- "Whiteboard: uma Ferramenta de Apoio ao Ensino e Aprendizado com uso de Anotação Eletrônica", demonstration, SBIE 2005 [Jardim et al., 2005.

- "Using UML Components for the specification of the Whiteboard tool", full paper, Workshop FAPESP TIDIA 2005 Kudo et al., 2005.

- "Whiteboard: a collaborative pen-based annotation tool for e-learning", demonstration, Workshop FAPESP TIDIA 2005 [Freire et al., 2005].

- "Um Suporte à Captura Informal de Design Rationale para documentação de Especificação de Requisitos", short paper, Webmedia 2004 Lara and Fortes, 2004b.

A autora deste trabalho, durante o período de mestrado, colaborou com os seguintes projetos de pesquisa em andamento no ICMC-USP: SAFE $^{1}$ e TIDIA-AE ${ }^{2}$.

\footnotetext{
${ }^{1}$ Disponível on-line no endereço http://safe.icmc.usp.br/safe/

${ }^{2}$ Disponível on-line no endereço http://tidia-ae.incubadora.fapesp.br/portal
} 


\subsection{Trabalhos Futuros}

A ferramenta DocRat está disponível como projeto de software livre ${ }^{3}$, sob licença GPL (General Public License) na incubadora da FAPESP ${ }^{4}$.

Portanto, espera-se que outras pesquisas continuem evoluindo para aprimorar o objetivo de auxiliar a captura de DR com suporte automatizado.

Testes e usos intensivos da ferramenta devem ser estimulados, nos cursos de graduação e pós-graduação do ICMC-USP, e para desenvolvedores de modo geral. Uma continuidade dessa iniciativa é a integração da ferramenta DocRat ao framework SAFE, que será viabilizada por meio de Web Service.

Dessa forma, uma pesquisa que se vislumbra é a de se caracterizar um modelo de processo de software que inclua suporte a DR.

Na pesquisa de doutorado de Paiva Paiva and Fortes, 2005a Paiva and Fortes, 2005b está sendo definido um novo modelo de representação de DR para processo de software acadêmico. Uma pesquisa futura será a de incorporar tal modelo na ferramenta DocRat.

Uma linha de pesquisa promissora, que pode ser de muito interesse à comunidade de HCI (Human-Computer Interaction), se refere a experimentos para medir o impacto de registro de DR em um processo de software considerando o mecanismo de computação ubíqua, uma vez que traz formas de interação que estimulam os usuários com a percepção de um recurso novo para sua tarefa e suscitam novas idéias e experiências.

\footnotetext{
${ }^{3}$ Disponível on-line no endereço http://notsafe.icmc.usp.br/docrat/

${ }^{4}$ Disponível on-line no endereço http://incubadora.fapesp.br/projects/docrationale/
} 


\section{Referências Bibliográficas}

[Aberer et al., 2003] Aberer, K., Datta, A., and Despotovic, Z. (2003). Separating Business Process from User Interaction in Web-Based Information Commerce. Kluwer Academic Publishers.

[Abowd, 1999a] Abowd, G. D. (1999a). Classroom 2000: An experiment with the instrumentation of a living educational environment. IBM Systems Journal, Special issue on Pervasive Computing, 38(4):508-530.

[Abowd, 1999b] Abowd, G. D. (1999b). Software engineering issues for ubiquitous computing. In Proceedings of the 21st International Conference on Software Engineering - ICSE 99, pages 75-84, Los Angeles.

[Abowd et al., 1998] Abowd, G. D., Atekenson, C., Brotherton, J., Enqvist, T., Gully, P., and Lemon, J. (1998). Investigating the capture, integration and access problem of ubiquitous computing in educational setting. In Proceedings of the The ACM Conference on Human Factors in Computing Systems, pages 440-447.

[Abowd and Mynatt, 2000] Abowd, G. D. and Mynatt, E. D. (2000). Charting past, present, and future research in ubiquitous computing. ACM Transactions on Computer-Human Interaction, $7(1)$.

[Alvarado, 2004] Alvarado, C. (2004). Sketch recognition user interfaces: Guidelines for design and development. In Making Pen-Based Interaction Intelligent and Natural. AAAI Fall Symposium.

[Andrade, 2002] Andrade, A. R. (2002). Acesso e apresentação de sessões capturadas e armazenadas pelo iclass. Projeto de Graduação, Instituto de Ciências Matemáticas e de Computação - ICMC-USP. 
[Arruda Jr. et al., 2002] Arruda Jr., C. R. E., Pimentel, M. G. C., and Izeki, C. A. (2002). Coteia: Uma ferramenta colaborativa de edição baseada na web. In Workshop de Ferramentas e Aplicações do VIII SBMIDIA, pages 371-375, Fortaleza - CE.

[Baldochi, 2002] Baldochi, L. (2002). Armazenamento, recuperação e extensão de informação proveniente de atividades de captura. Qualificação de Doutorado, Instituto de Ciências Matemáticas e de Computação - ICMC-USP.

[Bevan and Azuma, 1997] Bevan, N. and Azuma, M. (1997). Quality in use: Incorporating human factors into the software engineering lifecycle. In ISESS '97: Proceedings of the 3rd International Software Engineering Standards Symposium (ISESS '97), page 169, Washington, DC, USA. IEEE Computer Society.

[Burge and Brown, 2000] Burge, J. and Brown, D. C. (2000). Reasoning with design rationale. In Proceedings of the Artificial Intelligence Design Conference.

[Cattelan et al., 2003] Cattelan, R. G., Andrade, A. R., Rocha, C. F. P., and Pimentel, M. G. C. (2003). iclass: um sistema para captura e acesso de sessões em ambiente educacional. Revista Eletrônica de Iniciação Científica da Sociedade Brasileira de Computação (REIC-SBC).

[Chan and Yeung, 1999] Chan, K. F. and Yeung, D. Y. (1999). Recognizing on-line handwritten alphanumeric characters through flexible structural matching. Pattern Recognition, 32(7):1099-1114.

[Chikofsky and Cross, 1990] Chikofsky, E. J. and Cross, J. H. (1990). Reverse engineering and design recovery: A taxonomy. IEEE Software, 7(1):13-17.

[Coleman et al., 1994] Coleman, D., Arnold, P., Bodoff, S., Dollin, C., Gilchrist, H., Hayes, F., and Jeremaes, P. (1994). Object-Oriented Development: The FUSION Method. Prentice Hall.

[Costa, 1997] Costa, R. M. (1997). Um método de engenharia reversa para auxiliar a manutenção de software. Dissertação de Mestrado, Instituto de Ciências Matemáticas e de Computação - ICMC-USP, Maio/199\%.

[Cronholm, 1995] Cronholm, S. (1995). Why case tools in information systems development? an empirical study concerning motives for investing in case tools. In proceedings of the 18th Information Systems research In Scandinavia (IRIS 18).

[Dix et al., 2003] Dix, A., Finlay, J. E., Abowd, G. D., and Beale, R. (2003). Human-Computer Interaction. Prentice Hall. 
[Dix et al., 1998] Dix, A. J., Finlay, J. E., Abowd, G., and Beale, R. (1998). Human-Computer Interaction. Prentice Hall Europe.

[Ebraert and Tourwe, 2004] Ebraert, P. and Tourwe, T. (2004). A reflective approach to dynamic software evolution. Position Paper for RAM-SE.

[Fleming, 1998] Fleming, J. (1998). Web Navigation: Designing the User Experience. O'Reilly. $272 \mathrm{p}$.

[Forsberg et al., 1998] Forsberg, A., Dietrich, M., and Zeleznik, R. (1998). The music notepad. In In Proceedings of the 11th annual ACM Symposium on User Interface Software and Technology, pages 203-210.

[Fortes et al., 2005a] Fortes, R. P. M., Pansanato, L. T. E., Lara, S. M. A., and Freire, A. P. (2005a). Acessibilidade no projeto de aplicações web. Minicurso, WebMedia 2005.

[Fortes et al., 2005b] Fortes, R. P. M., Pansanato, L. T. E., Lara, S. M. A., and Freire, A. P. (2005b). Universalização do acesso a conteúdo educacional em aplicações web. Minicurso, XVI Simpósio Brasileiro de Informática na Educação - SBIE 2005.

[Fortes et al., 2004] Fortes, R. P. M., Silva, M. A. G., Freire, A. P., and Junqueira, D. C. (2004). SAFE - Software Engineering Available For Everyone. In Proceedings of $V$ Workshop sobre software livre (WSL 2004), pages 203-206.

[Francisco, 2004] Francisco, S. D. (2004). Docrationale: uma ferramenta para suporte a design rationale de artefatos de software. Dissertação de Mestrado, Instituto de Ciências Matemáticas e de Computação - ICMC-USP, Janeiro/2004.

[Francisco et al., 2003] Francisco, S. D., Izeki, C. A., Paiva, D. M. B., and Fortes, R. P. M. (2003). Um sistema de apoio à utilização de design rationale de artefatos de software. In Proceedings of the XXIX Conferência LatinoAmericana de Informática - CLEI2003, La Paz.

[Freeman, 1974] Freeman, H. (1974). Computer processing of line drawing images. ACM Computing Surveys, 6(1):57-98.

[Freire, 2005] Freire, A. P. (2005). Re-engenharia da interface da aplicação docrationale. Monografia de Conclusão de Curso, Instituto de Ciências Matemáticas e de Computação - ICMCUSP, Junho/2005.

[Freire and Fortes, 2005] Freire, A. P. and Fortes, R. P. M. (2005). Automatic accessibility evaluation of dynamic web pages generated through xslt. In W4A '05: Proceedings of the 
2005 International Cross-Disciplinary Workshop on Web Accessibility (W4A), pages 81-84, New York, NY, USA. ACM Press.

[Freire et al., 2005] Freire, J., Silva, E. Q., Jardim, C. H. O., Lara, S. M. A., Kudo, T. N., Martelini, A., Santos, F., Fortes, R. P. M., and Pimentel, M. G. C. (2005). Whiteboard: a collaborative pen-based annotation tool for e-learning. Demonstration, Workshop TIDIA FAPESP 2005.

[Goble et al., 2000] Goble, C., Harper, S., and Stevens, R. (2000). The travails of visually impaired web travellers. Proc. of Hypertext'2000, ACM, pages 1-10.

[Gould and Lewis, 1985] Gould, J. D. and Lewis, C. (1985). Designing for usability: key principles and what designers think. Commun. ACM, 28(3):300-311.

[Gruber and Russel, 1991] Gruber, T. R. and Russel, D. M. (1991). Design knowledge and design rationale: A framework for representation, capture, and use. Technical Report KSL 90-45, Knowledge Systems Laboratory, Standford, California. 40p.

[Hammond and Davis, 2002] Hammond, T. and Davis, R. (2002). Tahuti: A geometrical sketch recognition system for uml class diagrams. AAAI Spring Symposium on Sketch Understanding, pages 59-68.

[Harandi and Ning, 1990] Harandi, M. T. and Ning, J. Q. (1990). Knowledge-based program analysis. IEEE Software, 7:74-81.

[Hu et al., 2000] Hu, X., Pang, J., Pang, Y., Atwood, M., and Sun, W. (2000). A survey on design rationale: representation, capture and retrieval. Engineering with Computers: An Int'l Journal for Simulation-Based Engineering, 16:209-235.

[IEEE Std. 1061, 1998] IEEE Std. 1061 (1998). Software Quality Metrics Methodology.

[IEEE Std. 1348, 1996] IEEE Std. 1348 (1996). IEEE Recommended Practice for the Adoption of Computer-Aided Software Engineering (CASE) Tools.

[Iivari, 1996] Iivari, J. (1996). Why are CASE tools not used? Commun. ACM, 39(10):94-103.

[ISO 9126, 1991] ISO 9126 (1991). Software Product Evaluation: Quality Characteristics and Guidelines for their Use.

[ISO/DIS 9241-11, 1996] ISO/DIS 9241-11 (1996). Guidance on Usability. Ergonomic Requirements for Office Work with Visual Display Terminals (VDT). 
[Izeki, 2001] Izeki, C. A. (2001). Anotações colaborativas como hiperdocumentos de primeira classe na web semântica. Dissertação de Mestrado, Instituto de Ciências Matemáticas e de Computação - ICMC-USP.

[Jacobson et al., 1999] Jacobson, I., Booch, G., and Rumbaugh, J. (1999). The unified software development process. Addison Wesley.

[Jardim et al., 2005] Jardim, C. H. O., Martelini, A., Freire, J., Silva, E. Q., Lara, S. M. A., and Santos, F. (2005). Whiteboard: uma ferramenta de apoio ao ensino e aprendizado com uso de anotação eletrônica. Demonstration, XVI Simpósio Brasileiro de Informática na Educação SBIE 2005 .

[Jarzabek and Huang, 1998] Jarzabek, S. and Huang, R. (1998). The case for user-centered case tools. Commun. ACM, 41(8):93-99.

[Júnior, 2004] Júnior, V. R. I. (2004). Componentes para desenvolvimento de interfaces multimodais em aplicações de computação ubíqua. Qualificação de Mestrado, Instituto de Ciências Matemáticas e de Computação - ICMC-USP, Setembro/2004.

[Kudo et al., 2005] Kudo, T. N., Silva, E. Q., Jardim, C. H. O., Lara, S. M. A., Martelini, A., Freire, J., Pimentel, M. G. C., and Fortes, R. P. M. (2005). Using uml components for the specification of the whiteboard tool. Full Paper, Workshop TIDIA FAPESP 2005.

[Lara and Fortes, 2004a] Lara, S. M. A. and Fortes, R. P. M. (2004a). Documentação do software docrationale. Relatório técnico, ICMC - Universidade de São Paulo.

[Lara and Fortes, 2004b] Lara, S. M. A. and Fortes, R. P. M. (2004b). Um suporte à captura informal de design rationale para documentação de especificação de requisitos. short paper. WebMedia.

[Lara and Fortes, 2005] Lara, S. M. A. and Fortes, R. P. M. (2005). Um mecanismo de captura ubíquo para registro de design rationale de artefatos de software. Submetido como artigo completo em português, 4th International Information and Telecommunication Technologies Symposium.

[Lara et al., 2005a] Lara, S. M. A., Freire, A. P., and Fortes, R. P. M. (2005a). Docrat: Produto da re-engenharia da ferramenta docrationale. Relatório técnico, ICMC - Universidade de São Paulo. 
[Lara et al., 2005b] Lara, S. M. A., Freire, A. P., Paiva, D. M. B., and Fortes, R. P. M. (2005b). Captura de artefatos de software e design rationale com a ferramenta docrat. Submetido como Demonstration, WebMedia 2005.

[Lara et al., 2005c] Lara, S. M. A., Freire, A. P., Paiva, D. M. B., and Fortes, R. P. M. (2005c). Registering design rationale in collaborative software projects: a case study. Poster, 4th International Information and Telecommunication Technologies Symposium.

[Lee, 1997] Lee, J. (1997). Design rationale systems: Understanding the issues. IEEE Expert/Intelligent Systems and Their Applications, 12(3):78-85.

[Lin et al., 2000] Lin, J., Newman, M. W., Hong, J. I., and Landay, J. A. (2000). Denim: finding a tighter fit between tools and practice for web site design. In In Proceedings of the SIGCHI Conference on Human Factors in Computing Systems, pages 510-517.

[McCall, 1986] McCall, R. (1986). Issue-serve systems: A descriptive theory of design. Design Methods and Theories, 20(8):443-458.

[Müller and Ottmann, 2000] Müller, R. and Ottmann, T. (2000). The "authoring on the fly"system for automated recording and replay of (tele)presentations. ACM Spring-Verlag Multimedia Systems, (8):158-176.

[Monk et al., 1995] Monk, S., Sommerville, I., Pendaries, J. M., and Durin, B. (1995). Supporting design rationale for system evoluation. In Proceedings of the Fifth European Software Engineering Conference.

[Mukhopadhyay and Smith, 1999] Mukhopadhyay, S. and Smith, B. (1999). Passive capture and structuring of lectures. In Proceedings of the ACM Conference on Multimedia (Multimedia'99), pages 477-486, Orlando.

[Nielsen, 1993] Nielsen, J. (1993). Usability Engineering. Academic Press.

[Nielsen, 1994] Nielsen, J. (1994). Usability Inspection Methods. John Wiley.

[Nielsen, 2000] Nielsen, J. (2000). Designing Web Usability. New Riders Publishing.

[Paiva and Fortes, 2005a] Paiva, D. M. B. and Fortes, R. P. M. (2005a). Design rationale in software engineering: A case study. In Proceedings of the Seventeenth International Conference on Software Engineering and Knowledge Engineering (SEKE 2005), Taipei-Taiwan. 
[Paiva and Fortes, 2005b] Paiva, D. M. B. and Fortes, R. P. M. (2005b). Model for academic software development including design rationale elements. I IFIP Academy on the State of Software Theory and Practice - PhD Colloquium.

[Peña-Mora and Vadhavka, 1996] Peña-Mora, F. and Vadhavka, S. (1996). Design rationale and design patterns in reusable software design. In Proceedings of the Sixth International Conference on Artificial Intelligence in Design. J. S. Gero (editors), Kluwer Academic Press.

[Pear, 2005] Pear (2005). PEAR - PHP Extension and Application Repository. Disponível em http://pear.php.net/. Acesso em Junho/2005.

[Pedersen et al., 1993] Pedersen, E., Mccall, K., Moran, T. P., and Halasz, F. (1993). Tivoli: an electronic whiteboard for informal workgroup meetings. In Proceedings of the Interchi 1993, pages 391-398, Amsterdam.

[Penteado, 1996] Penteado, R. D. (1996). Um método para engenharia reversa orientada a objetos. Tese de Doutorado, Instituto de Física de São Carlos, Universidade de São Paulo, São Carlos, 1996.

[Pimentel et al., 2003] Pimentel, M. G. C., Catellan, R. G., and Fortes, R. P. M. (2003). Computação ubíqua em sala de aula: experiências e oportunidades. In Mini-cursos do XIV SBIE - Inclusão digital como instrumento de inclusão social, pages 49-72. Ed. Rio de Janeiro NCEIM, v.1.

[Pimentel et al., 2001a] Pimentel, M. G. C., Ishiguro, Y., Kerimbaev, B., Abowd, G. D., and Guzdial, M. (2001a). Supporting long-term educational activities through dynamic web interfaces. Interacting With Computers Journal, 13:353-374.

[Pimentel et al., 2001b] Pimentel, M. G. C., Izeki, C. A., and Arruda Jr., C. R. E. (2001b). An xml-based infrastructure supporting collaborative annotations as first-class hyperdocuments. In Proceedings of VII Brazilian Symposium of Multimedia and Hypermedia Systems, pages 173-186, Florianópolis - SC.

[Plamondon and Srihari, 2000] Plamondon, R. and Srihari, S. N. (2000). On-line and off-line handwriting recognition: A comprehensive survey. IEEE Trans. on Pattern Analysis and Machine Intelligence, 22(1):63-84.

[Pressman, 1995] Pressman, R. S. (1995). Engenharia de Software. Makron Books. 
[Richter et al., 2001] Richter, H., Abowd, G., Geyer, W., Fuchs, L., Daijavad, S., and Poltrock, S. (2001). Integrating meeting capture within a collaborative team environment. In Proceedings of the Ubicomp 2001, pages 123-138, Atlanta, GA, USA.

[Rocha and Baranauskas, 2003] Rocha, H. V. and Baranauskas, M. C. C. (2003). Design e Avaliação de Interfaces Humano-Computador. EdUnicamp.

[Schwabe and Rossi, 1995] Schwabe, D. and Rossi, G. (1995). The object-oriented hypermedia design model. Commun. ACM, 38(8):45-46.

[Seffah and Metzker, 2004] Seffah, A. and Metzker, E. (2004). The obstacles and myths of usability and software engineering. Commun. ACM, 47(12):71-76.

[Shi et al., 2003] Shi, Y., Xie, W., Xu, G., Shi, R., Chen, E., Mao, Y., and Liu, F. (2003). The smart classroom: Merging technologies for seamless tele-education. IEEE Pervasive Computing, 2(2):47-55.

[Shipman and McCall, 1997] Shipman, F. and McCall, R. (1997). Integrating different perspectives on design rationale: Supporting the emergence of design rationale from design communication. Artificial Intelligence in Engineering Design, Analysis, and Manufacturing, 11(2):141-154.

[Shneiderman, 1998] Shneiderman, B. (1998). Designing the user interface. Addison-Wesley Publishing Company. 639 p.

[Shum, 1991] Shum, S. (1991). A cognitive analysis of design rationale representation. Tese de doutoramento, University of York.

[Smarty, 2005] Smarty (2005). Smarty: Template Engine. Disponível em http://smarty.php.net/. Acesso em Junho/2005.

[Souza et al., 1998] Souza, C. R. B., Santos, D. B., Wainer, J., and Dias, K. L. (1998). A model tool for semi-automatic recording of design rationale in software diagrams. In Proceedings of the String Processing and Information Retrieval Symposium, pages 306-313.

[Stone and Dhiensa, 2004] Stone, R. G. and Dhiensa, J. (2004). Proving the validity and accessibility of dynamic web-pages. In W4A: Proceedings of the international cross-disciplinary workshop on Web accessibility, pages 45-49. ACM Press.

[Streitz et al., 1994] Streitz, N. A., Gleißler, J., Haake, J. M., and Hol, J. (1994). DOLPHIN: integrated meeting support across local and remote desktop environments and liveboards. 
In Proceedings of the 1994 ACM CSCW'94 Conference on Computer Supported Cooperative Work, pages 345-358, Chapel Hill, North Carolina, United States.

[Tappert et al., 1990] Tappert, C. C., Suen, C. Y., and Wakahara, T. (1990). The state of the art in on-line handwriting recognition. IEEE Trans. on Pattern Analysis and Machine Intelligence, 12(8):787-808.

[Thatcher et al., 2002] Thatcher, J., Bohman, P., Burks, M., Henry, S. L., Regan, B., Swierenga, S., and Urban, M. (2002). Constructing Accessible Web Sites. Glasshaus.

[W3C, 1999] W3C (1999). Web Content Acessibility Guidelines 1.0. Disponível em http://www.w3.org/TR/WCAG10/. Acesso em Abril/2005.

[Weiser, 1991] Weiser, M. (1991). The computer for the 21st century. Scientific American, pages 94-104. http://www.ubiq.com/hypertext/weiser/SciAmDraft3.html - Visitado em fevereiro/2004.

[Win et al., 2002] Win, B., Piessens, F., Joosen, W., and Verhanneman, T. (2002). On the importance of the separation-of-concerns principle in secure software engineering. Katholieke Universiteit Leuven, Dept. of Computer Science. 


\section{Apêndice A}

\section{Tarefas realizadas no teste de}

\section{usabilidade}

No teste de usabilidade, os usuários eram instruídos a cumprirem as seguintes tarefas no sistema, nas duas versões da ferramenta.

Supondo ser um usuário com a permissão de Administrador de tarefas, realize as seguintes tarefas:

1.1. Obtenha a lista de todos os projetos dos quais o seu usuário faz parte.

1.2. Cadastre um novo projeto fictício de forma interativa.

1.3. Visualize todos os dados do projeto que acabou de ser criado, tanto no sistema quanto na página CoTeia.

1.4. Insira um novo usuário como membro da equipe do projeto recém-criado.

2.1. Crie um novo projeto a partir de um arquivo de modelo de projeto.

2.2. Altere a data de previsão de término do projeto criado para uma data posterior a data que já está cadastrada.

2.3. Crie um artefato relacionado ao projeto em questão.

2.4. Anexe um documento de texto ao artefato criado.

3.1. Visualize a lista de artefatos de um projeto cadastrado no sistema.

3.2. Obtenha todas as informações cadastrais de um artefato do projeto.

3.3. Crie uma nova página colaborativa contendo a descrição do artefato.

3.4. Crie uma nova questão relacionada ao artefato.

4.1. Visualize todas as questões relacionadas a um artefato do projeto. 
4.2. Selecione uma das questões e insera uma posição a respeito dela.

4.3. Insira um argumento a favor da posição criada.

4.4. Insira um argumento contra a posição criada. 


\section{Apêndice B}

\section{Questionário aplicado para os}

\section{usuários no teste de usabilidade}

O questionário contido neste Apêndice foi aplicado aos usuários que efetuaram o teste de usabilidade das duas versões da ferramenta DocRationale e DocRat.

1) Qual foi o grau de dificuldade encontrado para criar um novo projeto?

( ) muito fácil ( ) fácil ( ) razoável ( ) difícil ( ) muito difícil

2) Qual foi o grau de dificuldade encontrado para criar de um novo artefato?

( ) muito fácil ( ) fácil ( ) razoável ( ) difícil ( ) muito difícil

3) Qual foi o grau de dificuldade encontrado para criar uma nova questão?

( ) muito fácil ( ) fácil ( ) razoável ( ) difícil ( ) muito difícil

4) Qual foi o grau de dificuldade encontrado para criar uma nova página?

( ) muito fácil ( ) fácil ( ) razoável ( ) difícil ( ) muito difícil

5) Qual foi o grau de dificuldade encontrado para abstrair a estrutura hierárquica das informações no sistema?

( ) muito fácil ( ) fácil ( ) razoável ( ) difícil ( ) muito difícil

6) Qual foi o grau de dificuldade encontrado para ter acesso a informações na ferramenta (em relação à quantidade de cliques necessários para alcançar a informação desejada)?

( ) muito fácil ( ) fácil ( ) razoável ( ) difícil ( ) muito difícil 
7) Como você classifica o auxílio à localização corrente fornecido pela ferramenta?

( ) muito ruim ( ) ruim ( ) razoável ( ) bom ( ) muito bom

8) Como você classifica a qualidade das informações para orientação sobre a realização de tarefas na interface do sistema?

( ) muito ruim ( ) ruim ( ) razoável ( ) bom ( ) muito bom

9) Você considera a quantidade de informações a respeito dos artefatos/projetos/questões disponíveis?

( ) suficiente ( ) insuficiente

10) Comentários: 